Computer Calculations of Eddy-Current Power Loss in Rotating Titanium Wheels and Rims in Localized Axial Magnetic Fields

D. J. Mayhall, W. Stein, J. B. Gronberg

May 17, 2006 
This document was prepared as an account of work sponsored by an agency of the United States Government. Neither the United States Government nor the University of California nor any of their employees, makes any warranty, express or implied, or assumes any legal liability or responsibility for the accuracy, completeness, or usefulness of any information, apparatus, product, or process disclosed, or represents that its use would not infringe privately owned rights. Reference herein to any specific commercial product, process, or service by trade name, trademark, manufacturer, or otherwise, does not necessarily constitute or imply its endorsement, recommendation, or favoring by the United States Government or the University of California. The views and opinions of authors expressed herein do not necessarily state or reflect those of the United States Government or the University of California, and shall not be used for advertising or product endorsement purposes.

This work was performed under the auspices of the U.S. Department of Energy by University of California, Lawrence Livermore National Laboratory under Contract W-7405-Eng-48. 


\title{
Computer Calculations of Eddy-Current Power Loss in Rotating Titanium Wheels and Rims in Localized Axial Magnetic Fields
}

\author{
David J. Mayhall, Werner Stein, and Jeffrey B. Gronberg \\ Lawrence Livermore National Laboratory
}

We have performed preliminary computer-based, transient, magnetostatic calculations of the eddy-current power loss in rotating titanium-alloy and aluminum wheels and wheel rims in the predominantly axially-directed, steady magnetic fields of two small, solenoidal coils. These calculations have been undertaken to assess the eddy-current power loss in various possible International Linear Collider(ILC) positron target wheels. They have also been done to validate the simulation code module against known results published in the literature. The commercially available software package used in these calculations is the Maxwell 3D, Version 10, Transient Module from the Ansoft Corporation.

\section{Calculations with Various Wheel and Wheel Sector Geometries}

The geometry for the wheel and the coils is shown in Figure 1. The wheel is $2 \mathrm{~m}$ in diameter and $1.5 \mathrm{~cm}$ thick. The wheel rotates at $900 \mathrm{rpm}$ in the counterclockwise direction about the z-axis. The electrical conductivity of the wheel is taken to be 5.618 $10^{5}$ siemens $/ \mathrm{m}$, which is the reciprocal of the electrical resistivity of the titanium alloy, Ti6Al4V(Grade 5), Annealed. The resistivity of this alloy is $1.7810^{-6} \mathrm{ohm}-\mathrm{m}$, as given by an ASTM material data sheet. The temperature corresponding to this value is not given. 


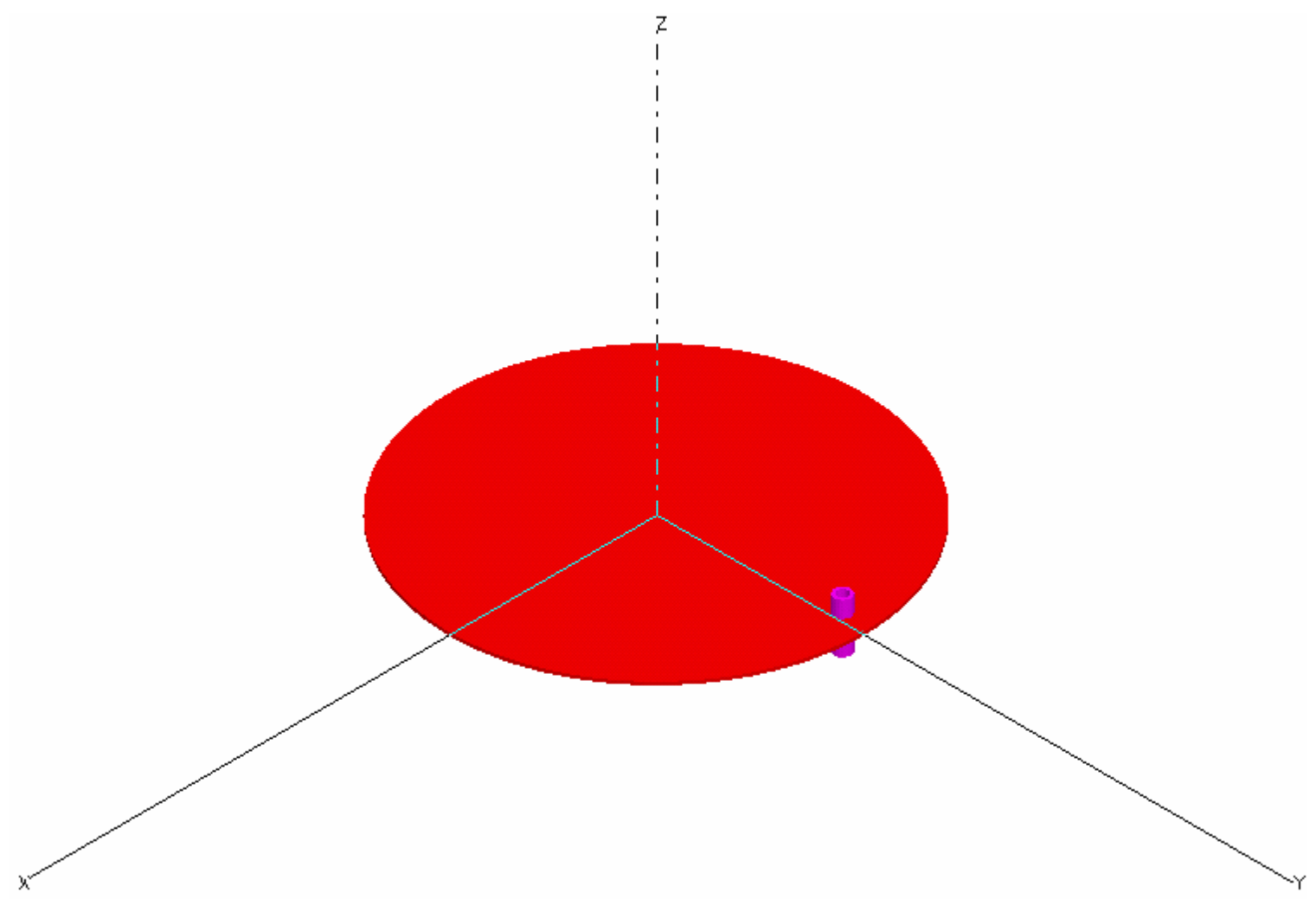

Figure 1 The geometry for the wheel and the coils.

Two small, current-carrying, cylindrical, solenoidal coils are located off the flat sides of the wheel at $0.9 \mathrm{~m}$ radially outward from the center of the wheel with their axes parallel to the axis of rotation of the wheel, which is the z-axis. The near end-plane of each coil is $3.27 \mathrm{~cm}$ from the corresponding wheel surface. Each coil is assumed to be a cylindrical annulus of solid copper with an inner diameter of $5 \mathrm{~cm}$ and an outer diameter of $8 \mathrm{~cm}$. Each coil is $8 \mathrm{~cm}$ in length. The steady, uniform current in each coil is adjusted to $2.17410^{6} \mathrm{~A}$ to produce a maximum value of approximately $5 \mathrm{~T}$ of $\mathrm{B}$ field or magnetic flux density at each lateral surface of the wheel, when stationary. The B field vector on the axial centerline of the coils is upward in the positive $\mathrm{z}$ direction. The coils are not models of actual physical coils, but are computational coils created to produce the desired $B$ field.

The first calculation spans two revolutions of the wheel or $0.1333 \mathrm{sec}$. The magnitude of the B field on the upper surface of the wheel is shown in Figure 2. The maximum value of the $\mathrm{B}$ field has increased to $5.695 \mathrm{~T}$, as shown in the color map in the figure. The location of the B field maximum has shifted upward from the coil centerline, which intersects the y-axis. The maximum has shifted in the direction of the rotational motion. The outline of the upper coil boundaries is superimposed on the B field pattern as two circles. 


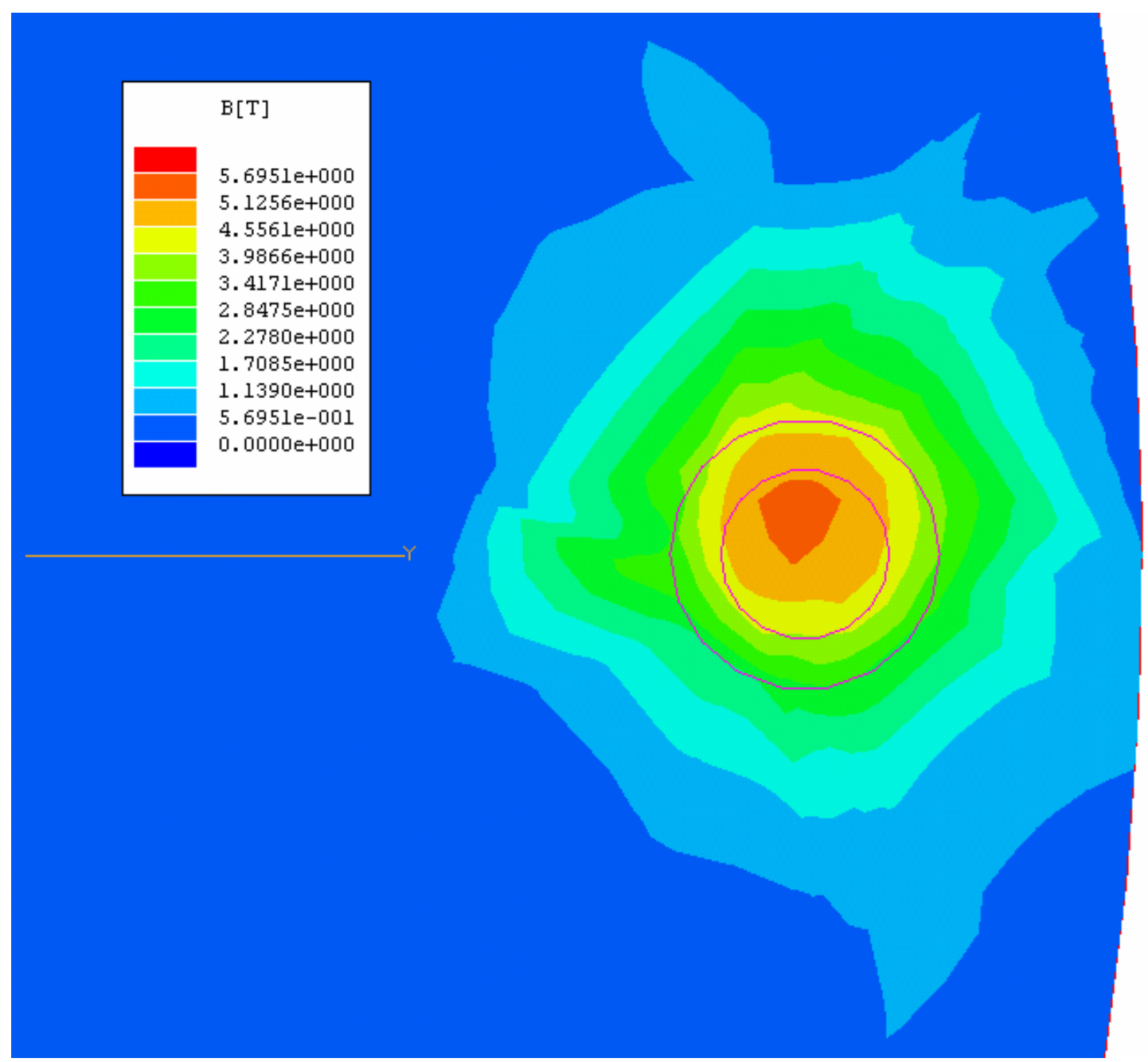

Figure 2 The magnitude of the B field on the upper surface of the wheel after two revolutions.

The current density vector on the upper surface of the wheel after two revolutions is shown in Figure 3. The current density has a strong component in the outer radial direction under the upper half of the coil projection on the wheel surface. The outwardly radial current density vector under the coil crossed into the upward B field vector causes a force density in units of $\mathrm{nt} / \mathrm{m}^{3}$ directed downward in the $\mathrm{x}$ direction. This motionretarding $\mathrm{J} X \mathrm{~B}$ force density results in a retarding force in the $\mathrm{x}$ direction when integrated over the volume of the wheel. In the preceding force density expression, $\mathrm{J}$ and $\mathrm{B}$ are vectors, and $\mathrm{X}$ indicates the vector cross product. 


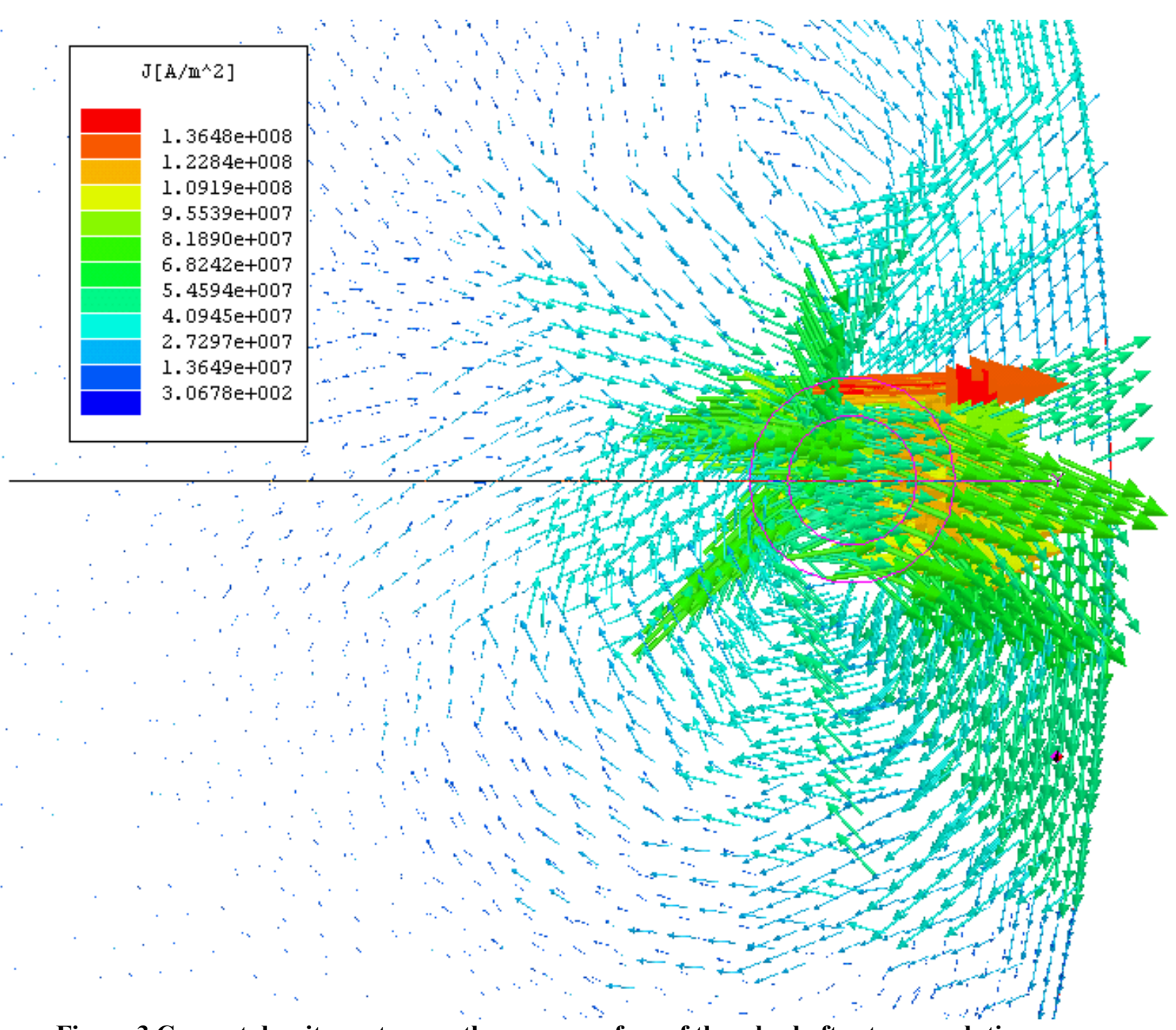

Figure 3 Current density vectors on the upper surface of the wheel after two revolutions.

The J X B force density vectors on the upper surface of the wheel near the coil endplate projection on the wheel are shown in Figure 4. The units for these vectors are $\mathrm{nt} / \mathrm{m}^{3}$. Notice that these force density vectors predominately oppose the upward motion of the wheel. Small force density vector components in the positive and negative radial directions are also present. 


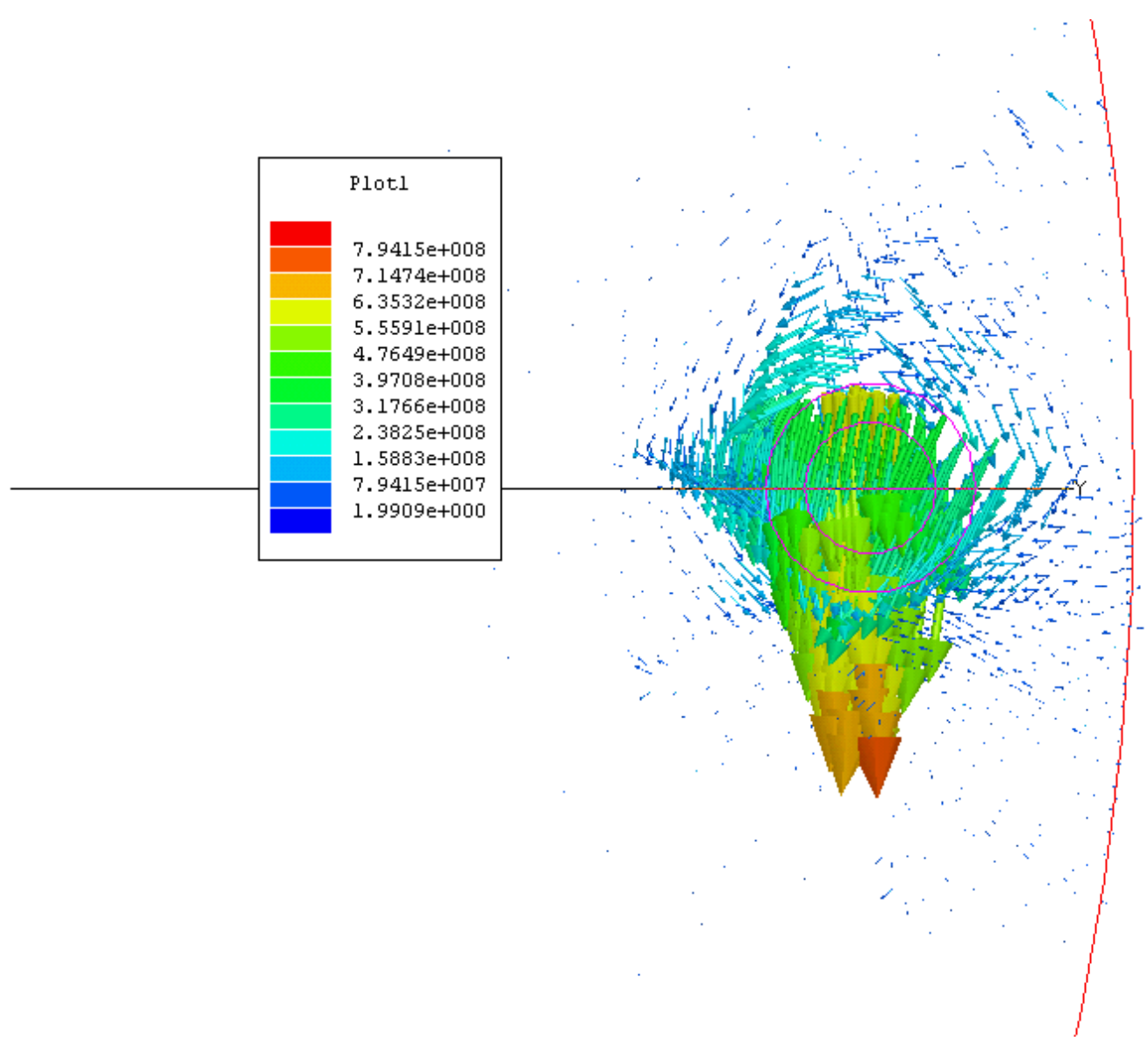

Figure 4 The $\mathbf{J} X$ B force density vectors on the upper surface of the wheel after two revolutions.

The time-dependent power loss in watts due to the eddy currents in the wheel for two revolutions is shown in Figure 5. The curve is noisy due to the somewhat unrefined finite element mesh, which is automatically made more dense in the region under the coils. Notice that the two peaks in the power loss curve occur at the end of the first and second revolutions, when the densest region of the mesh is under the coils. Conversely, the two minimal parts of the power loss curve occur when the least dense part of the mesh has rotated under the coils. Because of the variation in the power loss curve due to the varying mesh density, the average of the power loss over the two revolutions must be considered to be an estimate of the correct value. The estimate of, perhaps, $2.210^{6} \mathrm{w}$ can be improved upon by refining the mesh until the power loss curve converges. A present estimate of the average eddy-current power loss is thus about $2950 \mathrm{hp}$ from division by $746 \mathrm{w} / \mathrm{hp}$. A hand calculation of the power loss with the formula,

$$
\mathrm{P}_{\mathrm{dis}}=(\mathrm{vB})^{2} \mathrm{~V} / \rho,
$$

where $\mathrm{v}$ is the velocity of the wheel under the coils, $\mathrm{V}$ is the volume, $\pi \mathrm{D}_{\mathrm{c}}{ }^{2} \mathrm{~d} / 4$, and $\rho$ is the resistivity of the wheel material, gives an eddy-current power loss of $3990 \mathrm{hp}$. The quantity $D_{c}$ is taken as the coil inner diameter of $5 \mathrm{~cm}, \mathrm{~d}$ is taken as the wheel thickness of $1.5 \mathrm{~cm}, \mathrm{~B}$ is taken as $5 \mathrm{~T}, \mathrm{v}$ is taken as $900 \mathrm{rpm}(2 \pi \mathrm{radians} / \mathrm{rev})(0.9 \mathrm{~m}) /(60 \mathrm{sec} / \mathrm{min})=$ $84.8 \mathrm{~m} / \mathrm{sec}$, and $\rho$ is $1.7810^{-6} \mathrm{ohms} / \mathrm{m}$. 


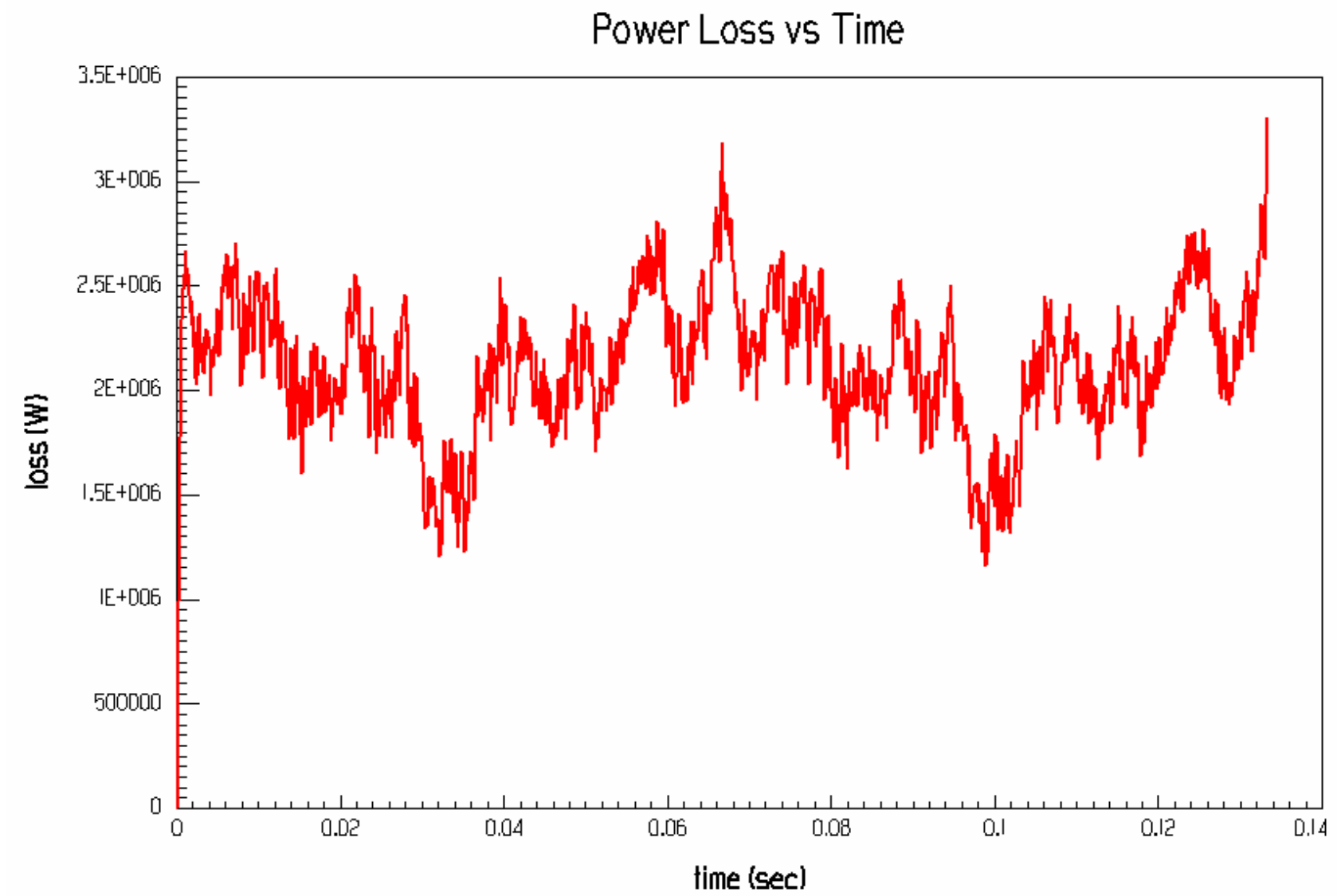

Figure 5 Time-dependent eddy-current power loss in the wheel over two revolutions.

We have also calculated the eddy-current power loss in a rim of the wheel when the interior of the wheel has been removed so that just the outer $3 \mathrm{~cm}$ of wheel radius remain. The coils have been moved outward radially so that their axial centerline is at $98.5 \mathrm{~cm}$ from the center of the wheel. This geometry is shown in Figure 6. The rim rotates counterclockwise about the $\mathrm{z}$-axis with the rotation vector pointing in the positive $\mathrm{z}$ direction. Once again, two full revolutions of the rim have been calculated. The magnitude of the B field on the upper surface of the rim is shown in Figure 7. 


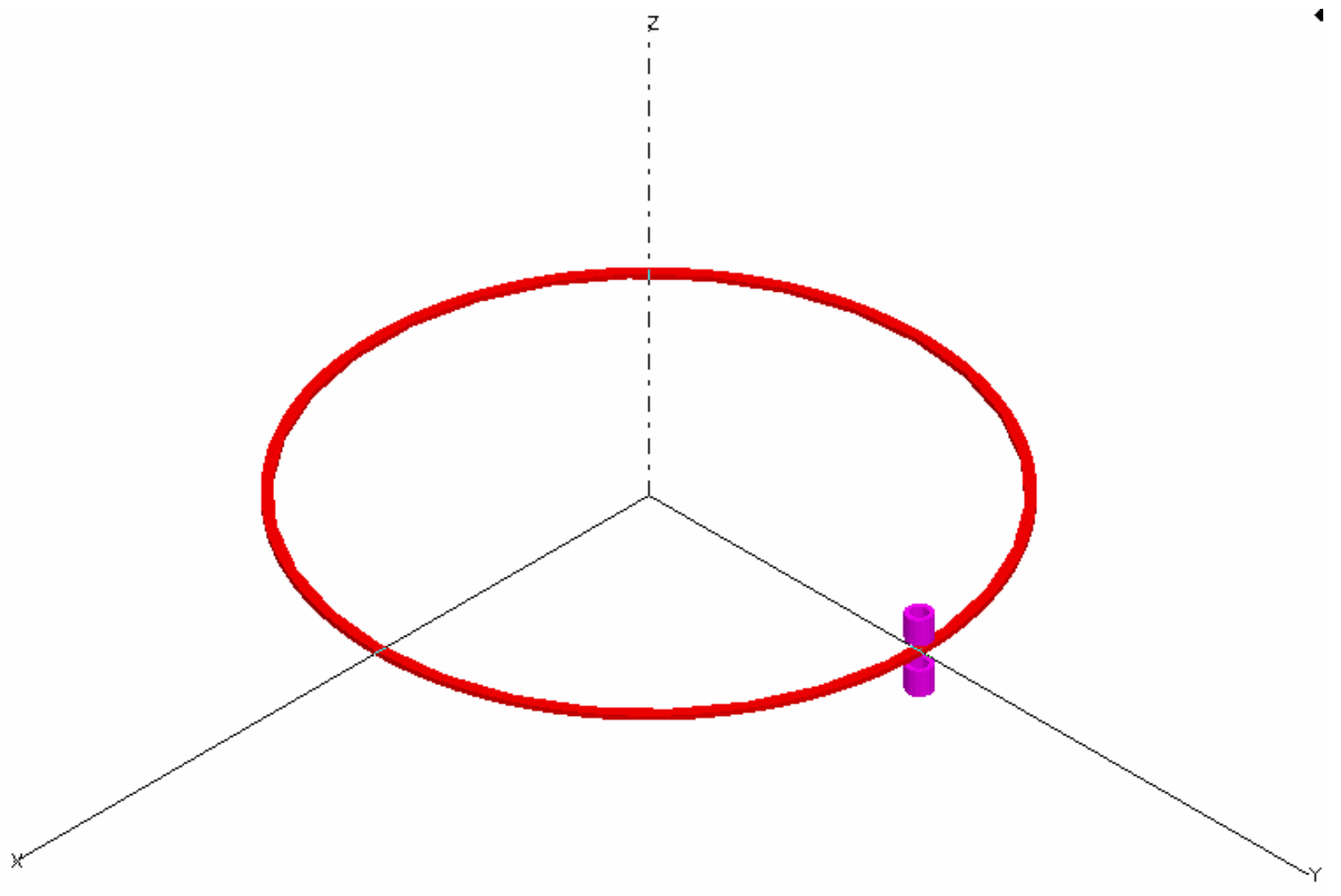

Figure 6 The geometry of the rim of the wheel and the coils. 


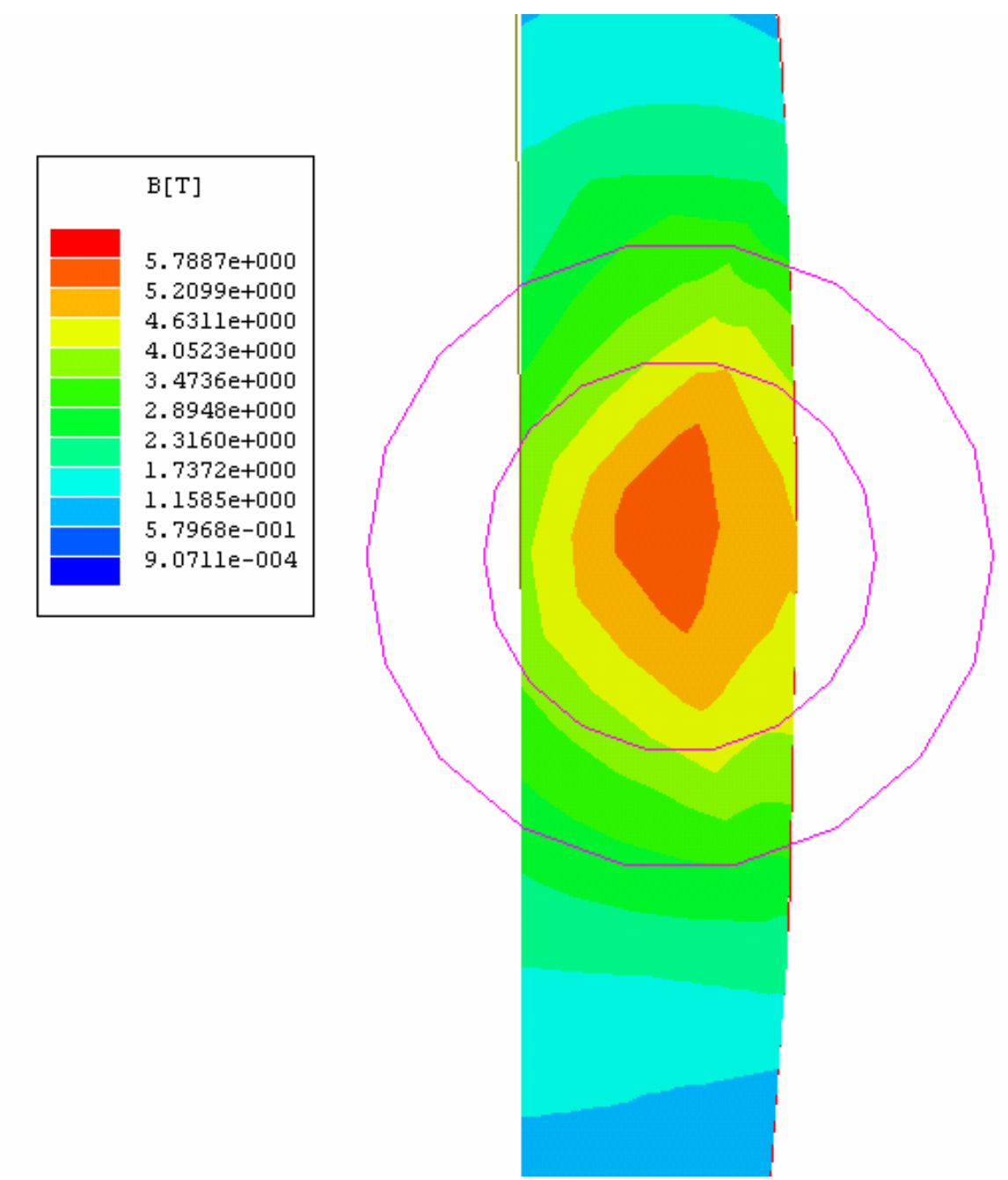

Figure 7 The magnitude of the B field on the upper surface of the rim after two revolutions.

The pattern of the current density vectors on the upper surface of the rim after two revolutions is shown in Figure 8. We notice that the peak current density for the rim upper surface is $5.79110^{7} \mathrm{~A} / \mathrm{m}^{2}$, instead of the value of $1.36410^{8} \mathrm{~A} / \mathrm{m}^{2}$ for the full wheel. We also notice that for the rim, the strong vectors are transverse to the rim circumference, instead of radial as for the full wheel. This different pattern means that the predominant $\mathrm{J}$ X B forces will be radially inward and outward and will cancel each other to some extent. We can thus expect less retardation of the rim than for the full wheel and less eddycurrent power loss for the rim. 

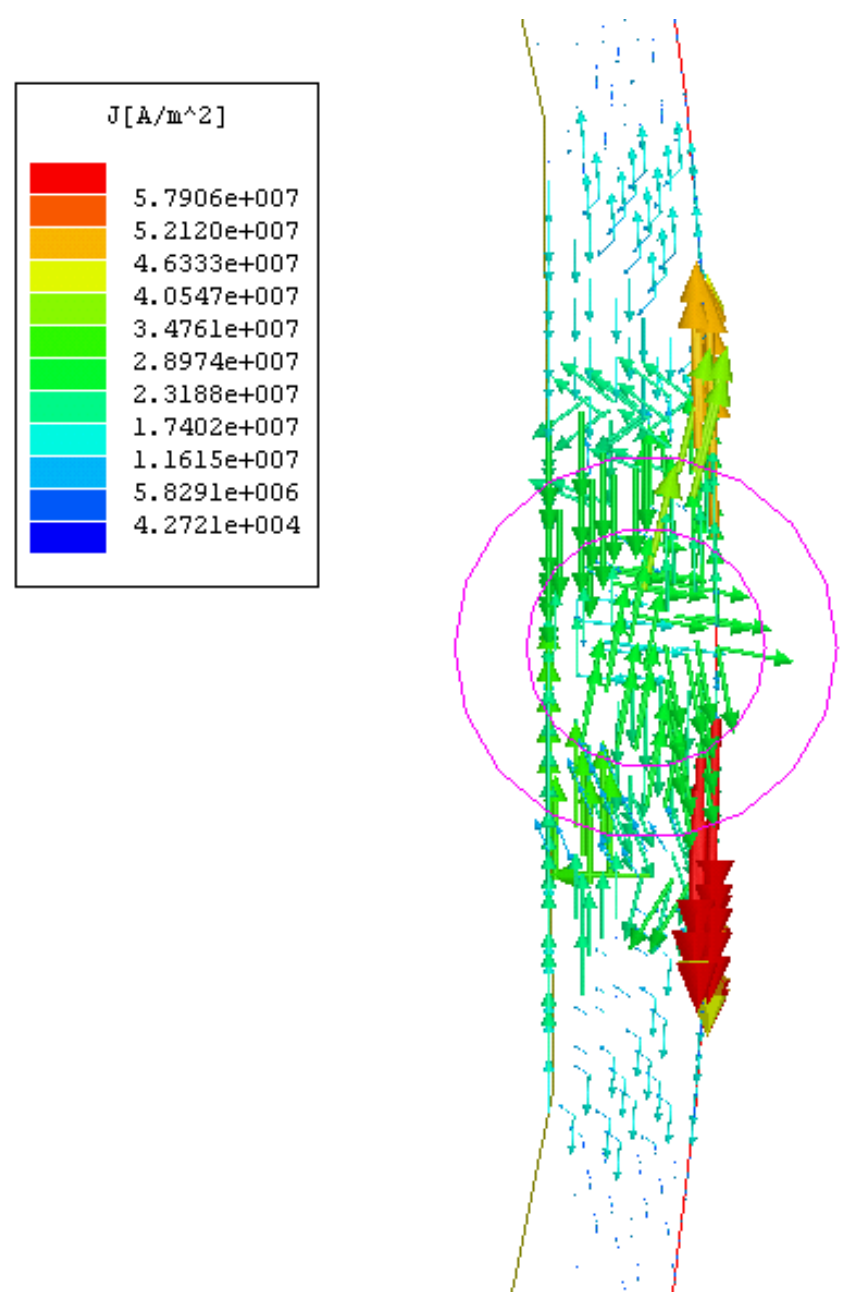

Figure 8 The current density vectors on the upper surface of the rim after two revolutions.

Figure 9 shows the J X B force density vector pattern on the upper surface of the rim after two revolutions. We see that the peak value of this force density is $3.01110^{8} \mathrm{nt} / \mathrm{m}^{3}$, instead of $7.94210^{8} \mathrm{nt} / \mathrm{m}^{3}$ for the full wheel. We also see that the strongest vectors are indeed in the inward and outward radial directions. Thus, much less retardation should occur for this geometry for which the eddy-current flow is restricted. 

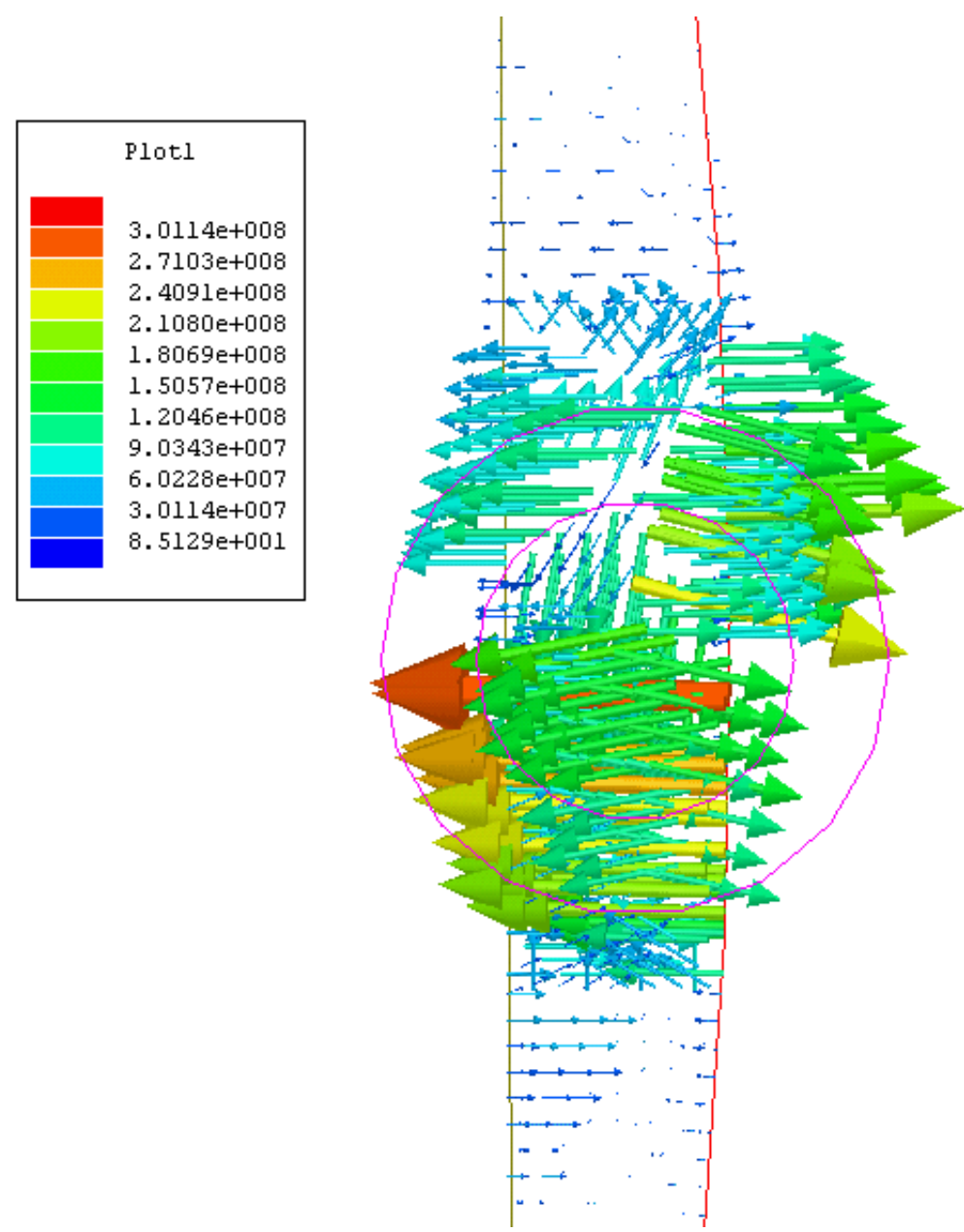

Figure 9 The J X B force density vectors on the upper surface of the rim after two revolutions.

The time-dependent eddy-current power loss for this case is very noisy due to the relatively small number of tetrahedra in the rim. The mesh had 4,906 tetrahedra with 501 in the rim. The power loss varied from about 16,000 w(21 hp) to about 94,000 w(126 hp).

Because of the variation in the time-dependent eddy-current power loss for the rim, further mesh refinement was desired so that reliable, converged power loss results could be obtained. To speed up the study of mesh refinement for the rim, 324 degrees of the rim were removed, and 36 degrees or $10 \%$ were retained. This new geometry is shown in Fig.10. The segment of the rim is shown in red. A pie-shaped region of air is shown in gray. Rotation is once again counterclockwise about the z-axis. The rim remains under the coils for about $0.00667 \mathrm{sec}$. The number of tetrahedra in the mesh, which included the air region and the rim segment, was varied from 2162 to 104,702 tetrahedra. For above 16,971 tetrahedra, the power loss curves were acceptably similar. The results for 104,702 tetrahedra, are shown in Fig. 11. The average eddy-current power loss for the plateau region is probably about $111,200 \mathrm{w}$ or $149 \mathrm{hp}$. This value is likely a reasonable estimate 
of the eddy-current power loss and hence the required minimal motor horsepower for this particular geometry and coil current.

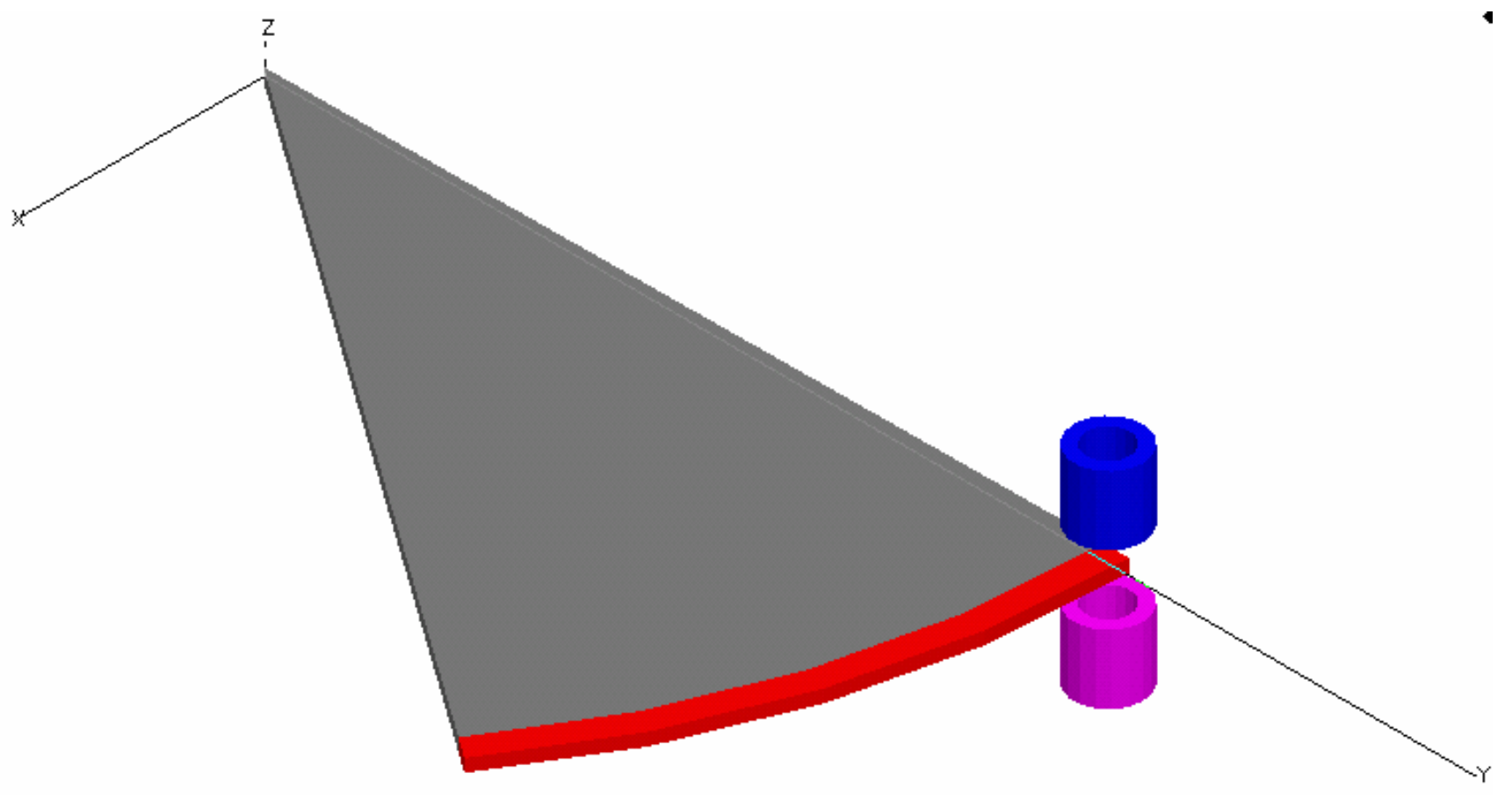

Figure 10 The geometry for 36 degrees of the rim and the coils. 


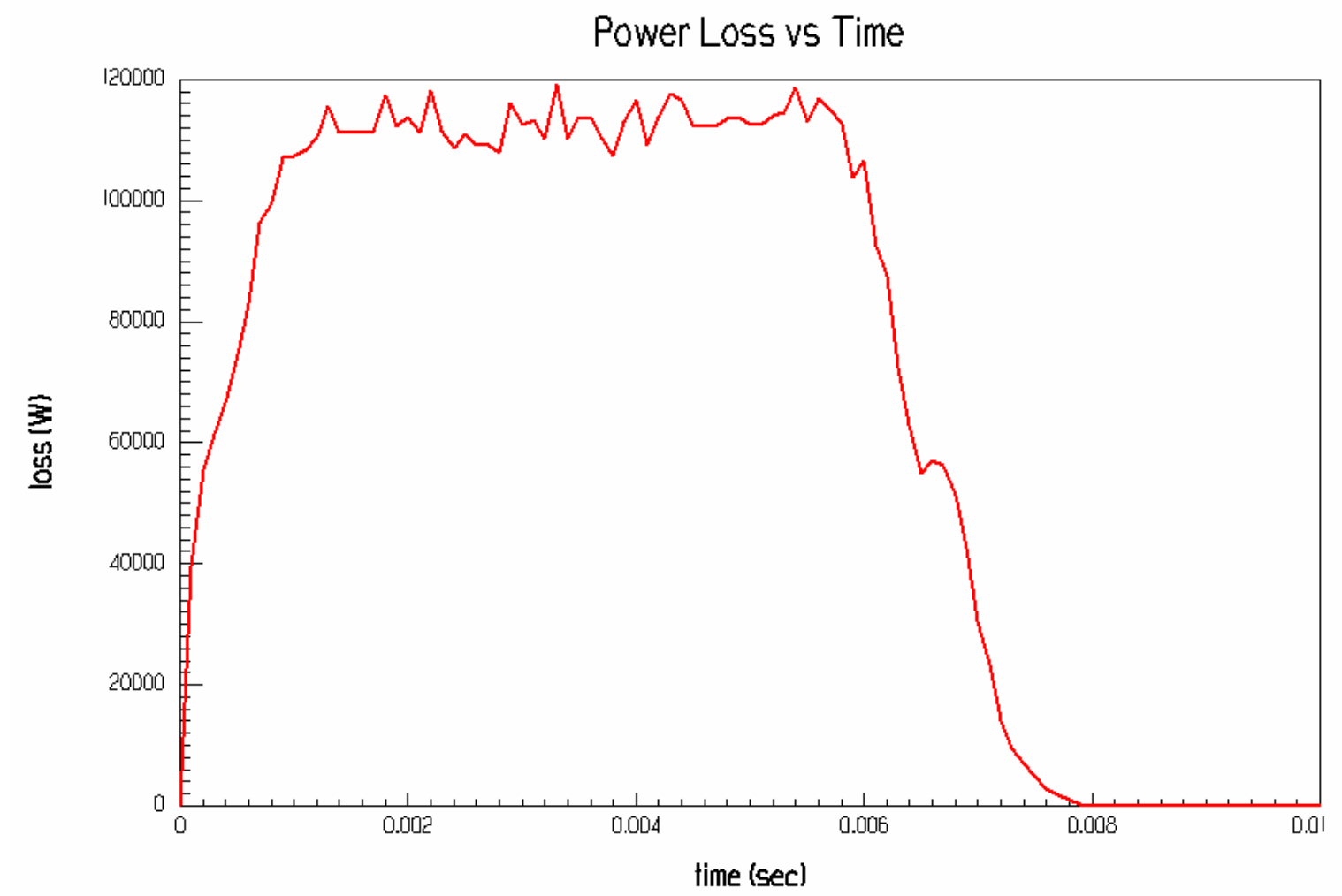

Figure 11 Eddy-current power loss for the 36 degree rim with 104,702 tetrahedra.

A question that has arisen during these calculations is the possible formation of skin effect current layers near the lateral surfaces of the wheel and the rim. If skin effect layers form near these surfaces, the mesh must be set up to resolve these layers in order to get decent results for the eddy-current loss. To investigate possible axial skin layers, we have subdivided the solid model of the rim segment into equally spaced parts in the axial or $\mathrm{Z}$ direction. Figure 12 shows the magnitude of the $\mathrm{B}$ field in the rim segment along the coil centerline at $0.004 \mathrm{sec}$ into the simulation for two axial layers and 53,425 tetrahedra. Although the B field magnitude decreases through the rim from either side to the center, a skin effect layer, in which the field drops by about $67 \%$ or e-folds over a short distance, is not formed. In Figure 12, the peak field at the right side is about $6.42 \mathrm{~T}$, while the minimal field at the center is about $6.09 \mathrm{~T}$. The decrease in the field from the right side to the center is about $5.14 \%$. 


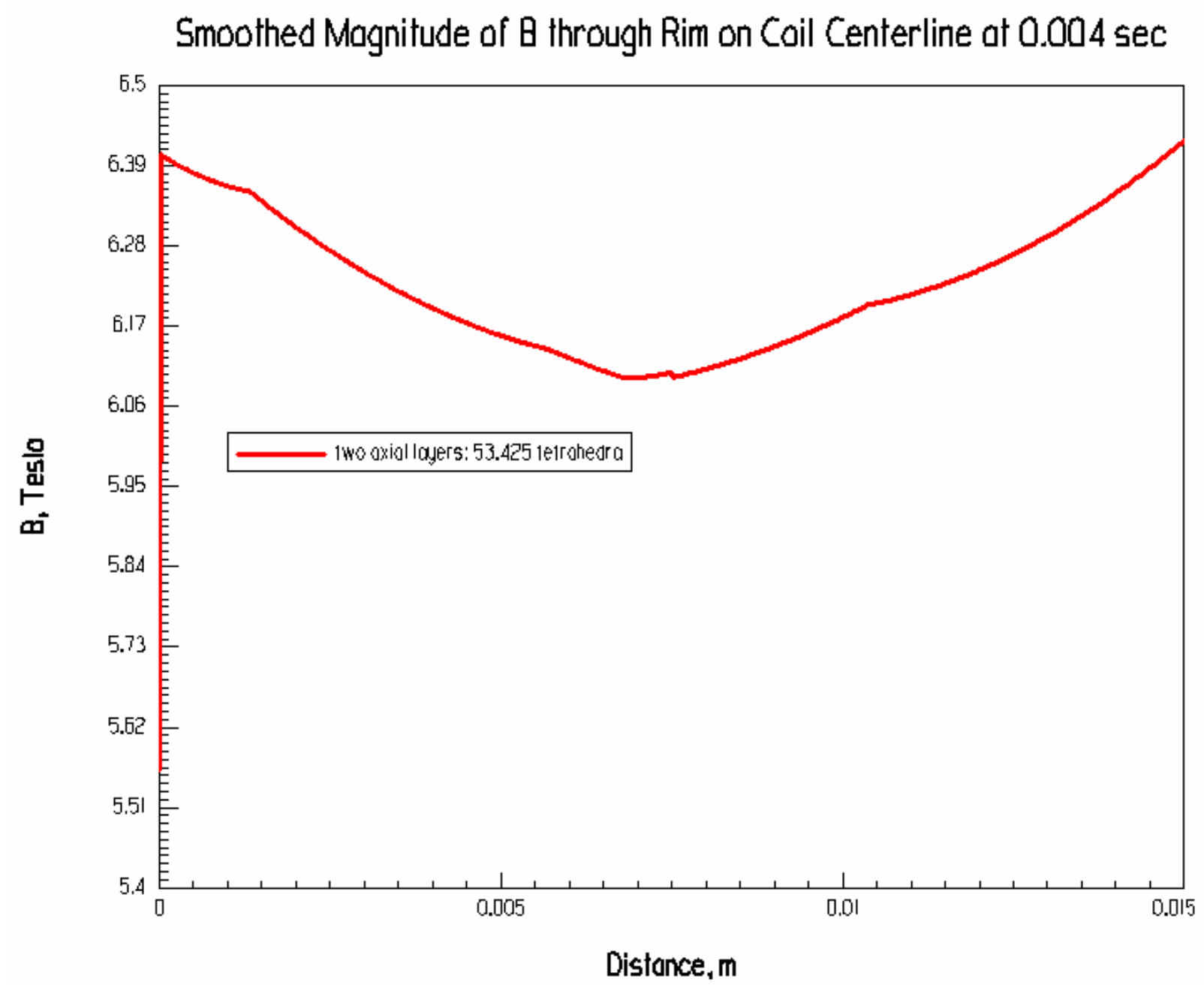

Figure 12 Magnitude of the rim $B$ field on the coil centerline for 2 axial layers.

Figure 13 shows the magnitude of the current density $\mathrm{J}$ in the rim along the coil centerline at $0.004 \mathrm{sec}$. The general trend of the current density distribution along the coil centerline is similar to that of the corresponding B field. The value of the magnitude of the current density at its minimum is about $1.57910^{7} \mathrm{~A} / \mathrm{m}^{2}$. The value of the current density at its maximum at the right side is about $1.87310^{7} \mathrm{~A} / \mathrm{m}^{2}$. The current density at the center of the rim is thus about $84.3 \%$ of its peak value. A more refined mesh should yield a smoother curve for the magnitude of the current density. 


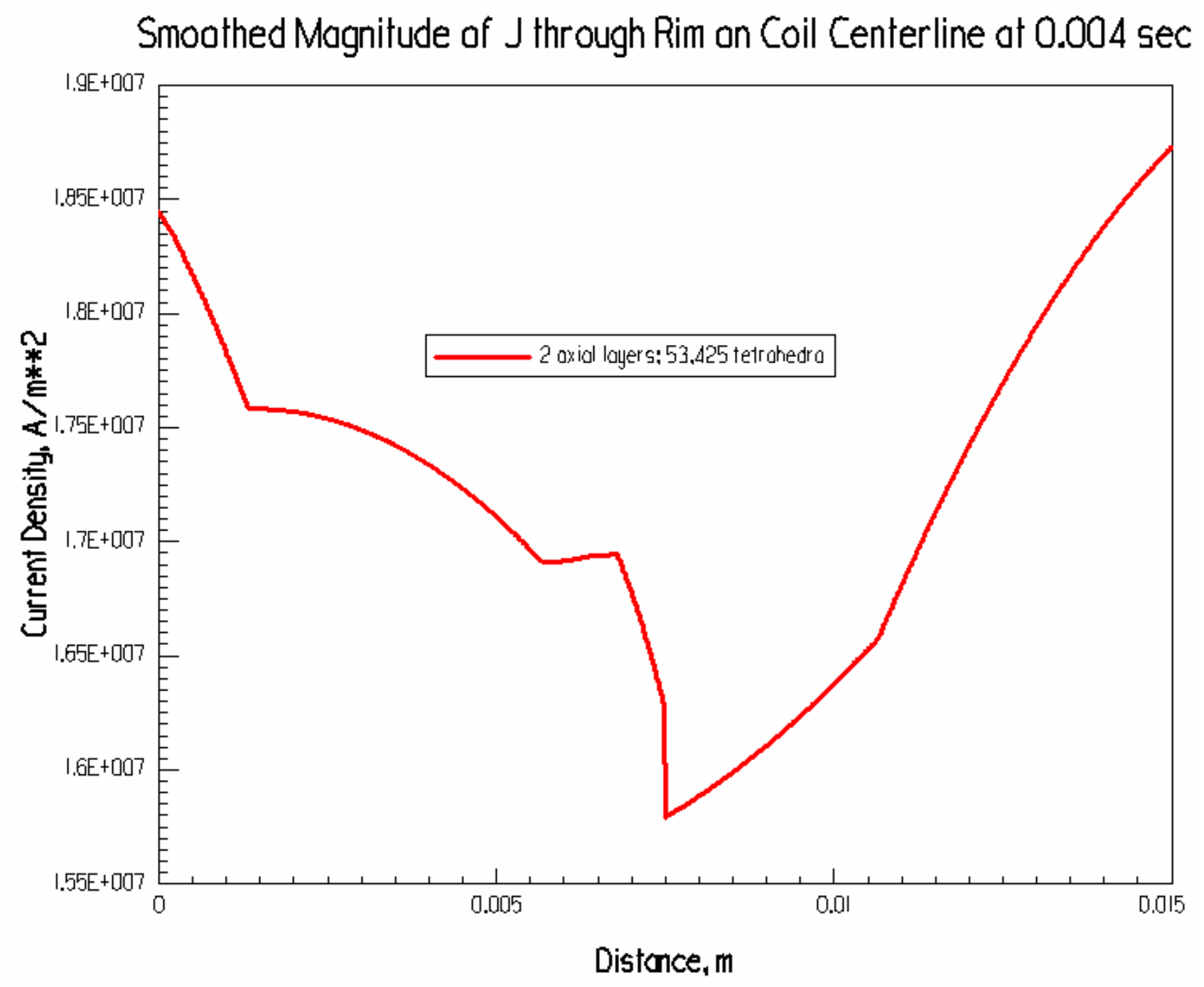

Figure 13 Magnitude of rim current density on the coil centerline for two axial layers.

Figure 14 shows the magnitude of the B field on the coil centerline at $0.004 \mathrm{sec}$ into the simulation for ten axial layers and 103,891 tetrahedra. Although the variation of the B field magnitude from either side to the center is more pronounced for this arrangement of the mesh, skin effect layers, once again, do not form. In Figure 14, the peak field near the left side is about $6.31 \mathrm{~T}$, while the minimal field at the center is about 5.76 T. The decrease in the field from the maximum near the left side to the center is about $8.72 \%$. The results of this investigation indicate that axial skin effect layers do not form for this geometry under these conditions at $900 \mathrm{rpm}$. At a much higher speed, axial skin effect layers are expected to form. These layers are also expected to form for an alloy, which has a much lower electrical resistivity than the one we are presently considering. 


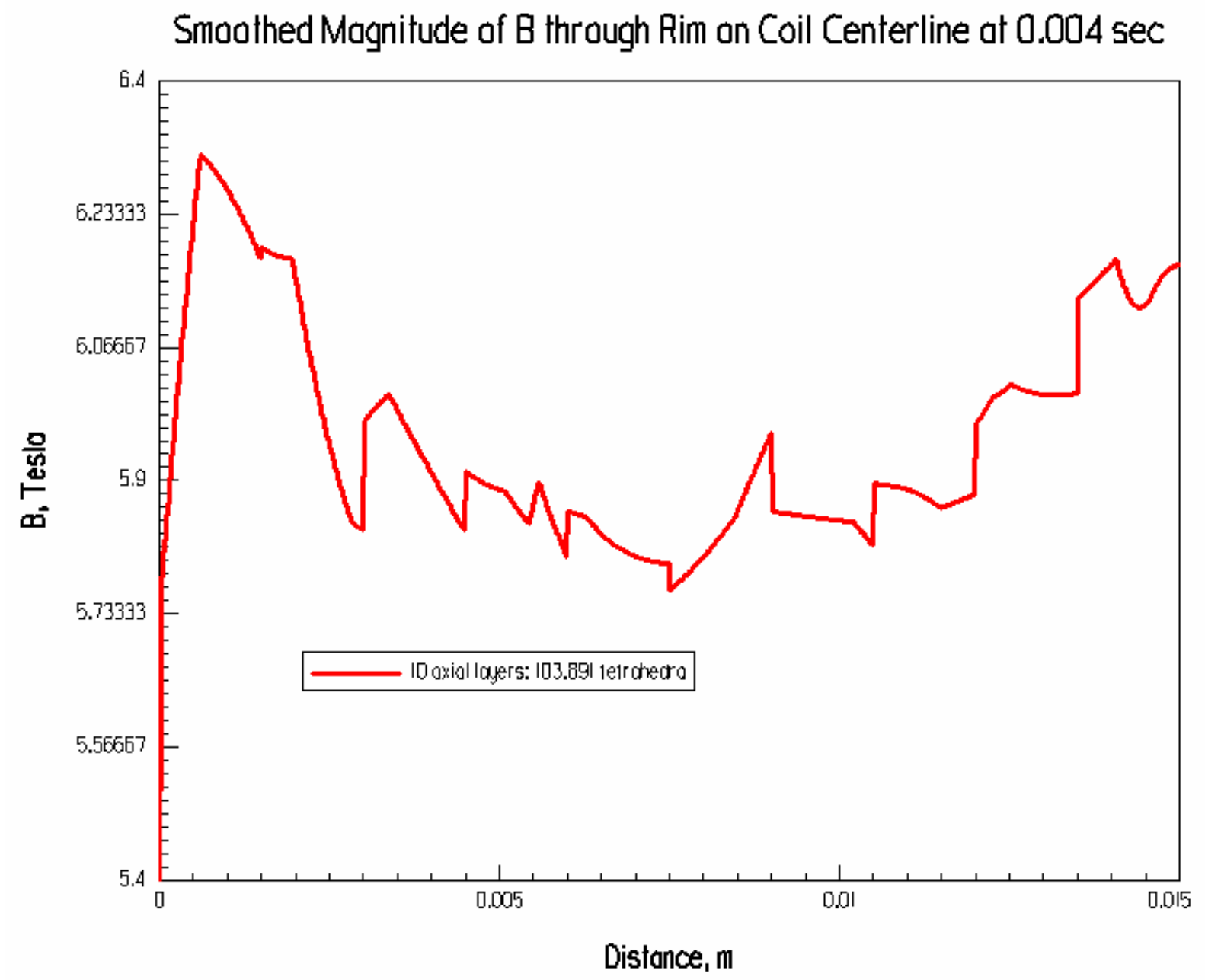

Figure 14 Magnitude of the rim $B$ field on the coil centerline for 10 axial layers.

Figure 15 shows the magnitude of the current density in the rim along the coil centerline at $0.004 \mathrm{sec}$ for the simulation with ten axial layers. For this simulation, the general trend of the current density distribution along the coil centerline is different from that of the corresponding B field. In this case, the current density is essentially constant from the upper face of the rim to about $1.1 \mathrm{~cm}$ into the rim, where it rises to a maximum at the lower face of the rim The value of the magnitude of the current density at its minimum is about $1.56110^{7} \mathrm{~A} / \mathrm{m}^{2}$. The value of the current density at its maximum at the right side is about $3.20410^{7} \mathrm{~A} / \mathrm{m}^{2}$. The current density at the center of the rim is thus about $51.3 \%$ of its peak value. A layer of increasing current density occupies the outer one-third of the rim. 


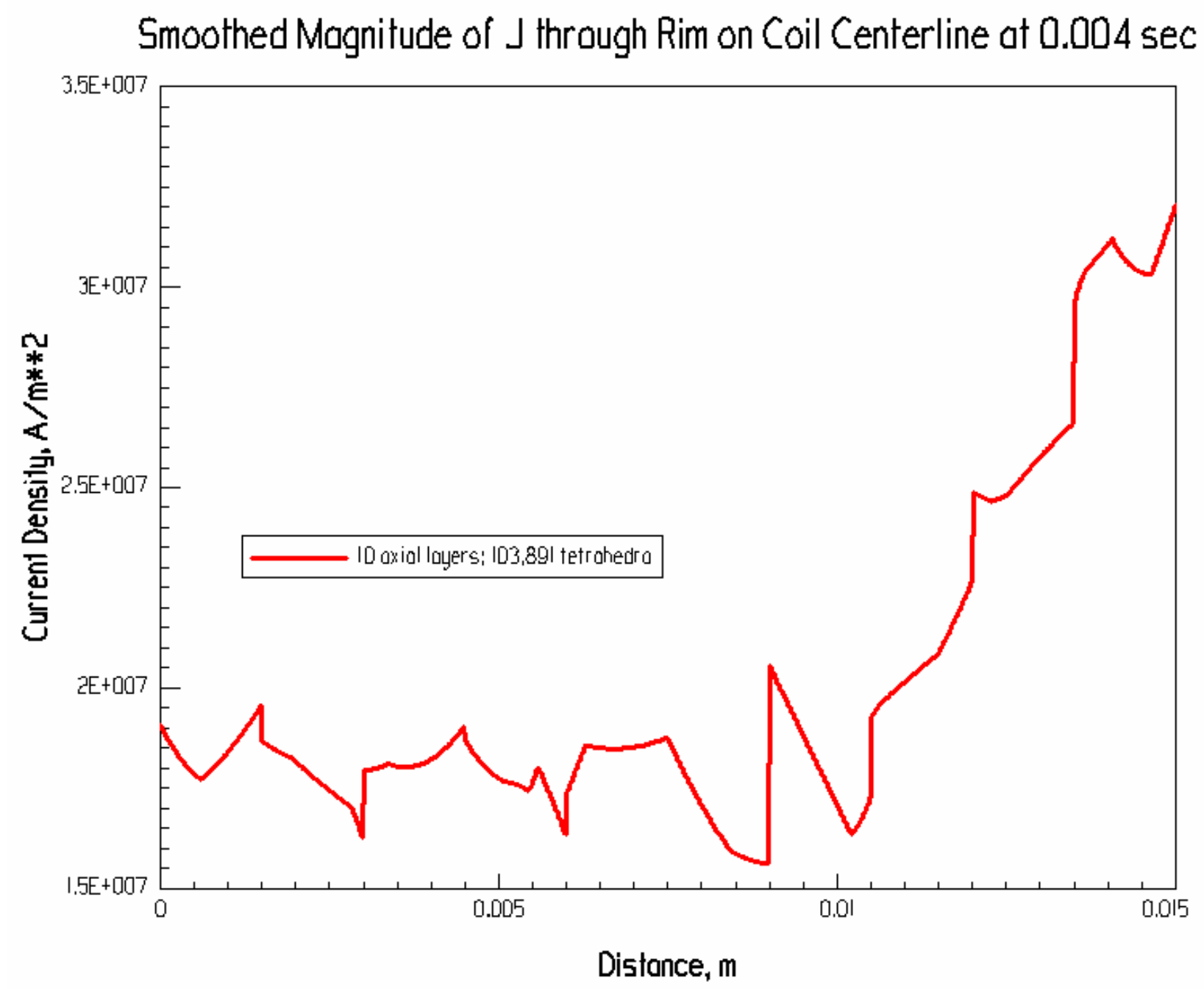

Figure 15 Magnitude of the rim current density on the coil centerline at 0.004 sec.

We have examined two configurations involving a spoke to be connected to the wheel rim. The first configuration is an isolated spoke rotating through the magnetic field of the coils at $900 \mathrm{rpm}$. The geometry for this configuration is shown in Figure 16. The spoke is a rectangular solid $10 \mathrm{~cm}$ in length with a cross section $1 \mathrm{~cm}$ wide and $0.25 \mathrm{~cm}$ high. The material of the spoke is the same titanium alloy as previously used for the wheel and the rim. The spoke rotates counterclockwise between the coils at $900 \mathrm{rpm}$. Eddy currents are generated in the spoke as it rotates in the magnetic field created by the coils. The mesh for this simulation contained 22,663 tetrahedra, 11,876 of which were allocated to the spoke. The time-dependent eddy-current power in the isolated spoke is shown in Figure 17. The power loss curve contains two major peaks. The first peak, at $0.00025 \mathrm{sec}$, is the larger. It has a value of about $161.6 \mathrm{w}$ or $0.217 \mathrm{hp}$. The second peak occurs at $0.0009 \mathrm{sec}$. The peak power loss in the isolated spoke is quite small compared to the loss in the rim of about $149 \mathrm{hp}$, which was estimated previously. The peak power loss in the isolated spoke is about $0.146 \%$ of the estimated average loss in the rim. Thus, the addition of spokes of the type considered to the rim should create only a very small perturbation to the eddycurrent loss in the rim. 


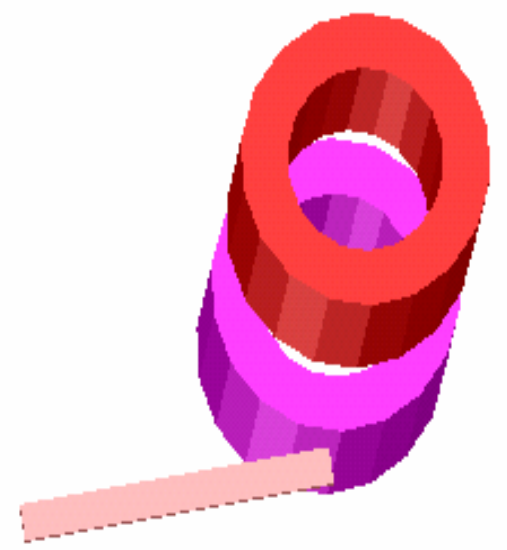

Figure 16 An isolated spoke rotating between the coils. 


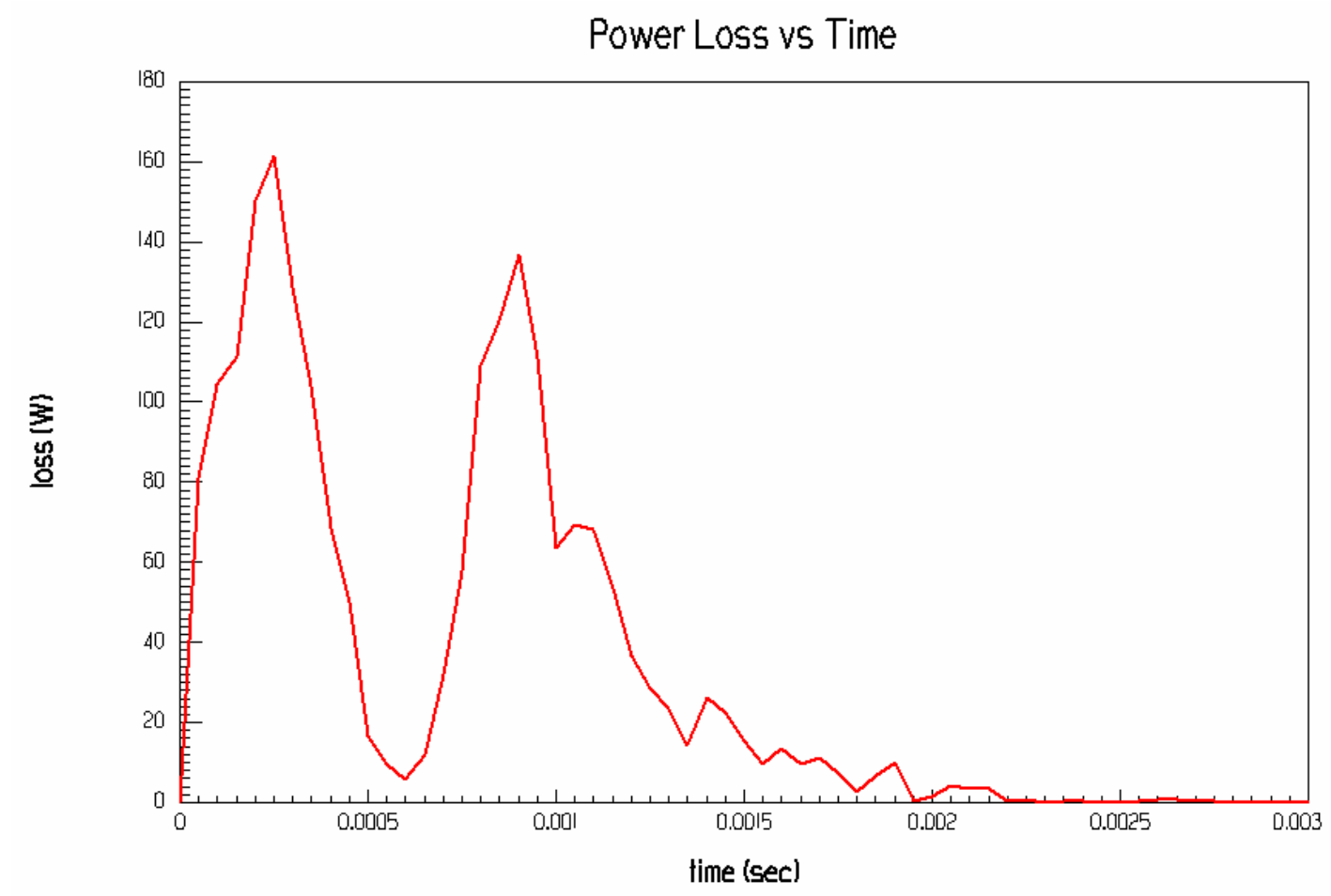

Figure 17 Power loss in the isolated spoke.

The current density pattern at the right end of the upper flat surface of the spoke at $0.00025 \mathrm{sec}$ is shown in Figure 18. At this time, the spoke is entering the bore of the coils. The view is downward from above the spoke. The projections of the coil inner and outer boundaries appear at the upper right as two sets of connected line segments. The eddy currents are flowing clockwise about the spoke. The current density is stronger at the right end, where the axial magnetic field is stronger. Due to some unknown error in the plotting software, the eddy current vectors are shifted downward from the upper edge of the spoke by about $0.5 \mathrm{~cm}$. The upper line of vector arrows should coincide with the upper edge of the spoke, which appears as two perpendicular line segments. The current density pattern at the right end of the upper flat surface of the spoke at $0.001 \mathrm{sec}$ is shown in Figure 19. At this time, as the spoke is emerging from beneath the coils, the eddy currents are flowing counterclockwise about the boundary of the spoke. Once again, the current density vectors should be translated upward about $0.5 \mathrm{~cm}$ to coincide with the outline of the spoke. Apparently, the eddy currents in the spoke change direction as the spoke passes beneath the center of the coils. The peak eddy-current flow in a given direction most likely occurs at the two major peaks of the time-dependent power loss curve 


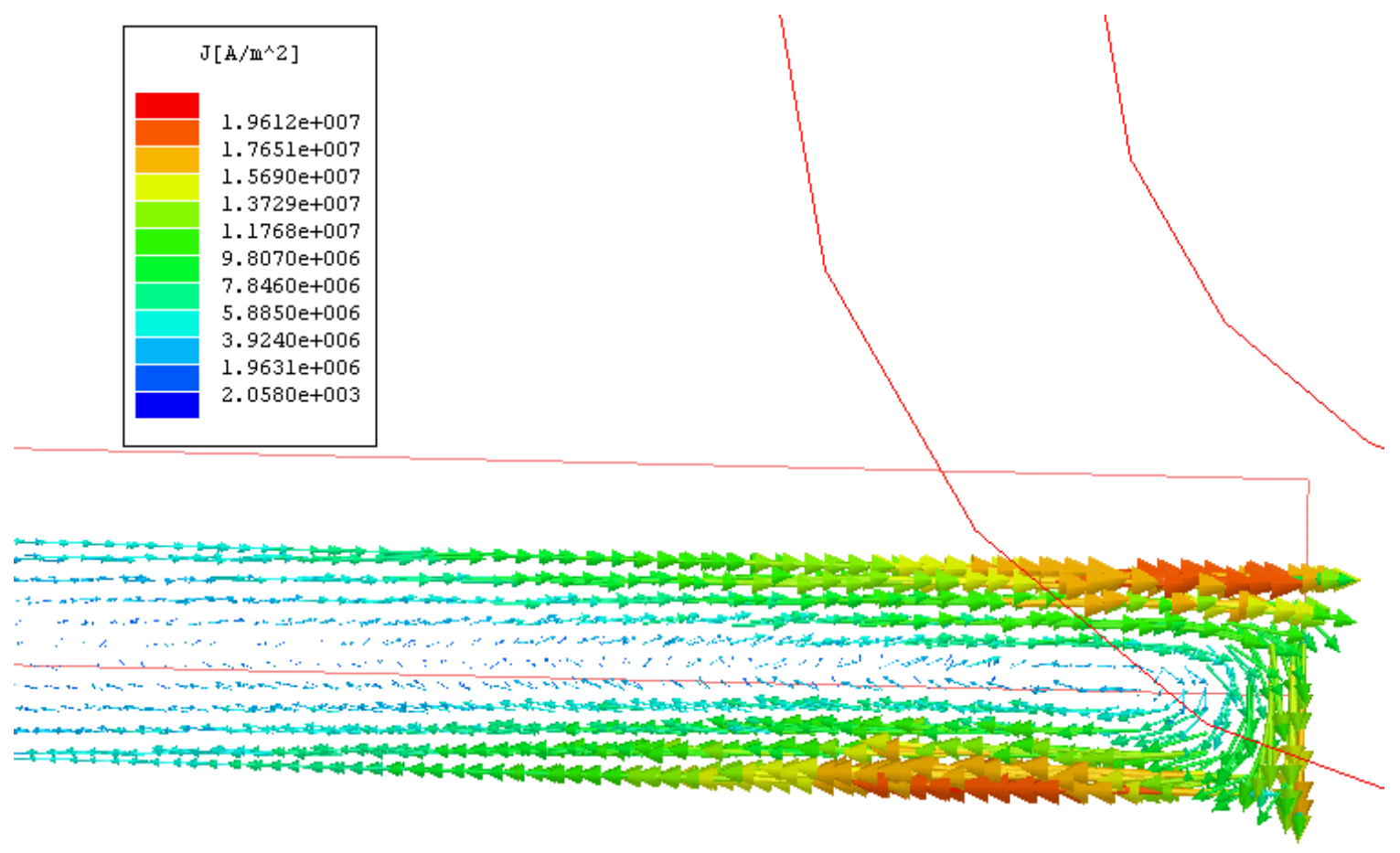

Figure 18 The current density vectors on the upper surface of the spoke at 0.00025 sec. 


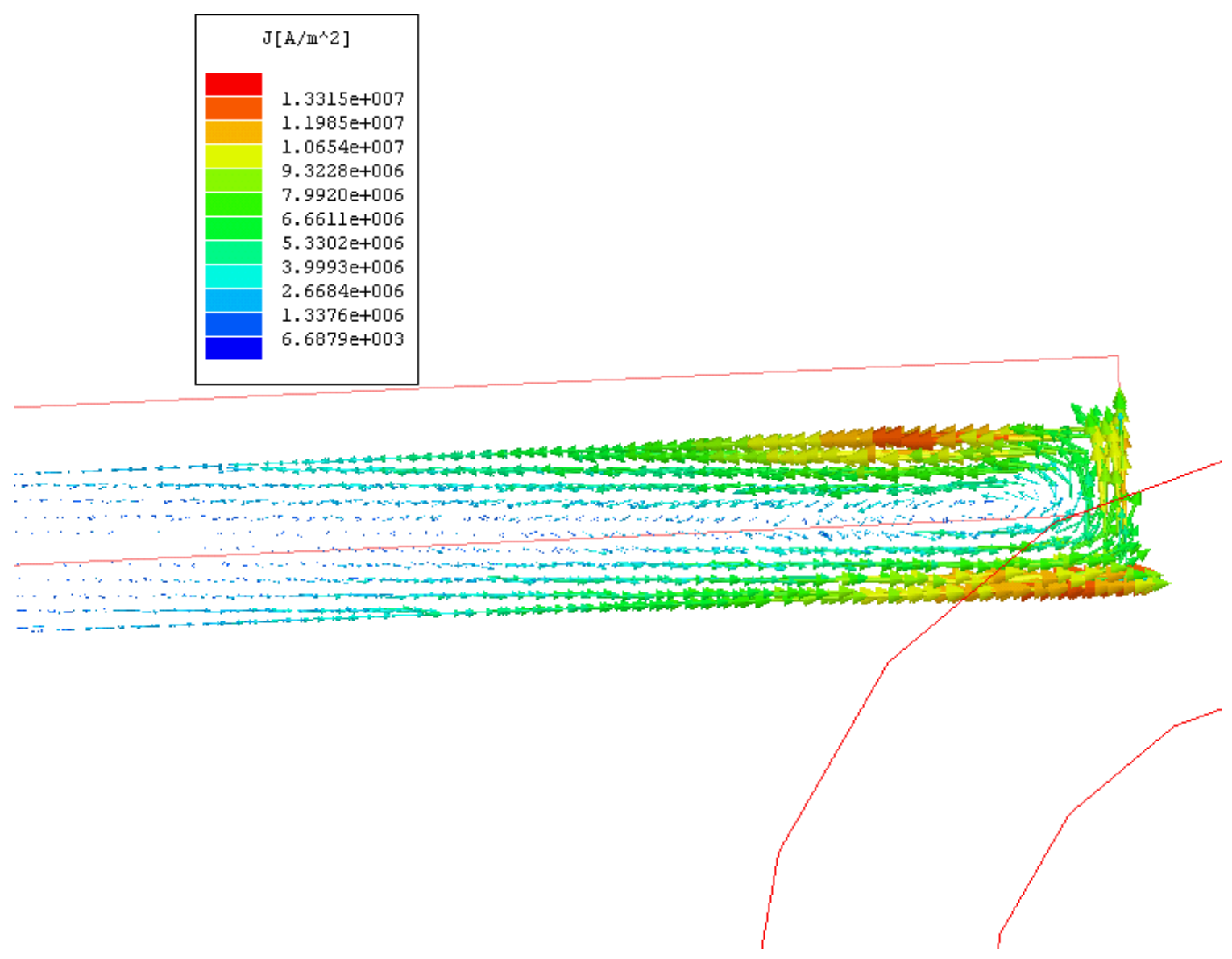

Figure 19 The current density vectors on the upper surface of the spoke at 0.001 sec.

We have also examined a single spoke connected to a 36-degree section of the rim. The geometry for this situation is shown in Figure 20. The simulation starts with the spoke and rim section in the position shown in the figure. The rim section then rotates counterclockwise between the coils at $900 \mathrm{rpm}$. In this simulation, 32,164 tetrahedra were used. 15,275 tetrahedra were allocated to the rim, and 1431 were allocated to the spoke. The eddy-current power loss is shown versus time in Figure 21. The average power loss during the plateau region is about $119,000 \mathrm{w}$ or $159.5 \mathrm{hp}$. This value is most likely greater than the previously cited $149 \mathrm{hp}$ because of the greater number of finite elements used in the rim section. The peak Lorentz or J X B forces on the spoke occur at 0.0003 sec and $0.0009 \mathrm{sec}$. At $0.0003 \mathrm{sec}$, the force on the spoke in the x-direction is $2.332 \mathrm{nt}$, and the force in the y-direction is $10.170 \mathrm{nt}$. The resultant force on the spoke in the xyplane is thus $10.434 \mathrm{nt}$. At $0.0009 \mathrm{sec}$, the force on the spoke in the x-direction is 1.788 $\mathrm{nt}$, and the force in the y-direction is $-7.590 \mathrm{nt}$. The resultant force on the spoke in the xy-plane at this time is then $7.798 \mathrm{nt}$. These two peak force values correspond to the two peaks of the power loss of the isolated spoke in Figure 17. 


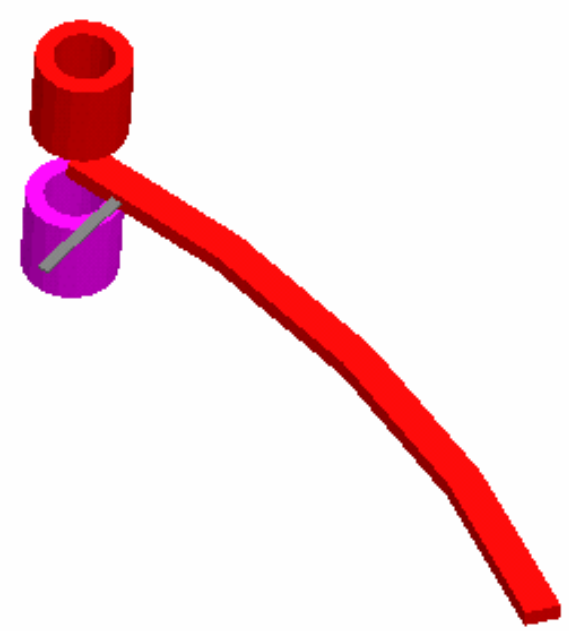

Figure 20 A spoke connected to the rim section. 


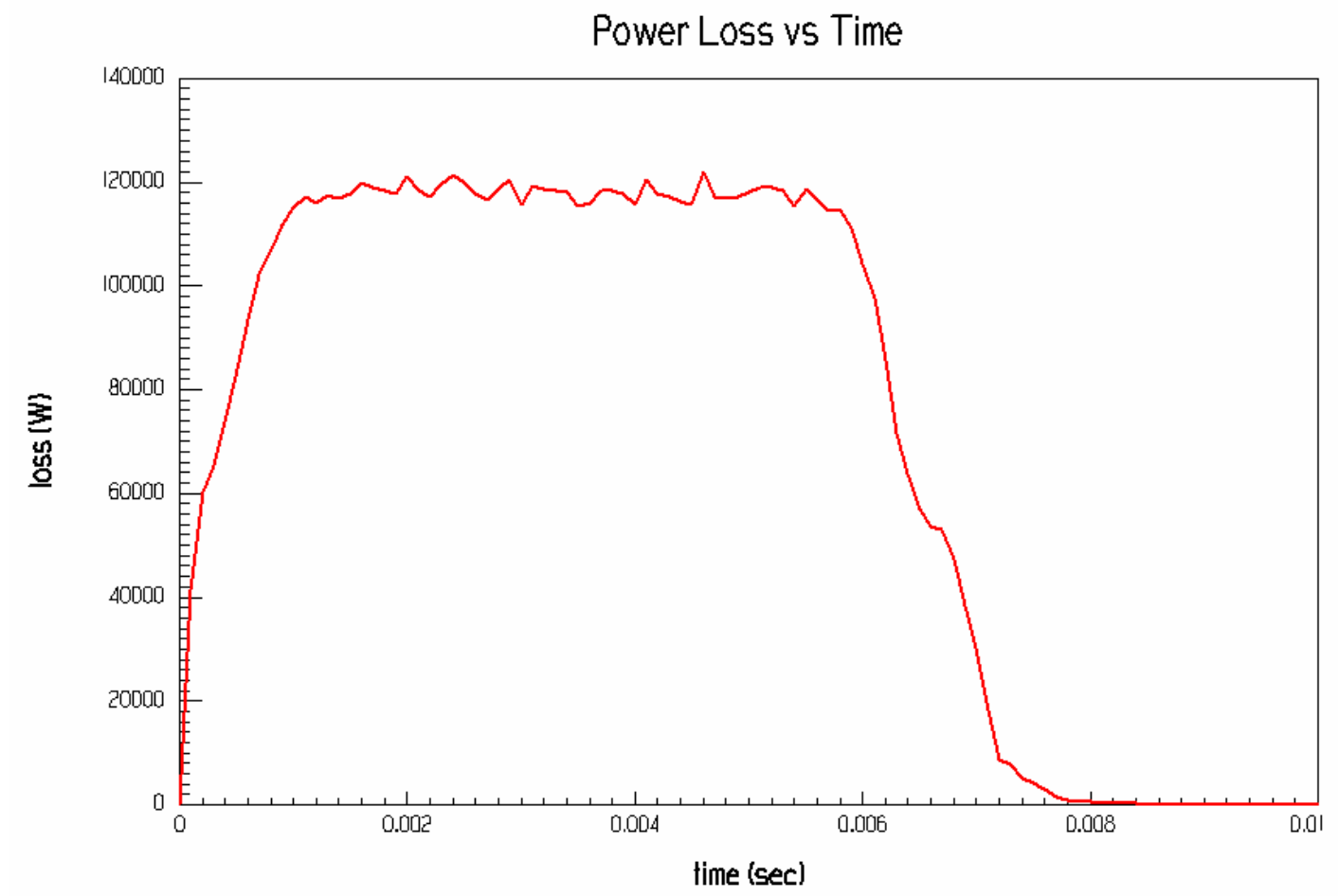

Figure 21 Eddy-current power loss in the spoke and the rim section.

We have carried out further simulations of titanium rims and spokes with watercooling passages. Figure 22 shows a hollow spoke connected to a rim with two watercooling passages in it. The titanium spoke, which is a tube, is shown in blue. It is $15 \mathrm{~cm}$ in length. The outer diameter is $9 \mathrm{~mm}$, and the inner diameter is $7 \mathrm{~mm}$. The hollow region is assumed to be vacuum in the simulation, thus ignoring eddy currents that might flow in the water. The spoke is connected to the rim section, shown in gray. The dimensions of the rim cross section are $2.2 \mathrm{~cm}$ in the radial direction and $1.43 \mathrm{~cm}$ in the axial direction. The outer dimension of the rim section is $1 \mathrm{~m}$ from the axis of rotation, which is the $\mathrm{z}$ axis. The rim section subtends 8.193 degrees relative to the center of rotation. The outer linear distance of the rim section in the circumferential direction is $14.28 \mathrm{~cm}$. The two water-cooling passages in the rim section are shown in blue near the inner circumferential boundary. They are centered at $4.5 \mathrm{~mm}$ from the inner radius of the rim section and 3.93 $\mathrm{mm}$ from each of the axially facing surfaces of the rim. The passages are $0.5 \mathrm{~mm}$ in diameter. The two passages are also assumed to contain vacuum. Two solenoidal electrical coils are shown in red. The coils are each $6 \mathrm{~cm}$ in outer diameter and $2 \mathrm{~cm}$ in inner diameter. They are $8 \mathrm{~cm}$ in height and located $3.285 \mathrm{~cm}$ from the corresponding axially facing surfaces of the rim section. The axial centerline of the two coils is located $98.9 \mathrm{~cm}$ radially outward from the coordinate origin. The current in each coil is set at $3.35510^{6}$ A to produce a B field magnitude of $5.00 \mathrm{~T}$ at the surface of the rim section when there is no motion. The solution mesh contains 23,478 tetrahedra.. The currents in each coil are in the same direction so that the B fields from each coil add to produce a magnetic flux vector in the positive $\mathrm{z}$ direction. The coils are thus in a "boost" configuration, as opposed to a "buck" configuration, in which the field vectors from the two coils oppose each other and generate smaller field values between the coils. Figure 
23 shows the magnitude of the B field along the axis of the coils from the top of the lower coil to the bottom of the top coil. The lower axially facing surface of the rim section is at $0.03285 \mathrm{~m}$ on Figure 23, the axial center of the rim section is at $0.04 \mathrm{~m}$, and the upper axially facing surface of the rim section is at $0.04715 \mathrm{~m}$ on Figure 23. Figure 24 shows the magnitude of the B field on the top surfaces of the rim section and the spoke for the rim section centered under the coils in the boost configuration with no motion. The wire frame outline of the coils are superimposed on the rim and the spoke.

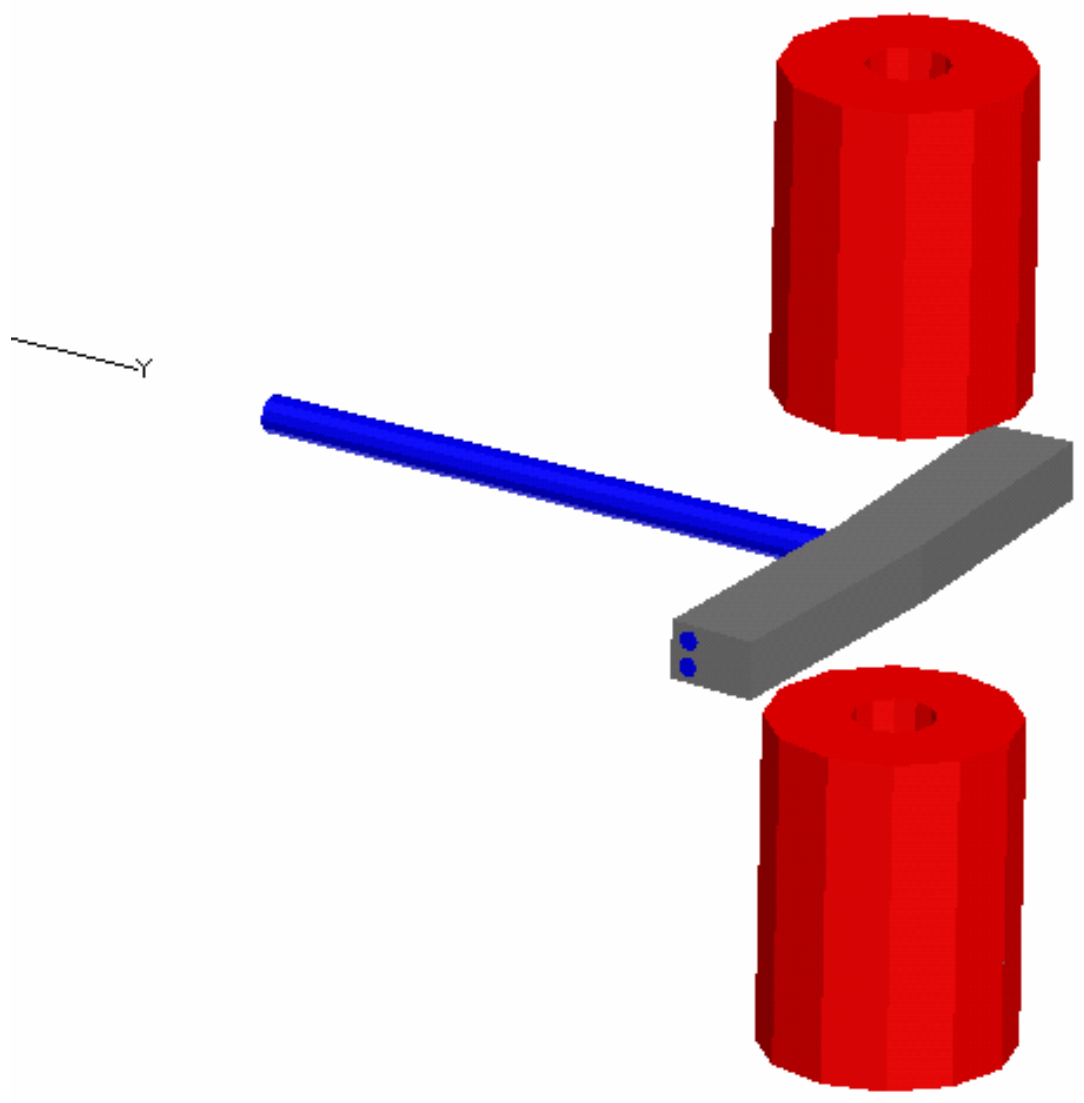

Figure 22 A hollow spoke and rim with water-cooling passages. 


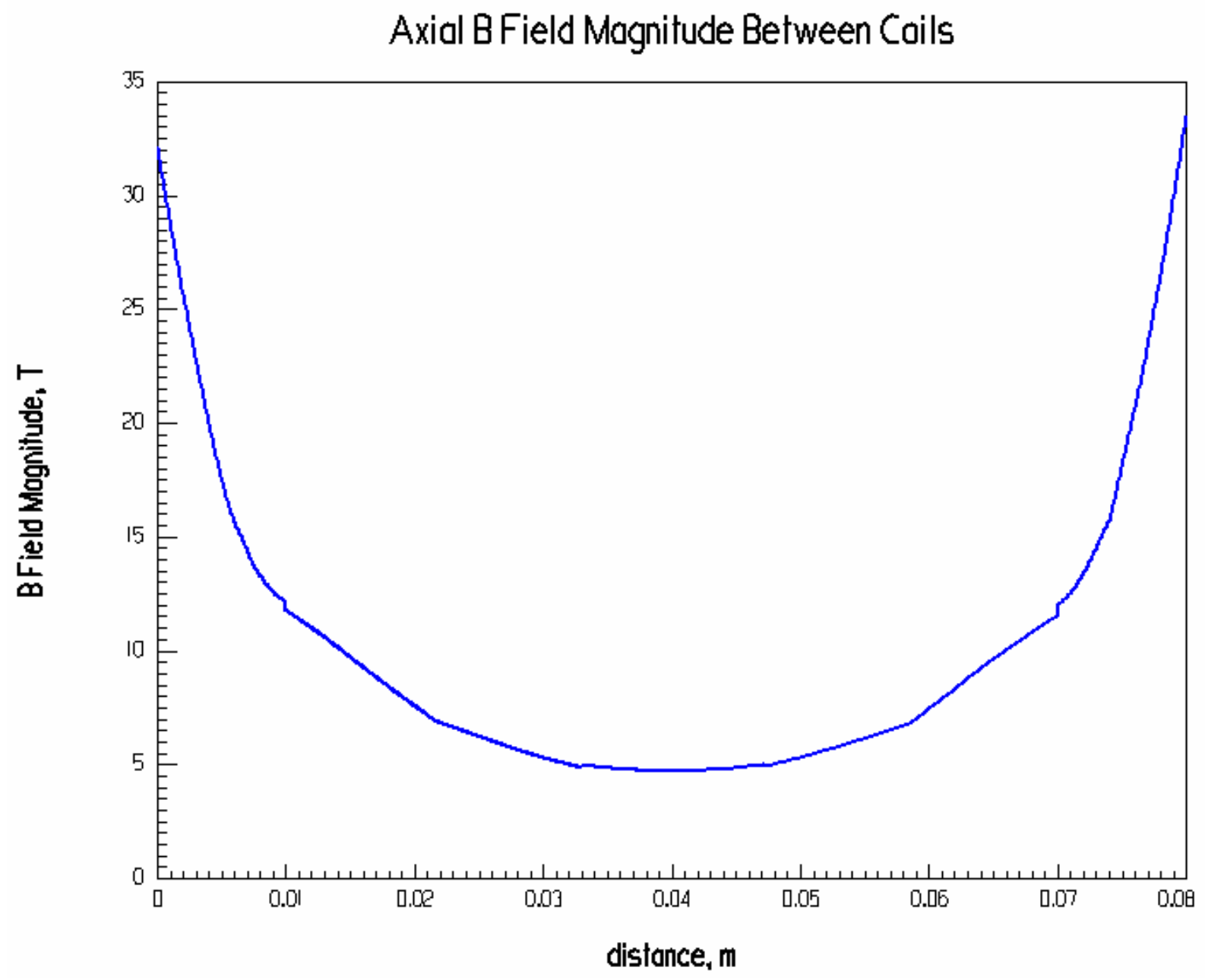

Figure 23 The magnitude of the axial $B$ field between the coils. 

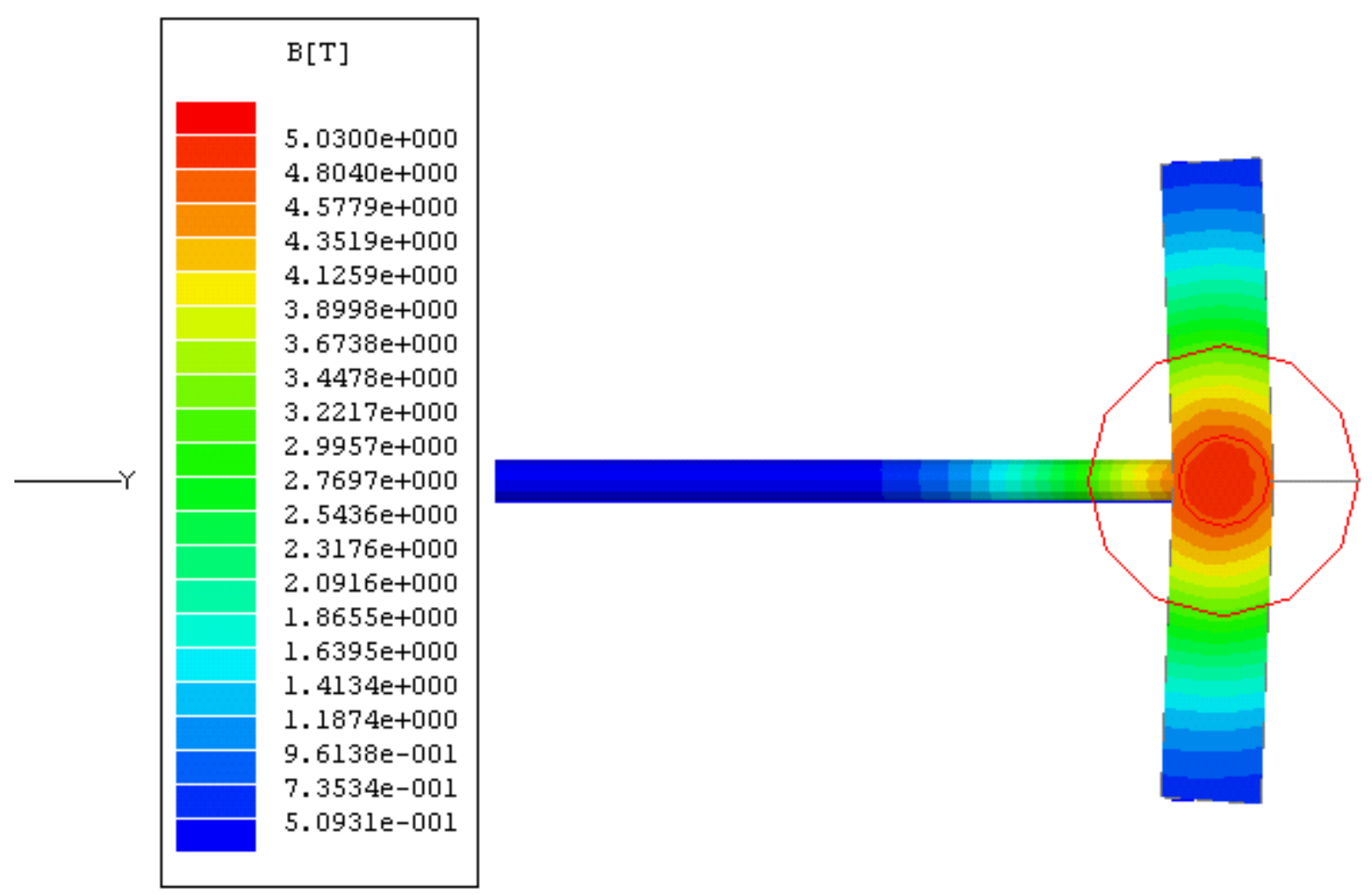

Figure 24 The B field magnitude for the boosting coil configuration without motion.

Figure 25 shows the eddy-current power loss for a solution mesh with 84,065 tetrahedra and a time step of $10^{-4} \mathrm{sec}$. The peak power loss is $22,385 \mathrm{w}$ or $30.01 \mathrm{hp}$. Thus, we see that using smaller bore coils and a smaller dimension spoke and rim section with cooling passages filled with vacuum reduces the peak power loss substantially from about $160 \mathrm{hp}$. The volume within which the strong eddy currents can flow has been substantially reduced. Figure 26 shows the B field magnitude along the axis of the coils when the rim section is centered under the coils with no motion, in red, and at $0.0014 \mathrm{sec}$ into the motional simulation when the rim section is almost centered under the coils at $900 \mathrm{rpm}$, in blue. The B field magnitude is plotted within the axial extent of the cylindrical computational band object. All rotational motion occurs within the band object. The band object extends from about $1 \mathrm{~cm}$ above the lower coil to about $1 \mathrm{~cm}$ below the upper coil. The B field magnitude for the stationary case is greater than the B 
field magnitude for motion at $900 \mathrm{rpm}$, except at the extreme right of the plot. The rim section extends axially from $0.03285 \mathrm{~m}$ to $0.04715 \mathrm{~m}$. It is demarcated by the discontinuities at the ends of the center sections of the two curves. The minimum value of the axial B field magnitude for $0.0014 \mathrm{sec}$ is $4.457 \mathrm{~T}$.

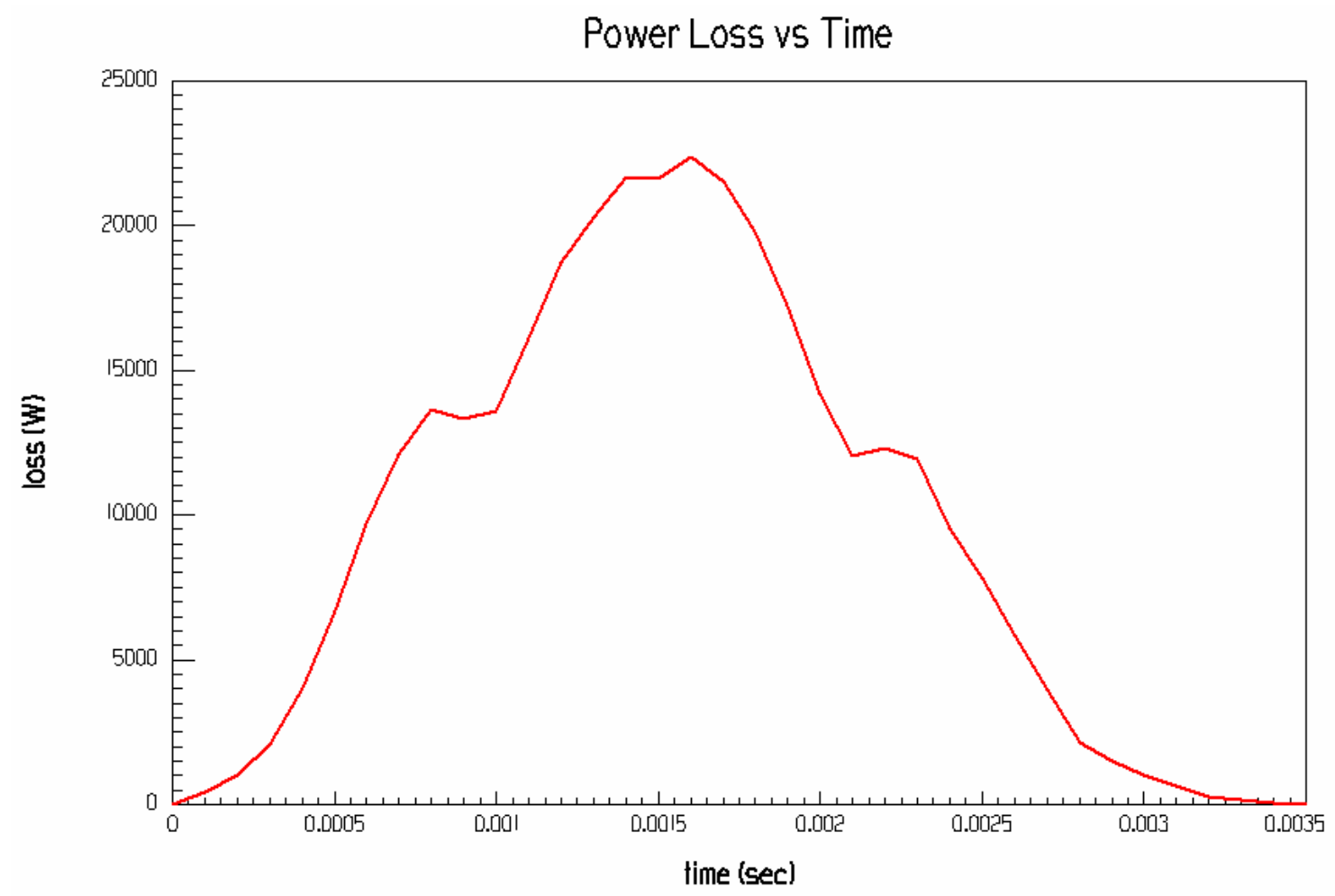

Figure 25 Eddy-current power loss for a spoke and rim section with cooling passages, boosting. 


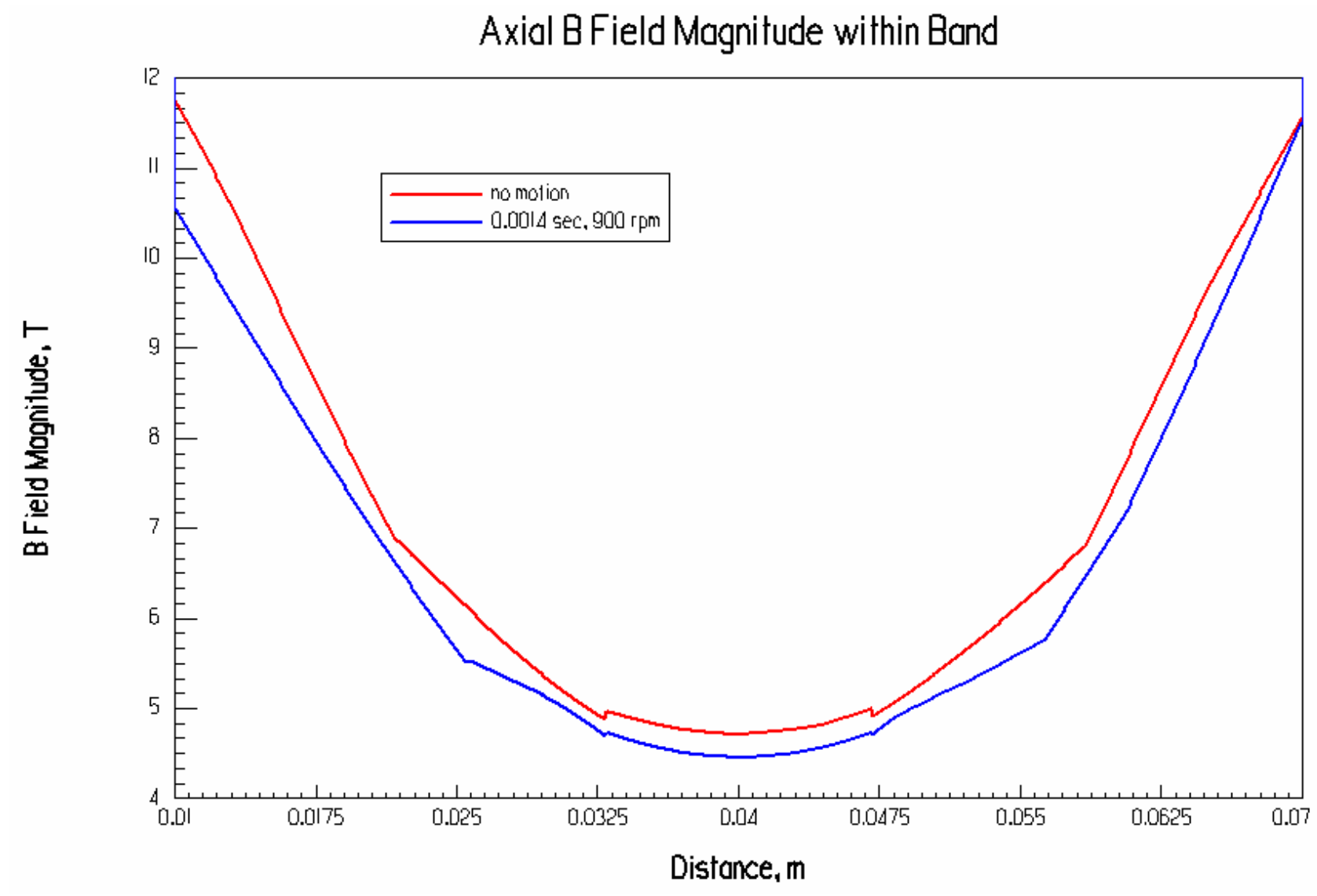

Figure 26 Axial B field magnitude with and without motion.

We have reversed the direction of the current in the top coil, so that the coils are in a bucking configuration. Figure 27 shows a color contour plot of the B field magnitude on the top surface of the spoke and the rim section when the rim section is centered under the coils and motionless. The outline of the coils is superimposed on the B field pattern. The corresponding axial profile of the B field magnitude between the coils is shown in Figure 28. The small discontinuities at about $0.01 \mathrm{~m}$ and $0.07 \mathrm{~m}$ show the locations of the axial edges of the computational band object. The minimum $\mathrm{B}$ field magnitude at the center of the rim section at $0.04 \mathrm{~m}$ is about $0.32 \mathrm{~T}$. 


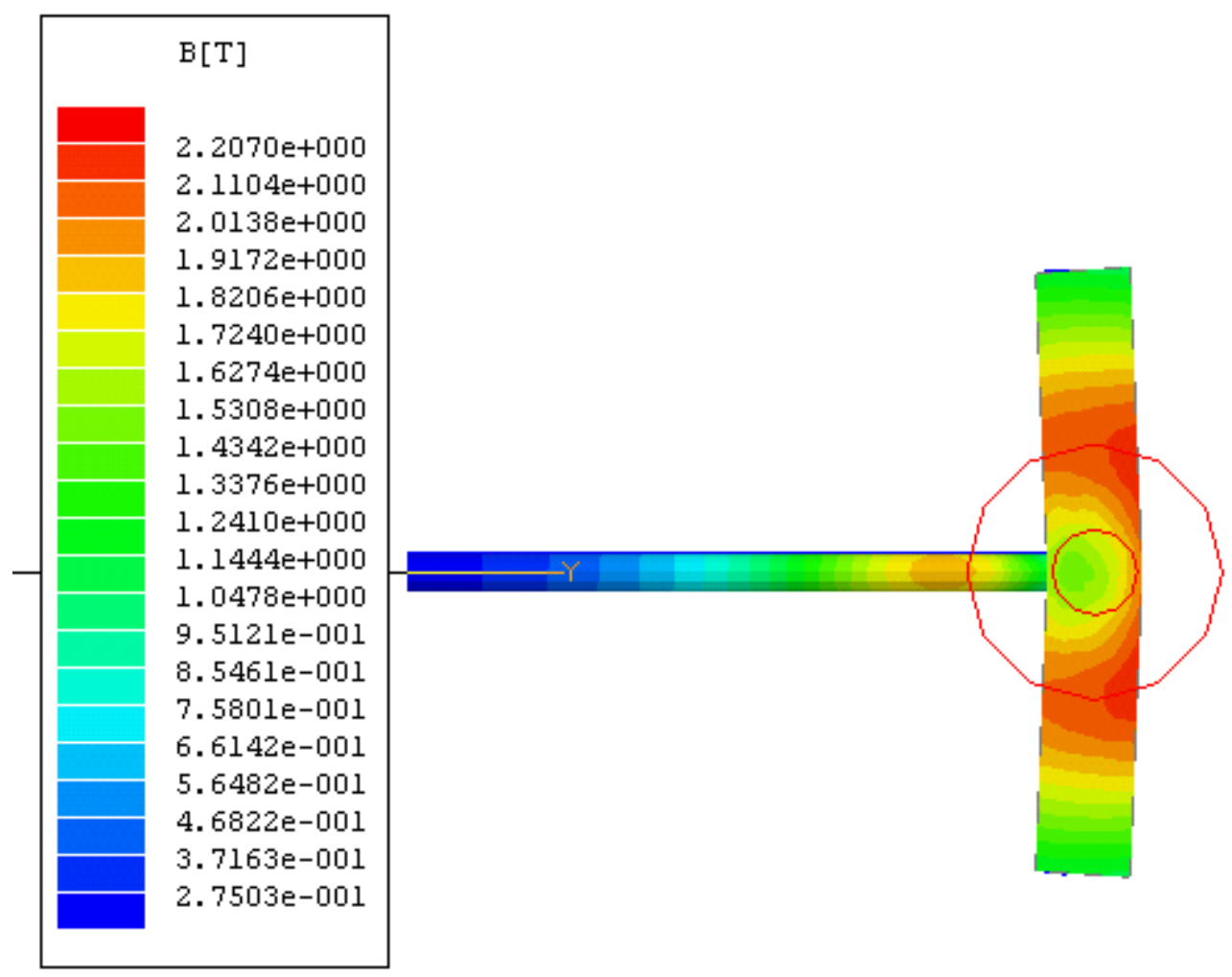

Figure 27 The B field magnitude for the bucking coil configuration without motion. 


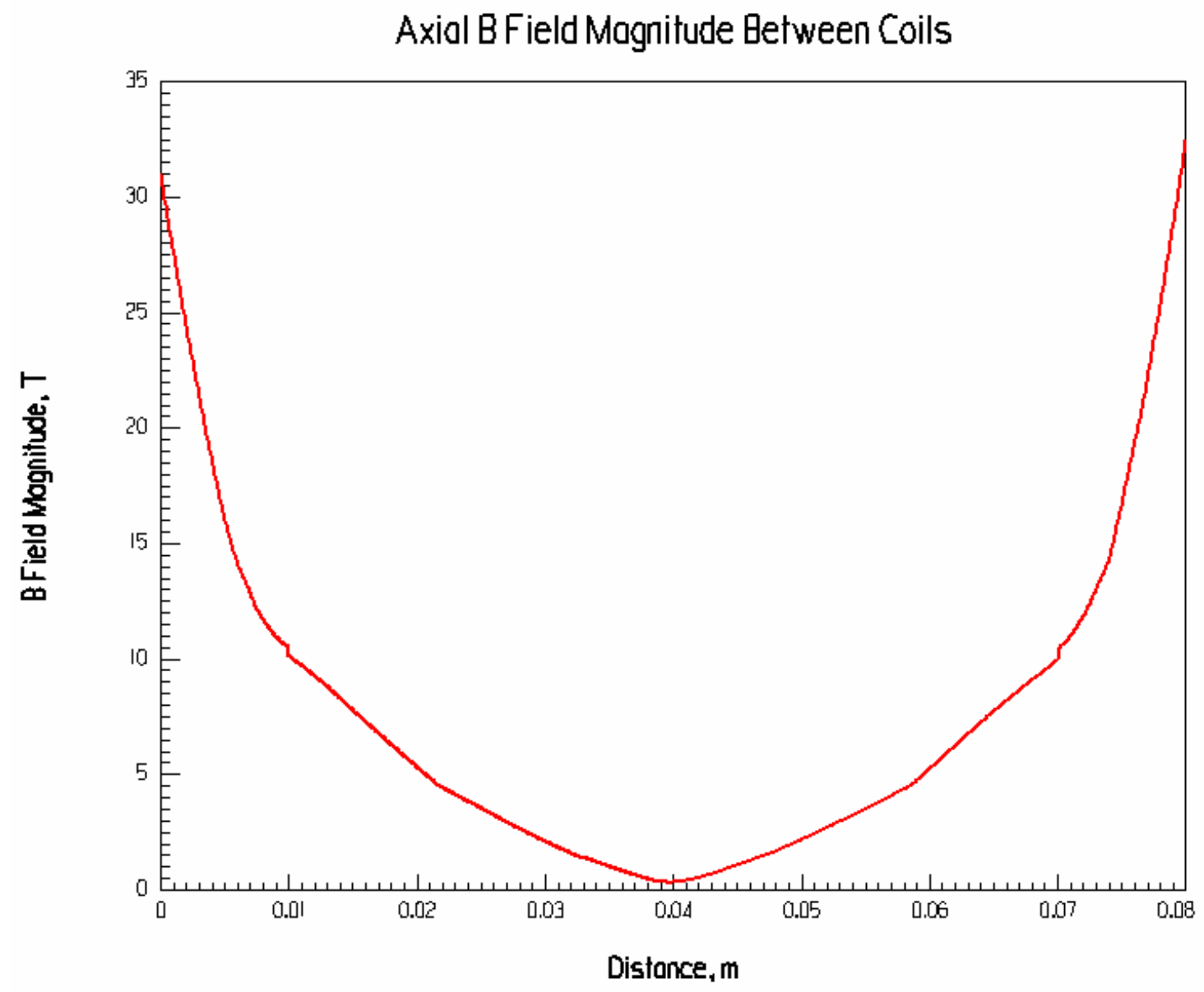

Figure 28 The axial B field magnitude for the bucking configuration without motion.

Figure 29 shows, in blue, the axial B field magnitude at $0.0014 \mathrm{sec}$ within the computational band object when the rim section is rotating at $900 \mathrm{rpm}$. The rim section is almost centered under the coils. The corresponding B field magnitude for no motion is shown in red. The curve for no motion is higher than the curve for $900 \mathrm{rpm}$, except from about $0.03 \mathrm{~m}$ to $0.037 \mathrm{~m}$, about $0.04 \mathrm{~m}$ to about $0.05 \mathrm{~m}$, and at $0.07 \mathrm{~m}$. The initial axial $\mathrm{B}$ field appears to be altered less by the motion in the bucking configuration than in the boosting configuration. 


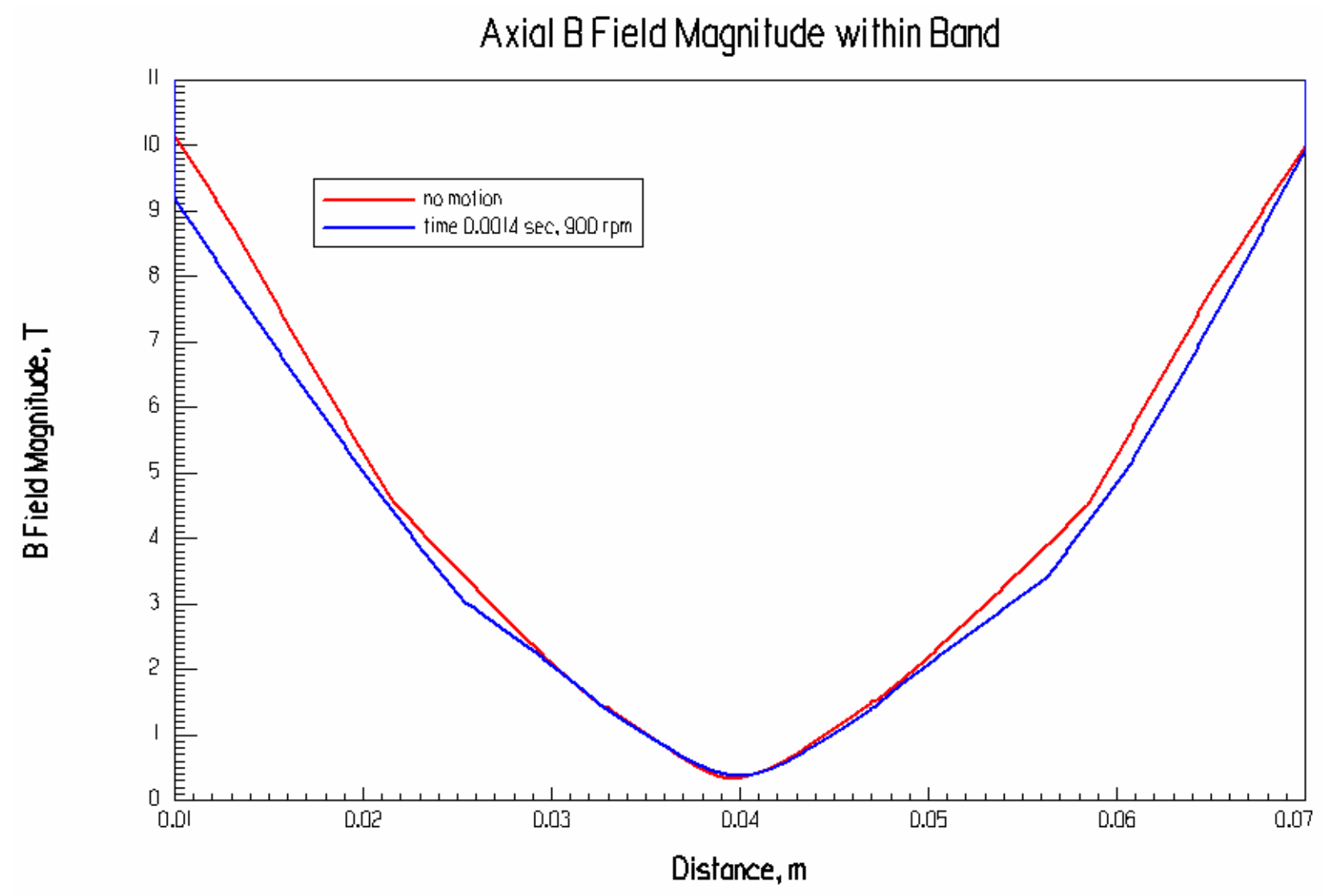

Figure 29 Axial B field magnitude with and without motion for the bucking configuration.

Figure 30 shows the time-dependent power loss of the rim section and the spoke in the bucking coil configuration. The peak power loss is now about $3740 \mathrm{w}$ or $5.01 \mathrm{hp}$ at $0.00160 \mathrm{sec}$. 


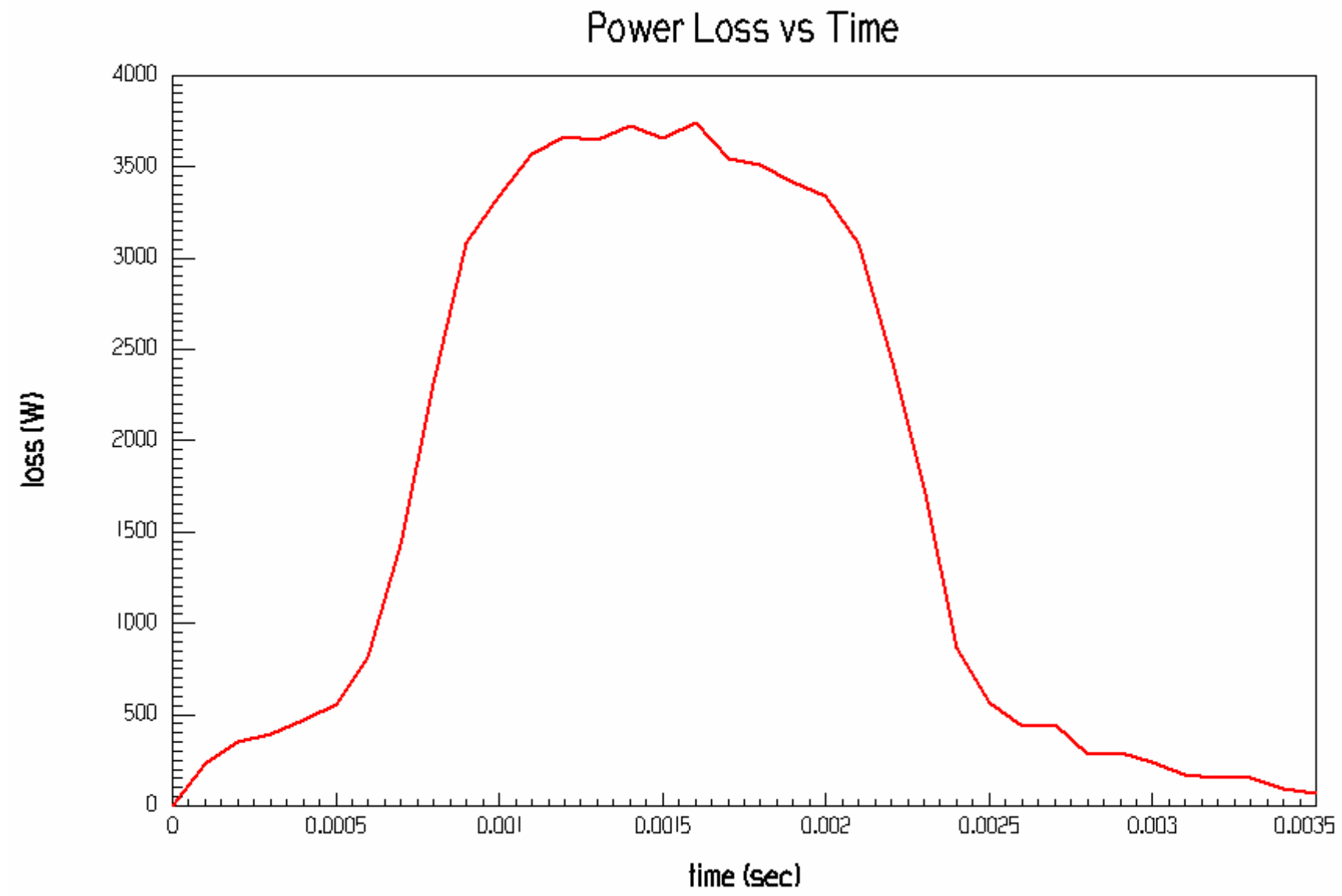

Figure 30 Eddy-current power loss for a spoke and rim section with cooling passages, bucking.

Next, we have considered a rim section of 0.820 degrees of radial extent, connected to a central spoke of the previous type. The objective of this exercise is to estimate the steady-state eddy-current power loss of a target wheel composed of many small, watercooled rim sections, which are electrically insulated from each other. The geometry for this case is shown in Figure 31. The linear distance between the outer radial corners of the axial-facing surface of the rim section is $1.43 \mathrm{~cm}$. The polarity of the coils was set to be boosting with the B field vector upward. 79,840 tetrahedra were used in the simulation. The time-dependent eddy current power loss is shown in Figure 32. The peak power loss is $1203 \mathrm{w}$ or $1.612 \mathrm{hp}$. Thus, azimuthally laminating the rim greatly reduces the eddy-current power loss by restricting the eddy-current path length. This technique of lamination to reduce eddy-current losses is used extensively in iron and steel in electrical power equipment. 


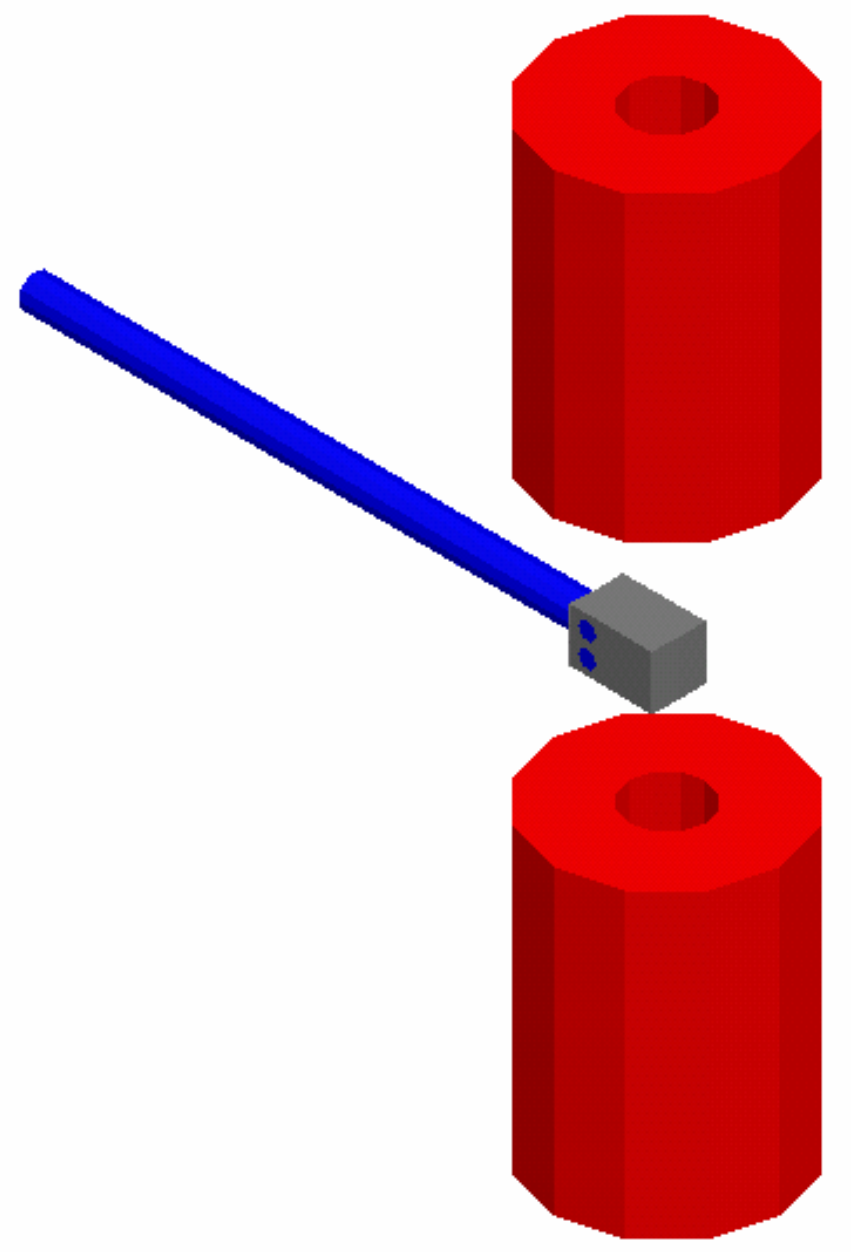

Figure 31 The 0.820-degree rim section between the coils. 


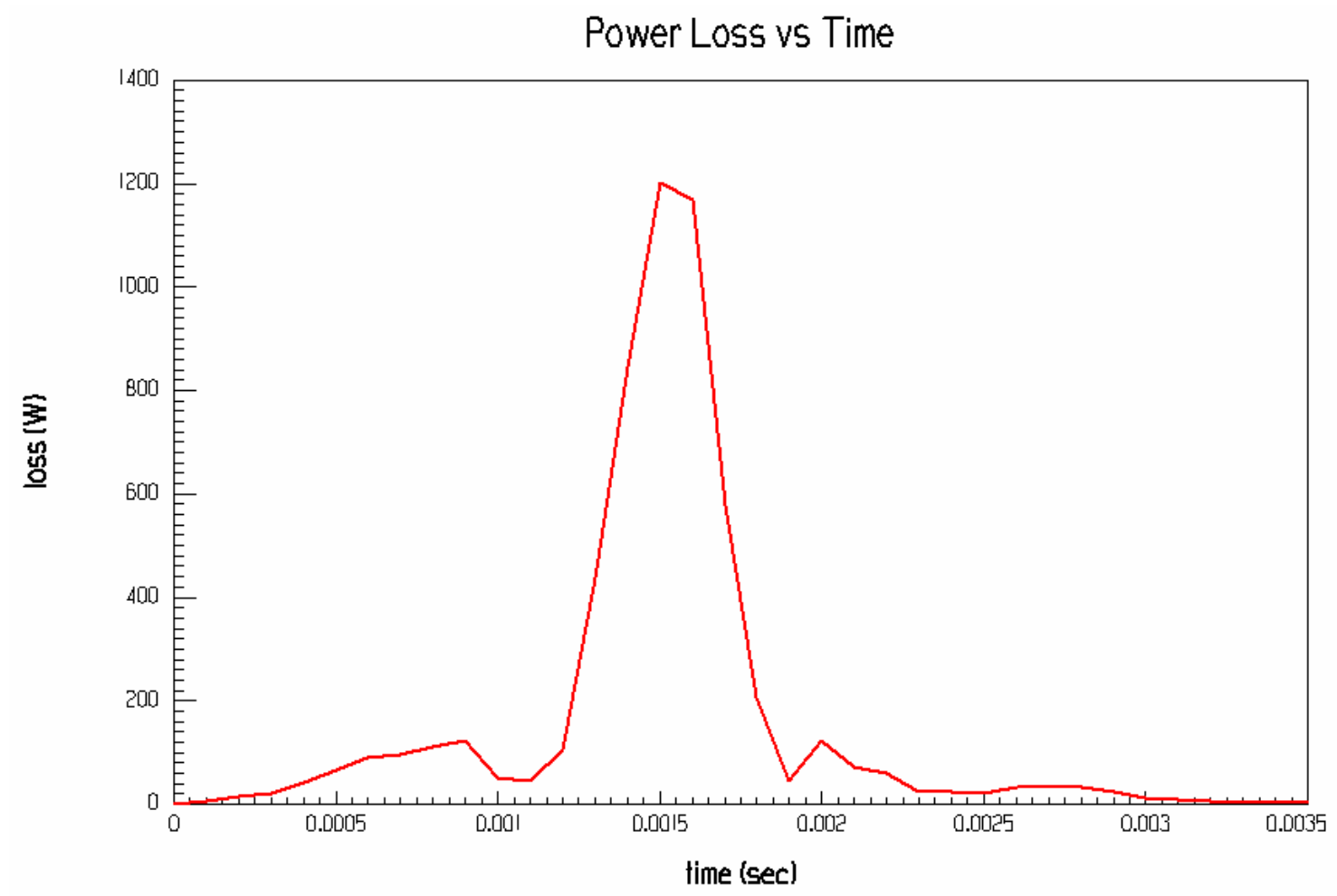

Figure 32 Eddy-current power loss for the 0.820-degree rim section and spoke, boosting.

Next, we have reversed the current polarity in one coil to produce a bucking magnetic field configuration. The resulting eddy-current power loss curve is shown in Figure 33. The power loss curve now consists of two peaks, indicating a reversal of the direction of the eddy-current flow in the axially-facing planes with time. Viewed from the top, the current first flows clockwise and then flows counterclockwise. The peak power loss, at the height of the first peak of the curve, is $1192 \mathrm{w}$ or $1.598 \mathrm{hp}$. The bucking configuration for the small rim section results in only a very small reduction in peak eddy-current power loss of about $0.868 \%$ from the boosting configuration. The reduction may be somewhat greater if the peak of the power loss curve in Figure 32 is captured with a reduction in time step or an increase in mesh refinement. 


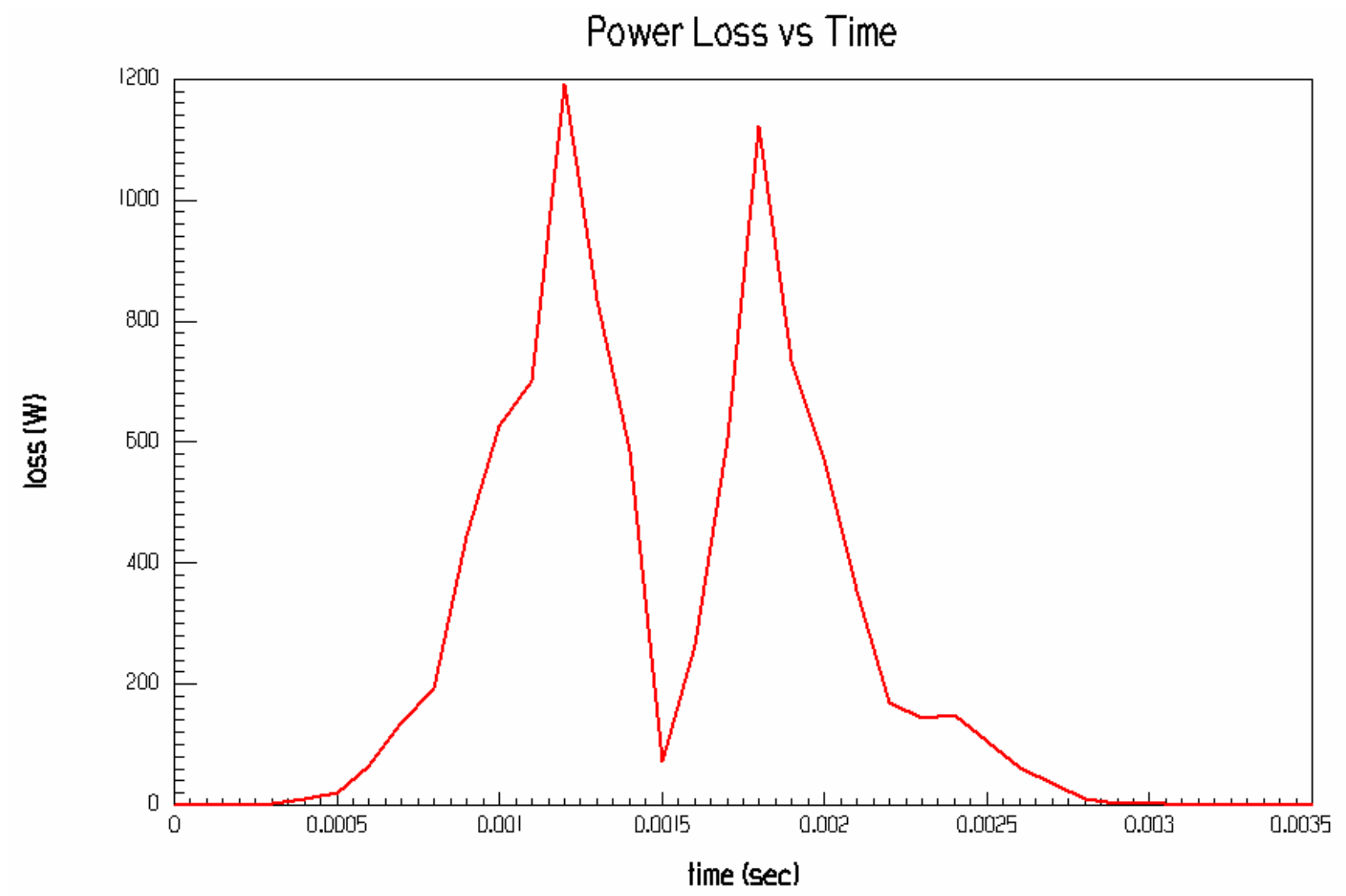

Figure 33 Eddy-current power loss for the 0.820-degree rim section and spoke, bucking.

\section{Simulation of Experiments with Small Wheels}

We have simulated a proposed experiment with a solid Ti6Al4V wheel with a diameter of $0.60 \mathrm{~m}$ and a thickness of $1.4 \mathrm{~cm}$. Initially, a 63-degree sector of the wheel is used to reduce computation time. The coils from the previous simulations of the watercooled rim sections were also used in this simulation. The radial coil centers are located at $0.29 \mathrm{~cm}$ radially outward from the sector axis of rotation. An end of each coil is placed $2.0 \mathrm{~cm}$ from the corresponding axial wheel sector surface. The geometry for this case is shown in Figure 34. The current in each coil is set to $172,132.15 \mathrm{~A}$ to produce a B field magnitude of $0.500 \mathrm{~T}$ at the upper surface of the disk sector when stationary. The first simulation was performed with 57,753 tetrahedra at a speed of $600 \mathrm{rpm}$. The time dependent eddy-current power loss is shown in Figure 35. The average power loss is about $108 \mathrm{w}$ or $0.145 \mathrm{hp}$. The eddy-current torque curve is shown in Figure 36. An estimate of the average steady-state torque from observation of the plateau of the curve in Figure 36 gives about $-1.68 \mathrm{nt}-\mathrm{m}$. The negative sign indicates that the torque opposes the rotation of the wheel. 


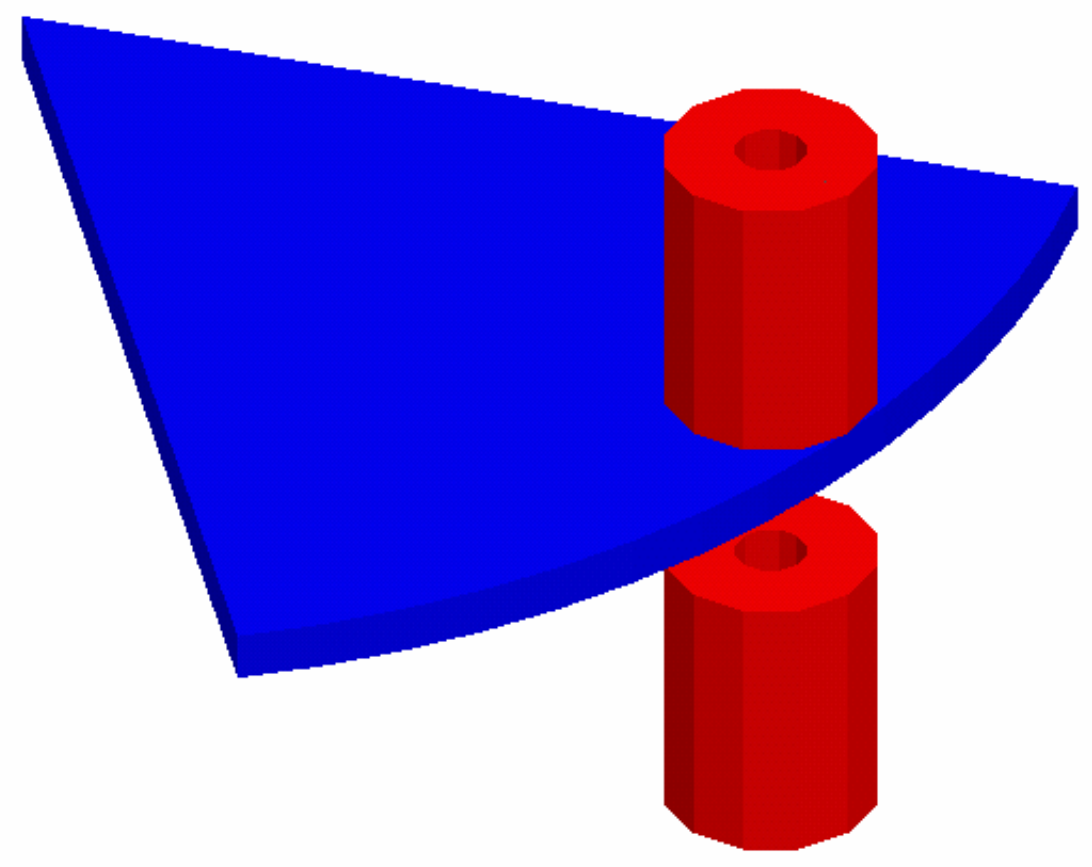

Figure 34 Geometry for simulation of a small Ti6Al4V wheel. 


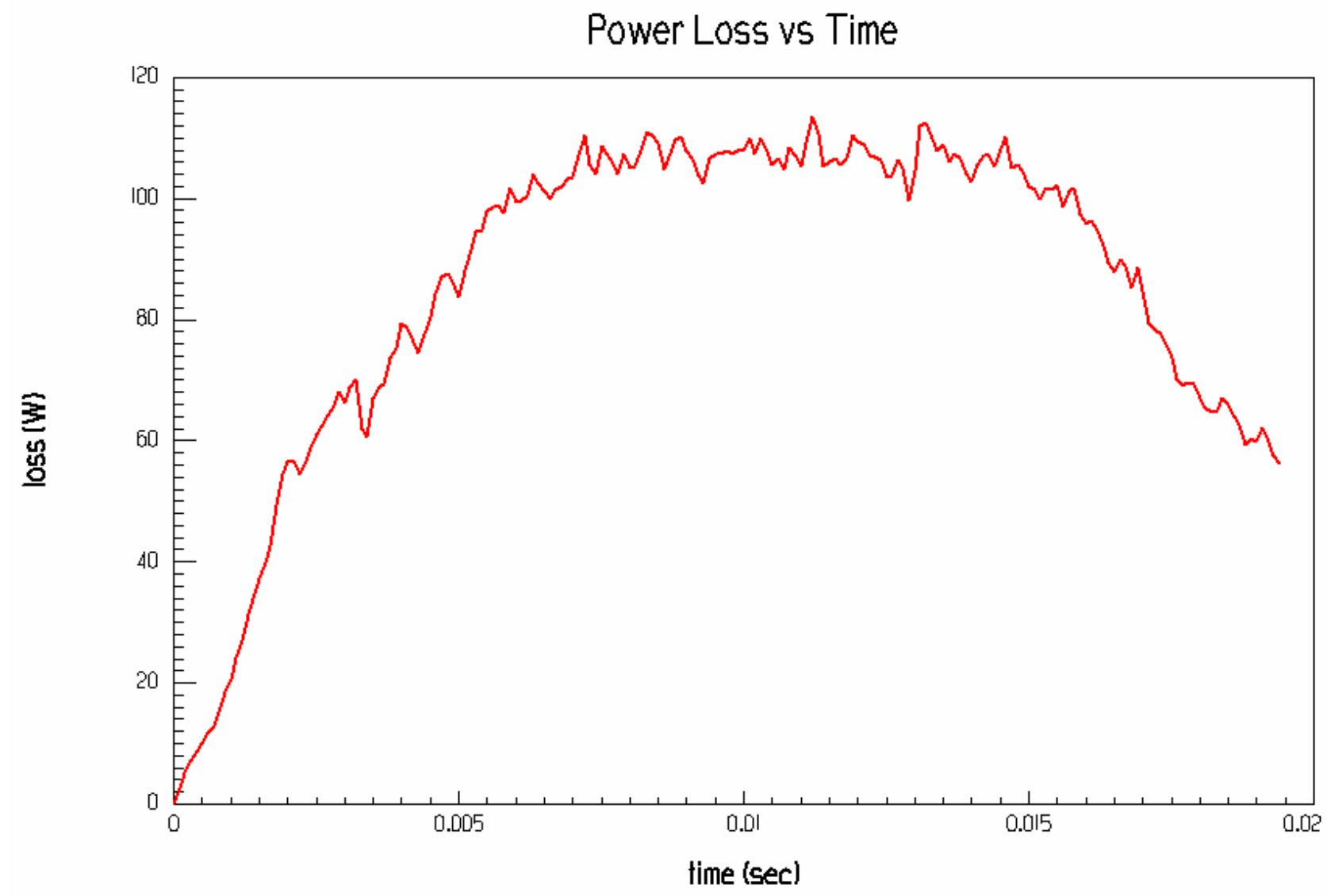

Figure 35 Eddy-current power loss for a $60-\mathrm{cm}$ diameter Ti6Al4V wheel at $600 \mathrm{rpm}$. 


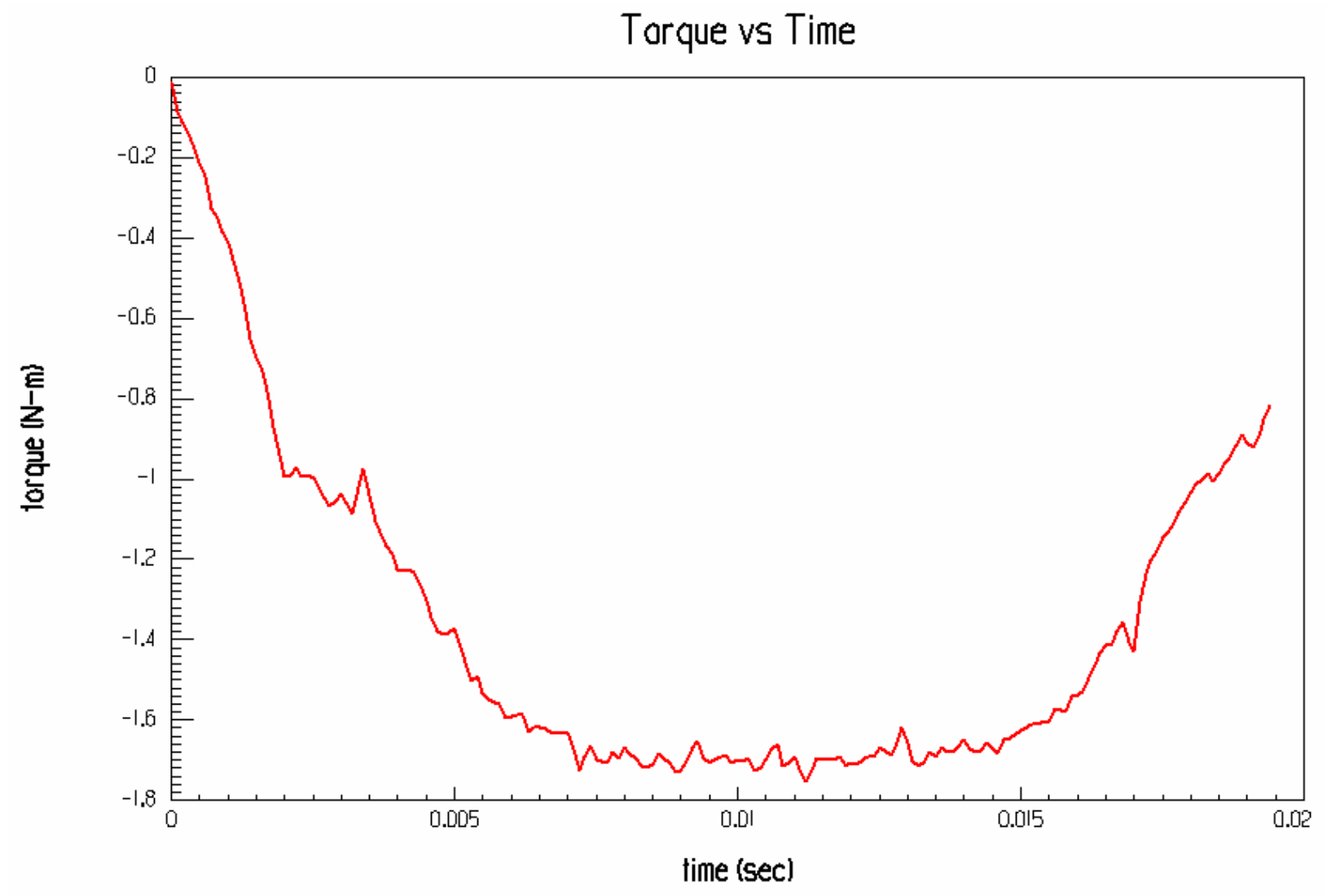

Figure 36 Torque for a $60-\mathrm{cm}$ diameter Ti6Al4V wheel at $600 \mathrm{rpm}$.

We have performed a number of simulations at a range of speeds using two differently sized sectors and two different time steps to estimate the speed at which the peak torque occurs. The results of these simulations are shown in Figure 37. Three separate curves of estimated steady-state torque in nt-m versus angular frequency in rpm are shown. The orange curve is for a 67 -degree sector with a time step of $10^{-4} \mathrm{sec}$. It extends from 600 to $5,000 \mathrm{rpm}$. The black curve is for the same 67-degree sector with a time step of $210^{-5}$ sec. It extends from 0 to $11,000 \mathrm{rpm}$. The blue curve is for a 123-degree sector with a time step of $210^{-5} \mathrm{sec}$. It extends from 0 to $30,000 \mathrm{rpm}$. The simulations were begun with the 67-degree sector with the time step of $10^{-4} \mathrm{sec}$ at $600 \mathrm{rpm}$. After the torque appeared to diverge from an expected trajectory at $5,000 \mathrm{rpm}$, the time step was switched to $210^{-5}$ $\mathrm{sec}$ for better resolution. At 11,000 rpm, the 123-degree sector was started as a check on the simulation results. The minimal torque, which occurs at 16,000 rpm and 17,000 rpm, is estimated from the simulations to be $-19.4 \mathrm{nt}-\mathrm{m}$.

We will estimate the expected speed for the minimal torque from the formulas in the paper by J. H. Wouterse [7]. We will assume that the distance between the top of the bottom electrical coil and the bottom of the top coil, $5.4 \mathrm{~cm}$, corresponds to Wouterse's pole face air gap, $\mathrm{x}$. We will take the coil bore diameter, $2 \mathrm{~cm}$, to correspond to Wouterse's pole face diameter, D. We will take Wouterse's disk thickness, d, to be the simulation disk thickness, $1.4 \mathrm{~cm}$. We will take Wouterse's distance from the center of the disk to the center of the pole, $\mathrm{R}$, to be the distance from the center of the simulation disk to the center of the coil bores, $29 \mathrm{~cm}$. We will take Wouterse's disk radius, A, to be 
the simulation disk radius, $30 \mathrm{~cm}$. We will take $\rho$, the resistivity of the Ti6Al4V disk, to be $1.7810^{-6} \mathrm{ohm}-\mathrm{m}$. We will take $\xi$, Wouterse's ratio of the zone width of the asymptotic current distribution around the iron poles to the air gap, to be 1.0, which he proposes as a reasonable estimate. Wouterse uses $\mathrm{c}$ to stand for the ratio of the total contour eddy current resistance to the resistance of the contour part under the iron poles. He gives the formula for $\mathrm{c}$ as

$$
c=0.5\left(1-1 /\left(4(1+R / A)^{2}((A-R) / D)^{2}\right) .\right.
$$

Substitution of our values in $\mathrm{m}$ into Equation 2 gives,

$$
\begin{aligned}
& \mathrm{c}=0.5\left(1-1 /\left(4(1+0.29 / 0.3)^{2}((.3-.29) / .02)^{2}\right),\right. \\
& \mathrm{c}=0.5\left(1-1 /\left(4 \times(1+0.9666667)^{2}(.01 / .02)^{2}\right)\right), \\
& \mathrm{c}=0.5\left(1-1 /\left(4 \times(1.9666667)^{2}(.5)^{2}\right),\right. \\
& \mathrm{c}=0.5(1-1 /(4 \times 3.8677778 \times 0.25)), \\
& \mathrm{c}=0.5(1-1 / 3.8677778), \\
& \mathrm{c}=0.5(1-0.2585464), \\
& \mathrm{c}=0.5 \times 0.7414536, \\
& \mathrm{c}=0.3707268 .
\end{aligned}
$$

Wouterse gives the formula for the speed at the minimal torque or the maximum resisting force, $\mathrm{v}_{\mathrm{k}}$, as

$$
v_{k}=\left(2 / \mu_{0}\right)(1 /(c \xi))^{.5}(\rho / d)(x / D)^{5},
$$

where $\mu_{0}$ is the free space permeability of $1.25710^{-6}$ henrys $/ \mathrm{m}$ in the MKS system of units.

Substitution of our values into Equation 11 for $\mathrm{v}_{\mathrm{k}}$, gives

$$
\begin{aligned}
\mathrm{v}_{\mathrm{k}}=2 \times 1.78 \mathrm{e}-6 /(1.257 \mathrm{e}-6 \times 0.014) \\
\mathrm{v}_{\mathrm{k}}=202.29572(7.2829911)^{.5}, \\
\mathrm{v}_{\mathrm{k}}=202.29572 * 2.6987018, \\
\mathrm{v}_{\mathrm{k}}=545.9358 \mathrm{~m} / \mathrm{sec} .
\end{aligned}
$$

The critical angular frequency, in radians $/ \mathrm{sec}$, is $\omega_{\mathrm{k}}=\mathrm{v}_{\mathrm{k}} / \mathrm{r}$, where $\mathrm{r}$ is an appropriate radius in $\mathrm{m}$. Taking $\mathrm{r}$ as the outer radius of wheel at $0.3 \mathrm{~m}$, the critical angular frequency is $\omega_{\mathrm{k}}=545.9358 / 0.3=1,819.786 \mathrm{rad} / \mathrm{sec}$. Converting rad/sec to rpm, we get $\omega_{\mathrm{k}}=$ $1,819.786 \mathrm{rad} / \mathrm{sec} \times 60 \mathrm{sec} / \mathrm{min} /(2 \pi \mathrm{rad} / \mathrm{rev})=17,377.676 \mathrm{rpm}=17,380 \mathrm{rpm}$. This estimated value is close to the estimated range from the simulations of 16,000 to 17,000 $\mathrm{rpm}$, which can be refined with more exact simulation. If we take the radius as the radius at the center of the coil bore, $0.29 \mathrm{~m}$, we get $\omega_{\mathrm{k}}=17,377.676^{*} 0.3 / 0.29=17,977 \mathrm{rpm}$. These results indicate that Wouterse's formulas for the critical speed for widely separated soft iron pole faces can be used for estimation for our case of separated electrical coil pairs. 
Torque versus Angular Frequency for Ti6Al4V Wheel

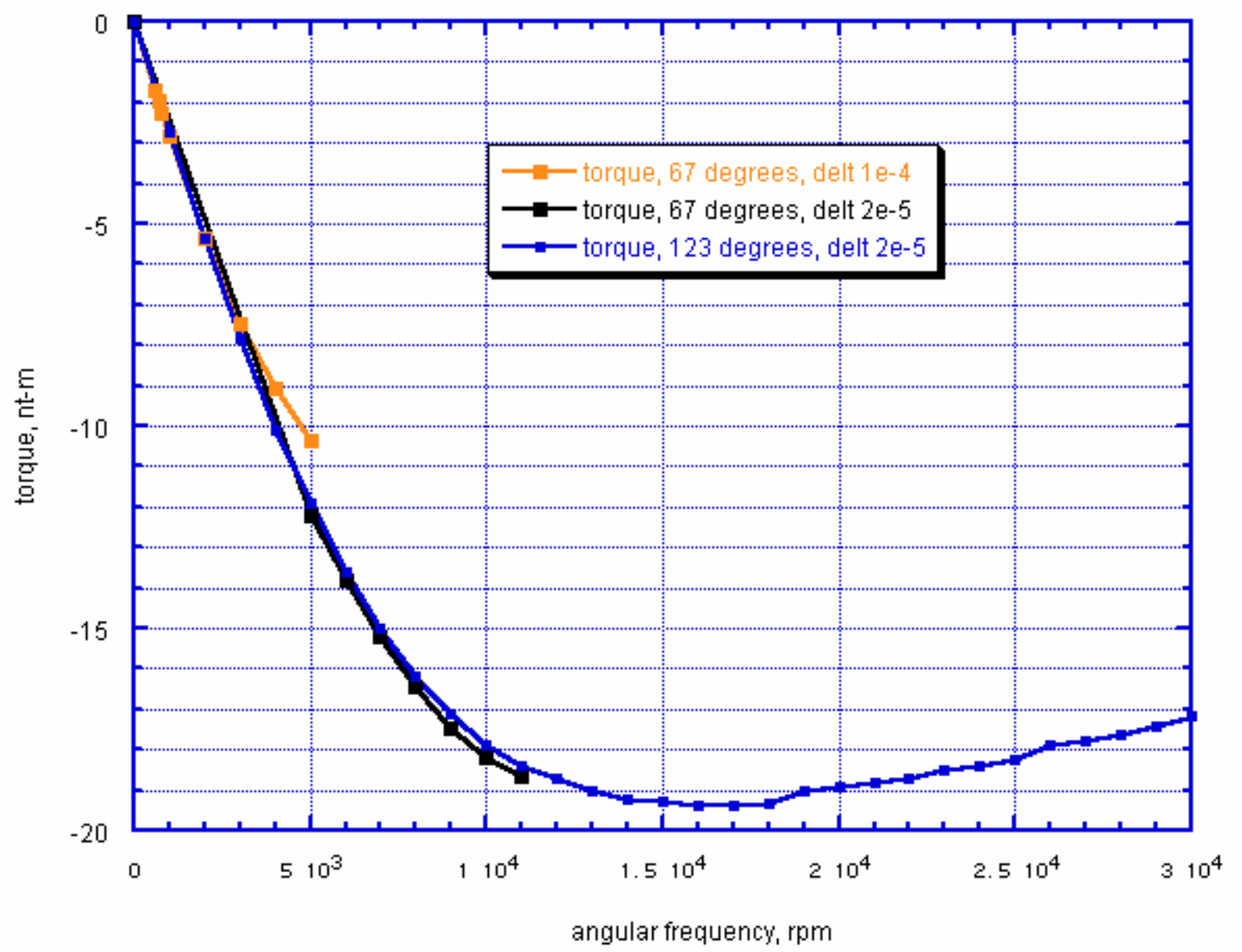

Figure 37 Eddy-current torque versus angular frequency for the Ti6Al4V wheel.

We have also calculated estimates of the torque versus angular frequency for the Ti6Al4V wheel from a computer-program implementation of Wouterse's formulas [7]. A comparison of these estimates of torque with the simulations with the 123-degree sector at a time step of $210^{-5} \mathrm{sec}$ is shown in Figure 38. This implementation is discussed in some detail in the later section on the simulation of Smythe's case for an electromagnet. At $10,000 \mathrm{rpm}$, Wouterse's formulas give a torque of $-15.41 \mathrm{nt}-\mathrm{m}$. The simulations give a value of about $-17.7 \mathrm{nt}-\mathrm{m}$. The percent difference between the two curves at that point is $12.9 \%$ with the simulated value as the base. The angular frequency for the minimal torque from Wouterse's formulas in Figure 38 is 17,982 rpm, which is slightly greater than we previously estimated from hand calculations. We expect Wouterse's formulas for an electromagnet with iron poles to be only an estimate for our case with the magnetic field created by coils for a number of reasons. The boundary conditions on the B and $\mathrm{H}$ fields at the surfaces of the iron poles are that the fields are zero. For an analytic treatment of our case, the boundary conditions at the end of the coils would be quite different and more complicated. Wouterse's formulas are for the ratio of the pole gap to 
the pole diameter, $x / D$, to be small. For Smythe's electromagnet case, $x / D=0.075$. For our case here, the coil gap to coil bore ratio, $\mathrm{x} / \mathrm{D}=.054 / .02=2.7$. In the simulation, we undoubtedly have magnetic induction beyond the coil bore projection on the wheel. Wouterse's model assumes no magnetic induction beyond the pole piece projection on his disk. The estimate from Wouterse's formulas may be lower than the simulated results because Maxwell 3D includes the added drag effect of the field and eddy-currents beyond the coil bore projection on the wheel. It is interesting that Wouterse's formulas, when applied to our obviously different case, give such relativity decent agreement.

Torque versus Angular Frequency for Ti6Al4V Wheel

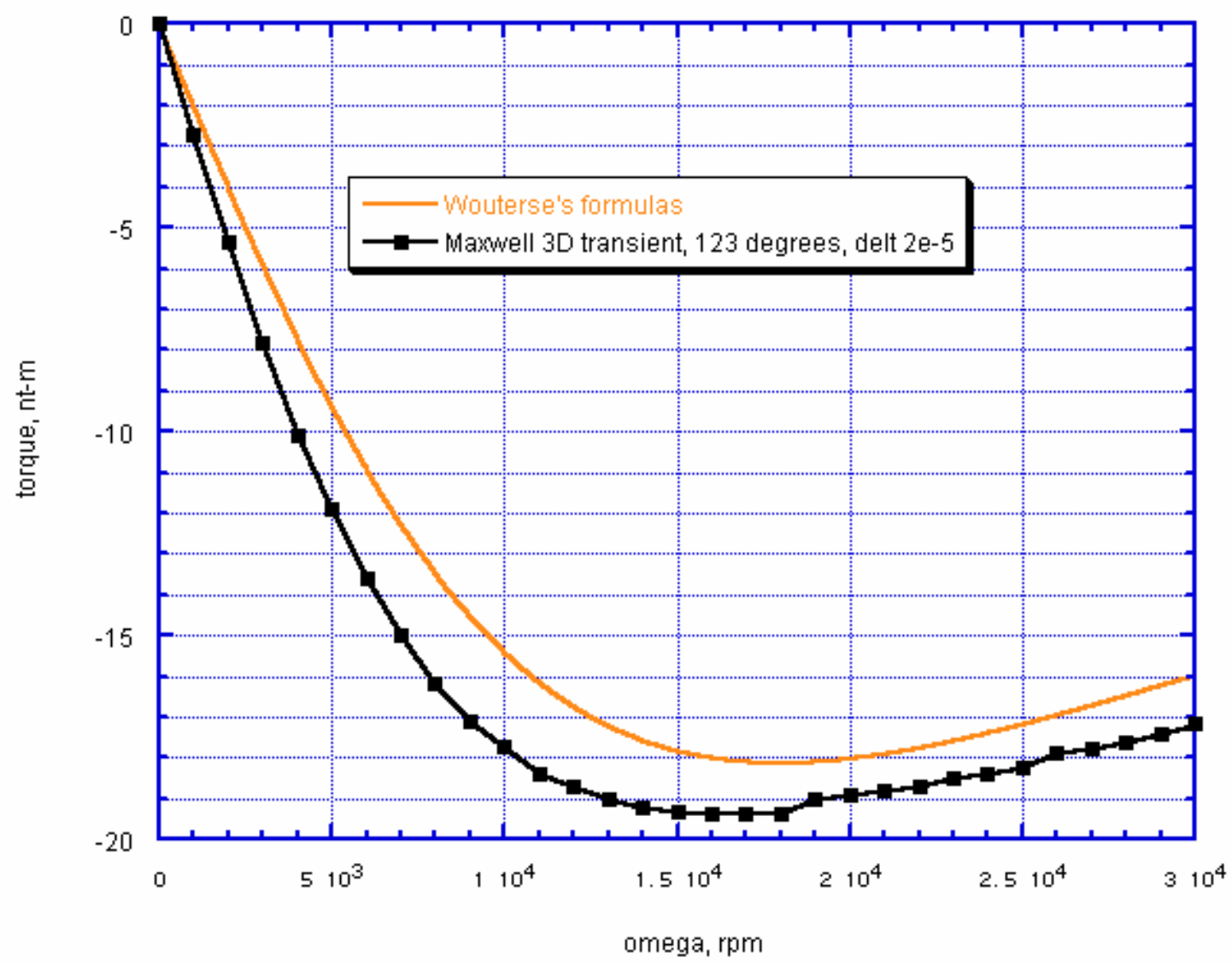

Figure 38 Comparison of Wouterse's and simulated torque for the Ti6Al4V wheel.

One may wonder what factors control the location of the speed at which the minimal torque occurs for situations like that in Figure 34 . We believe that the wheel permeability and conductivity and the geometry determine the location of the peak absolute value of the torque versus speed curve. The permeability, the resistivity or inverse conductivity, and several geometric factors, ratios, and quantities occur in Wouterse's Equation 10(our Equation 27, to be encountered later) for the critical velocity. In addition, the analysis of Woodson and Melcher [9] of the differential equation for the diffusion of an external magnetic induction into a steadily translating conductive plate, reveals a parameter, $R_{m}=$ 
$\mu v 1 / \rho$, called the magnetic Reynolds number, where $\mu$ is the plate magnetic permeability, $1 / \rho$ is the plate conductivity, $\mathrm{v}$ is the speed of the plate and 1 is the length of the external induction region. If $R_{m}$ is 1 , the external induction is unaffected by the eddy currents induced in the moving plate. If $\mathrm{R}_{\mathrm{m}}>1$, the eddy currents annihilate enough of the external induction to affect the initial distribution of the external induction. The greater that $R_{m}$ is above unity, the greater is the initial external induction changed. If $\mathrm{R}_{\mathrm{m}}$ is infinite, the external induction is completely excluded from the moving plate. $R_{m}$ is the ratio of two time scales - the time scale for diffusion of the induction into the conductive plate, $\mu 1^{2} / \rho$, and the time scale of the translation, $1 / \mathrm{v}$, or the time for the plate to pass through the region of the magnetic induction. For another geometry, some other characteristic distance is substituted for the length 1. For example, Boulnois and Giovacchini [1] choose the height of their rectangular coil above their rotating wheel for the characteristic distance in their definition of the magnetic Reynolds number in their Figures 4 and 5. Part of their work is discussed in a later section on a simulation of the experiment reported in their paper.

To demonstrate that the value of the magnetic induction should not affect the critical speed for an otherwise fixed situation, we have doubled the current in the two coils in Figure 34 and then estimated from more simulations the steady state eddy-current torque versus angular frequency. The results are shown in Figure 38 by the blue curve. The peak induction at the axial surface of the wheel sector with no motion is now $1.0171 \mathrm{~T}$. We have also plotted the results from Wouterse's formulas as the red curve without data points. The simulations predict a critical frequency of 17,000 rpm; whereas, Wouterse's formulas predict a critical frequency of $17,982 \mathrm{rpm}$. This value, $17982 \mathrm{rpm}$, is the same value predicted by the orange curve in Figure 37. Figure 38 also shows the previous two curves from Figure 37 for comparison. As expected, if the peak field is doubled, the peak absolute value of the torque is quadrupled. The peak absolute value of the simulated torque from Figure 37 is about 19.4 nt-m. The peak absolute value of the simulated torque from the blue curve in Figure 38 is about $77.6 \mathrm{nt}-\mathrm{m}$. The peak absolute value from Wouterse's formulas in Figure 37 is $18.13 \mathrm{nt}-\mathrm{m}$, whereas the corresponding value from the red curve in Figure 38 is $75.04 \mathrm{nt}-\mathrm{m}$. This is about $3.5 \%$ greater than the product four times $18.13 \mathrm{nt}-\mathrm{m}$. 


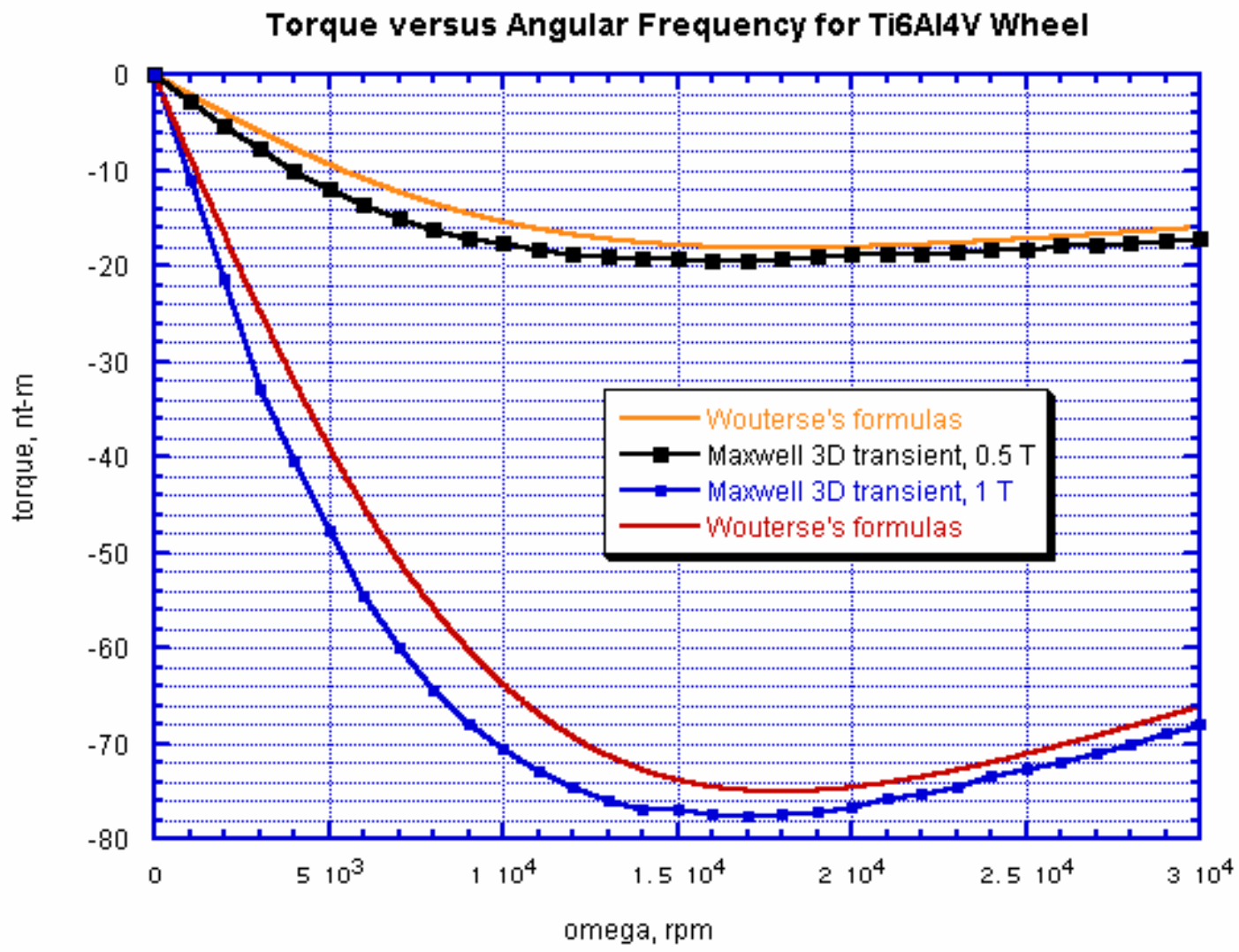

Figure 39 Comparison of Wouterse's and simulated torque for two magnetic inductions.

We have performed a set of simulations with the material Al substituted for Ti6Al4V by using the value, $2.631610^{-8} \mathrm{ohm}-\mathrm{m}$, for the wheel resistivity. We have done this to ascertain where the angular frequency for the minimal torque occurs for an Al wheel. The angular frequency was varied from 200 to $800 \mathrm{rpm}$. Figure 40 shows the eddy-current torque versus the angular frequency for the $\mathrm{Al}$ wheel as the black curve with data points. The angular frequency for the minimal torque occurred at $300 \mathrm{rpm}$. We will estimate this angular frequency by scaling our previous calculation for the Wouterse critical angular frequency by the Al resistivity. Then, we get $\omega_{\mathrm{kAl}}=17,377.676 \times 2.631610^{-8} / 1.7810^{-6}=$ $256.91625 \mathrm{rpm}=257 \mathrm{rpm}$. This estimate is fairly close to the value that the simulations give. The percent difference with $300 \mathrm{rpm}$ as the base for comparison is $-14.3 \%$. If we further scale for the radius at the coil bore center, rather than the radius at the edge of the disk, we get $\omega_{\mathrm{kAl}}=256.91625(0.3 / 0.29)=266 \mathrm{rpm}$. The percent difference is then improved to $-11.3 \%$. We have also plotted the results for estimated torque from a computer program implementation of Wouterse's formulas [7] as the orange curve.. At $200 \mathrm{rpm}$, Wouterse's formula gives $-17.42 \mathrm{nt}-\mathrm{m}$ for the torque. The simulation gives about $-22.2 \mathrm{nt}-\mathrm{m}$. At $800 \mathrm{rpm}$, Wouterse's formulas give $-10.86 \mathrm{nt}-\mathrm{m}$ for the torque. The 
simulation gives about $-19.3 \mathrm{nt}-\mathrm{m}$. With the simulated value as the base, the percent difference between the two curves is $21.5 \%$ at $200 \mathrm{rpm}$ and $43.4 \%$ at $800 \mathrm{rpm}$. Beyond the minimal torque, Wouterse's curve falls more rapidly than the simulated curve.

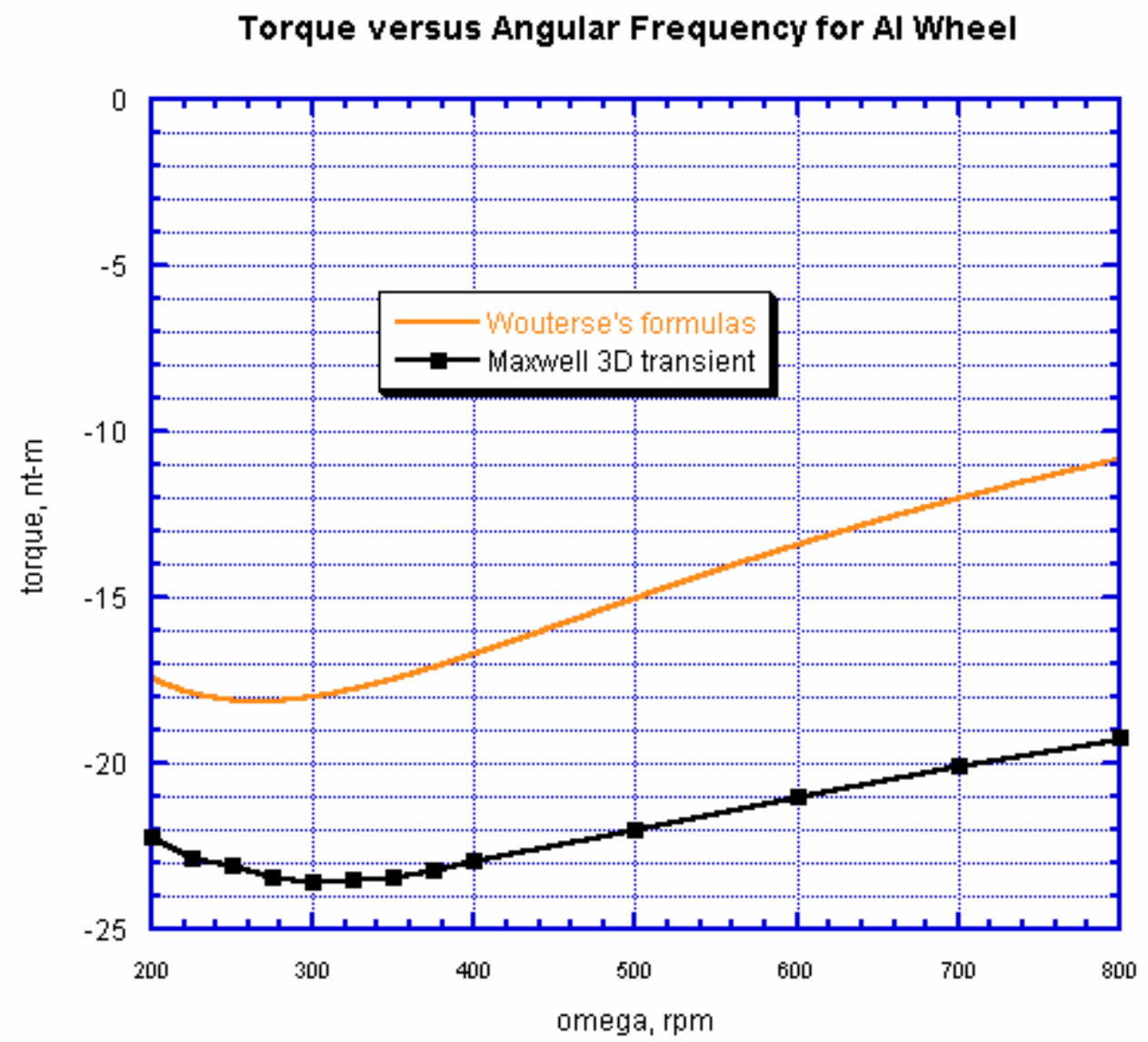

Figure 40 Eddy-current torque versus angular frequency for the Al wheel.

We have also have simulated a notched Ti6Al4V wheel with a notched circular sector. The solid model is shown in Figure 41. The wheel sector shown in Figure 34 has been notched a number of times. The notches are $10 \mathrm{~cm}$ in radial extent by $1 \mathrm{~cm}$ wide. The linear distance between the notches at their base is about $1.667 \mathrm{~cm}$; the linear distance between the notches at the outer radius of the wheel is about $3 \mathrm{~cm}$. The notch centers are radially-spaced at 7.642 degrees. A mesh of 60,751 tetrahedra was used in a simulation at $600 \mathrm{rpm}$. The resulting eddy-current power loss is shown in Figure 42. The peak power loss is about $24.5 \mathrm{w}$ or $0.0328 \mathrm{hp}$. A simulation at $500 \mathrm{rpm}$ yields a peak power loss of $17.0 \mathrm{w}$ or $0.0228 \mathrm{hp}$. 


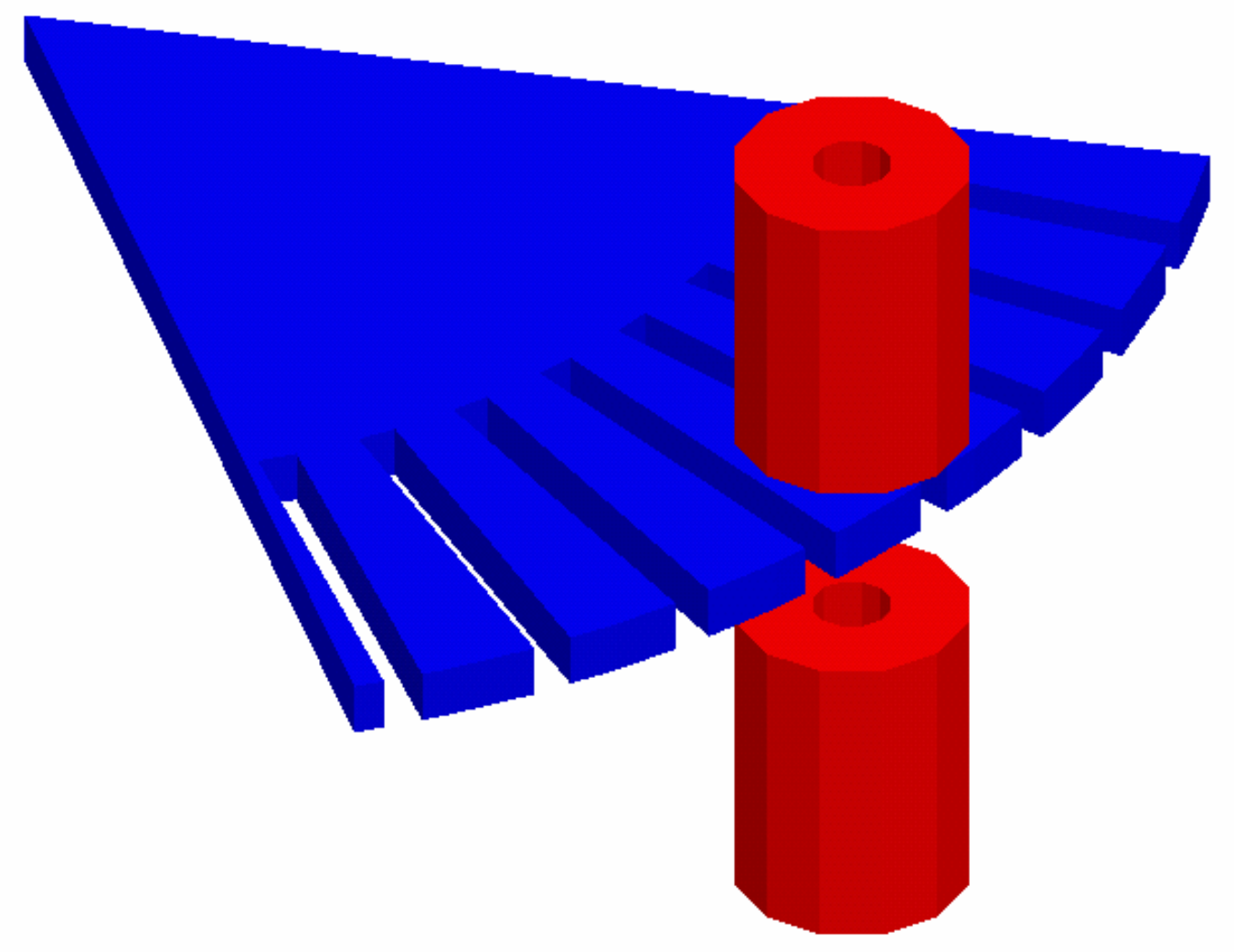

Figure 41 The notched circular sector between the two coils. 


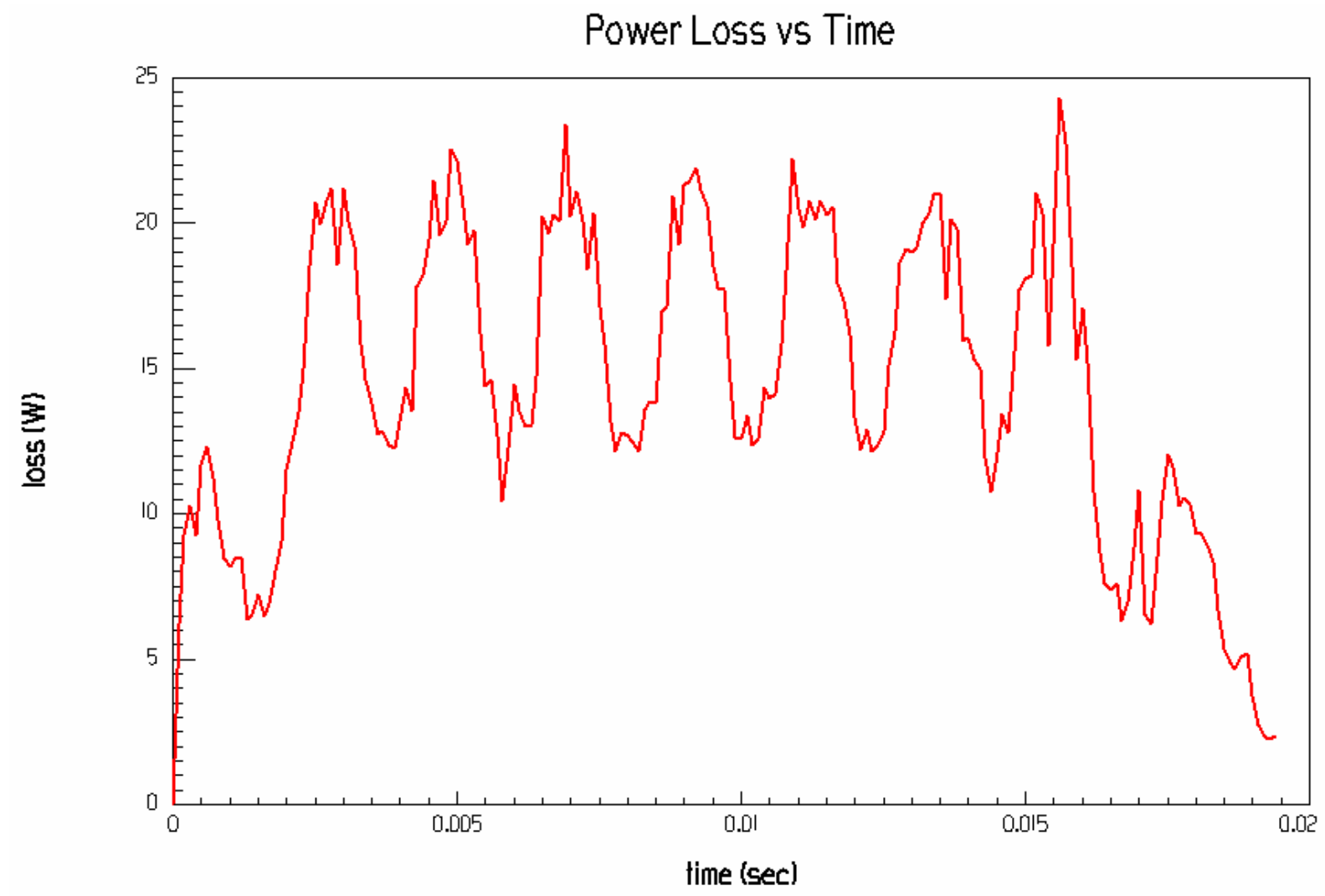

Figure 42 Eddy-current power loss for a notched experimental Ti6Al4V wheel at $600 \mathrm{rpm}$.

\section{Comparison of Code Simulations with Reported Experiments and Analytic Formulas}

We have completed a first set of simulations in an effort to reproduce the experimental drag force results for a thick rectangular coil moving over the rim of a thick rotating, conducting disk of an aluminum alloy in Section C.1. of the paper by Boulnois and Giovachini [1]. In this experiment, a rectangular electrical coil of size $20 \mathrm{~cm}$ by $10 \mathrm{~cm}$ has its long dimension in the direction of motion. The coil carries a magnetomotive force of $\mathrm{NI}=4000$ A-turns. The rectangular coil cross section is $2 \mathrm{~cm}$ in the horizontal direction and $1 \mathrm{~cm}$ in the vertical direction. The details of the construction of the coil are not given in the paper. The coil is suspended at a height of about $5 \mathrm{~mm}$ above the rim of a rotating solid wheel. The wheel is $60 \mathrm{~cm}$ in diameter and $40 \mathrm{~cm}$ thick. The maximum rim speed of the wheel is about $16 \mathrm{~m} / \mathrm{sec}$. The wheel is made from an Al alloy with a permeability-conductivity product approaching 20 MKSA units. From this value, we calculate that the conductivity of the wheel alloy is about $1.592 \mathrm{siemens} / \mathrm{m}$ for a free space permeability of $12.5610^{-7}$ henrys $/ \mathrm{m}$. The drag force on the coil "is measured with a conventional dynamometric gauge." Boulnois and Giovachini performed two calculations of the drag force on the coil with their Green's function formulation. One calculation assumed a 4-mm air gap between the coil lower extremity and the wheel rim surface. The other calculation assumed a 5-mm air gap. "The reason stems from the great difficulty encountered during the experiment in monitoring the flight height with reasonable 
accuracy." The agreement between the experimental and calculated results is reported to be within plus or minus $12 \%$. Rather than being straight above the wheel rim, the coil was given some curvature. The extent of this curvature is not revealed in the paper. Boulnois and Giovachini report that the coil curvature creates an additional component in the drag force, which is difficult to estimate. They believe that their agreement between calculated and measured results is reasonable. Boulnois and Giovachini's experimental results extend from a velocity of just above 0 to about $14 \mathrm{~m} / \mathrm{sec}$. Up to about $3 \mathrm{~m} / \mathrm{sec}$, the calculated curve for a 5-mm gap falls very close to the experimental data points. Beyond about $3 \mathrm{~m} / \mathrm{sec}$, the calculated curve falls below the experimental data points. The calculated curve for the 4-mm gap is above the experimental data points for the entire velocity range. The experimental data points appear to be everywhere closer to the 5-mm theoretical curve. Above about $2.75 \mathrm{~m} / \mathrm{sec}$, the two theoretical curves bracket the experimental data points.

Our solid model for simulation of the experiment is shown in Figure 43. A straight rectangular coil, colored red, is located $5 \mathrm{~mm}$, at closest approach, above the cylindrical surface of a $40-\mathrm{cm}$ thick wheel. The wheel, colored green, rotates counterclockwise in this view. In a reference frame fixed to the cylindrical centerline of the wheel, it appears that the coil moves toward the right side of the figure or clockwise. Thus, the drag force restraining the coil is expected to be predominately horizontally toward the left side of the figure. This is in the negative y direction. A lift force on the coil upward in the positive $\mathrm{z}$ direction also occurs when the wheel rotates.

The dimension of the coil in the y-direction is $22 \mathrm{~cm}$. The dimension of the coil in the $\mathrm{x}$-direction, along the wheel axis, is $12 \mathrm{~cm}$. The cross section of the coil is $2 \mathrm{~cm}$ in the $\mathrm{xy}$ plane and $1 \mathrm{~cm}$ in the $\mathrm{z}$-direction. We have used a computational mesh of 28,416 tetrahedra. The wheel contains 21,397 tetrahedra, and the coil contains 94 tetrahedra. Simulations are performed at wheel rim speeds of $1,2,3,5,7.5,10,12.5$, and $15 \mathrm{~m} / \mathrm{sec}$ with the same mesh out to $0.10 \mathrm{sec}$. Figure 44 shows the time-dependent torque on the wheel for $12.5 \mathrm{~m} / \mathrm{sec}$. The torque falls from 0 to a minimum at about $0.01 \mathrm{sec}$, then increases to a steady value at about $0.028 \mathrm{sec}$. From about $0.07 \mathrm{sec}$, the torque increases to a maximum at about $0.084 \mathrm{sec}$, then decreases until about $0.98 \mathrm{sec}$. The initial pulse to about $0.028 \mathrm{sec}$ is probably a start-up transient as the initial B field and the induced eddy currents for zero speed at the time 0 diffuse into the surrounding wheel region and dissipate. The increase and decline from about 0.07 to $0.98 \mathrm{sec}$ is probably due to uneven meshing about the circumference of the wheel. The mesh is automatically the most refined near the coil and the least refined diametrically opposite the coil. Simulations with a finer wheel mesh should reveal if this is truly the reason for the variation of the torque on the wheel after about $0.028 \mathrm{sec}$. For each wheel rim velocity, the Lorentz drag force on the coil is calculated at $0.04,0.06,0.08$, and $0.10 \mathrm{sec}$. The worst agreement with the experimental data should be from the values at $0.08 \mathrm{sec}$. 


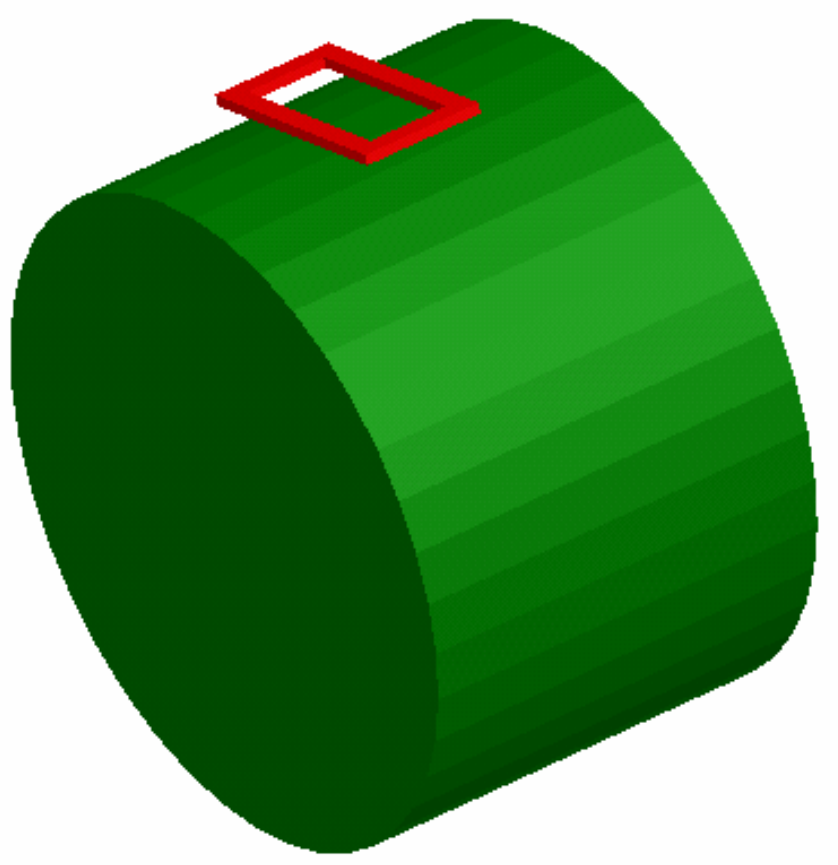

Figure 43 A straight rectangular coil centered $5 \mathrm{~mm}$ above a cylindrical wheel. 
Torque vs Time

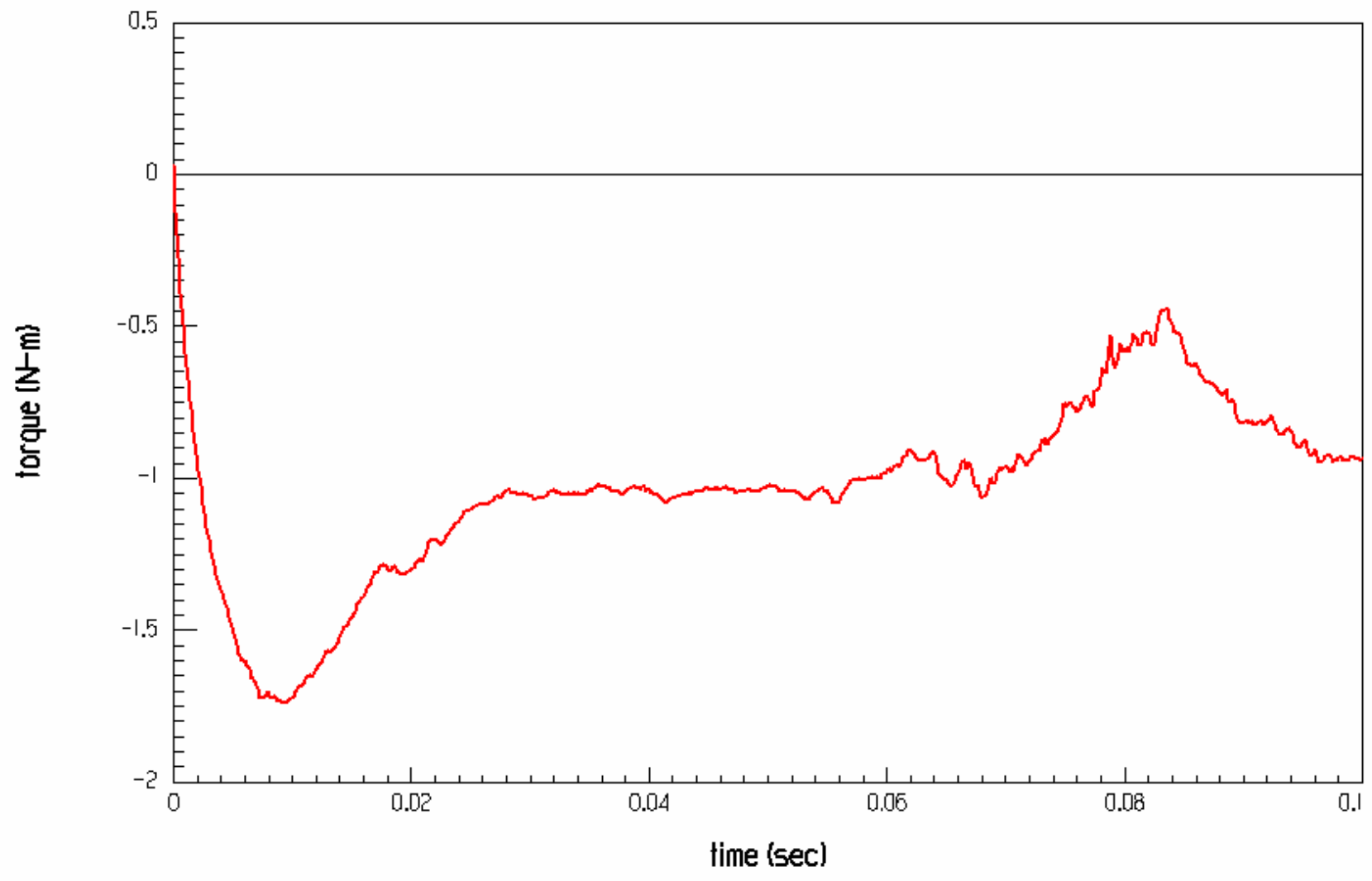

Figure 44 Time-dependent torque on the wheel at $12.5 \mathrm{~m} / \mathrm{sec}$.

Figure 45 shows the calculated drag force on the coil for each of the four times and estimates of values from the experimental data of Figure 3 of Boulnois and Giovachini. Our experimental data points are generally not the experimental data points of Boulnois and Giovachini, but estimates from a roughed-in experimental curve based on their data points. The experimental error bars are set at plus and minus $12 \%$ of the data point value. We see that the agreement is fairly good up to $5 \mathrm{~m} / \mathrm{sec}$. The agreement is worse from 7.5 to $12.5 \mathrm{~m} / \mathrm{sec}$. The agreement then becomes better at $15 \mathrm{~m} / \mathrm{sec}$. Figure 46 shows the point-wise best match of the four calculated points and the average of the four points compared to the estimated experimental points. The agreement between the simulated drag values and estimates of the experimental values of Boulnois and Giovachini, athough imperfect at several velocities, indicate that the simulation code we are using can do a good job of approximating eddy current effects in wheels rotating in the magnetic fields generated by electrical coils.

Several changes in the simulations can be explored in the future in order to improve the agreement between the simulation and the experimental results of the drag force on the coil. The mesh in the wheel can be refined in an effort to reduce the variation of the torque on the wheel after the start-up transient. The mesh in the coil can be refined. The coil can be curved on the radius from the point of closest approach to the wheel rim 
surface to the wheel axis of rotation. The simulations can be repeated at coil-to-wheel gaps of $4.25,4.5$, and $5 \mathrm{~mm}$.

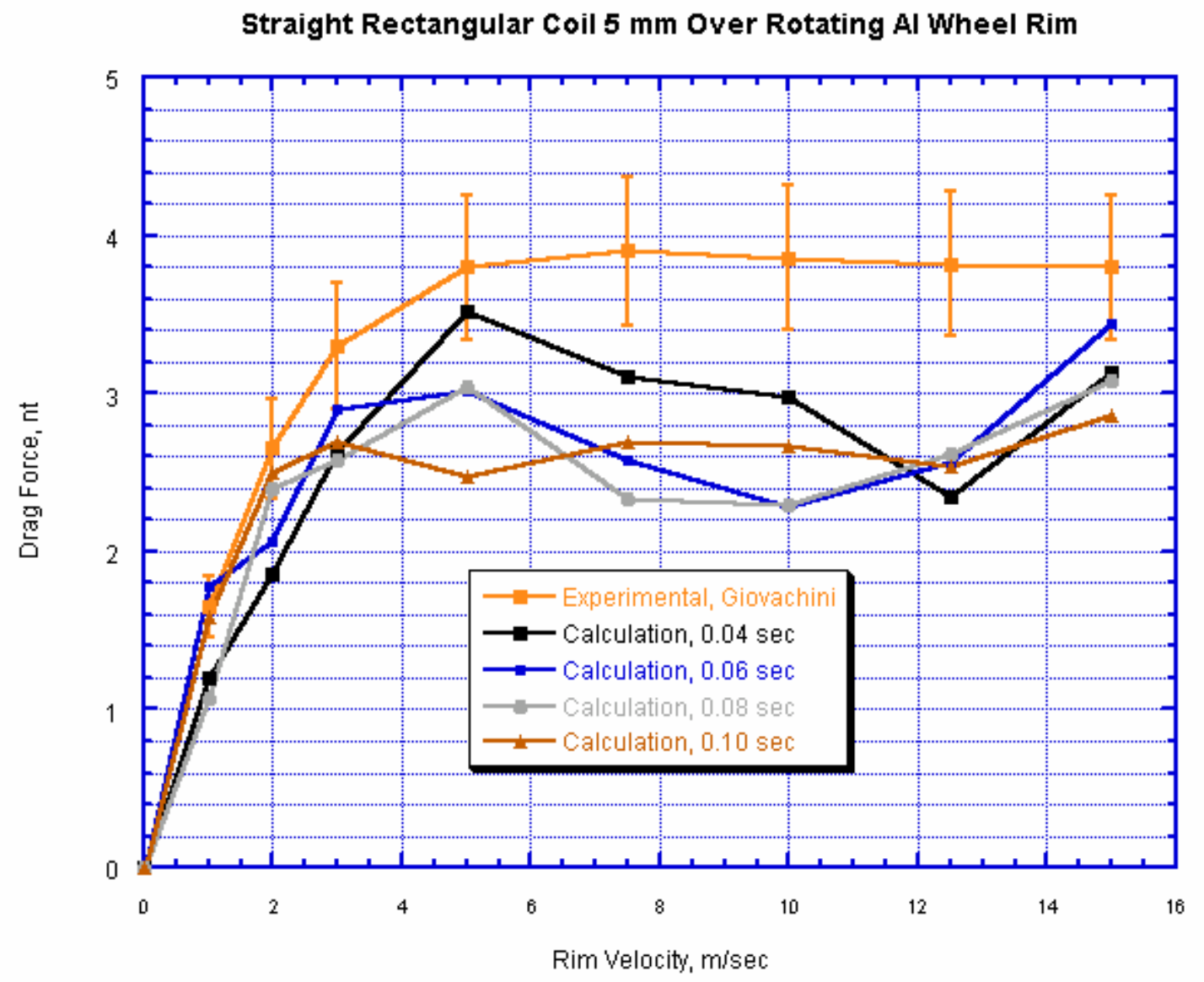

Figure 45 Calculated and estimated experimental drag force results. 


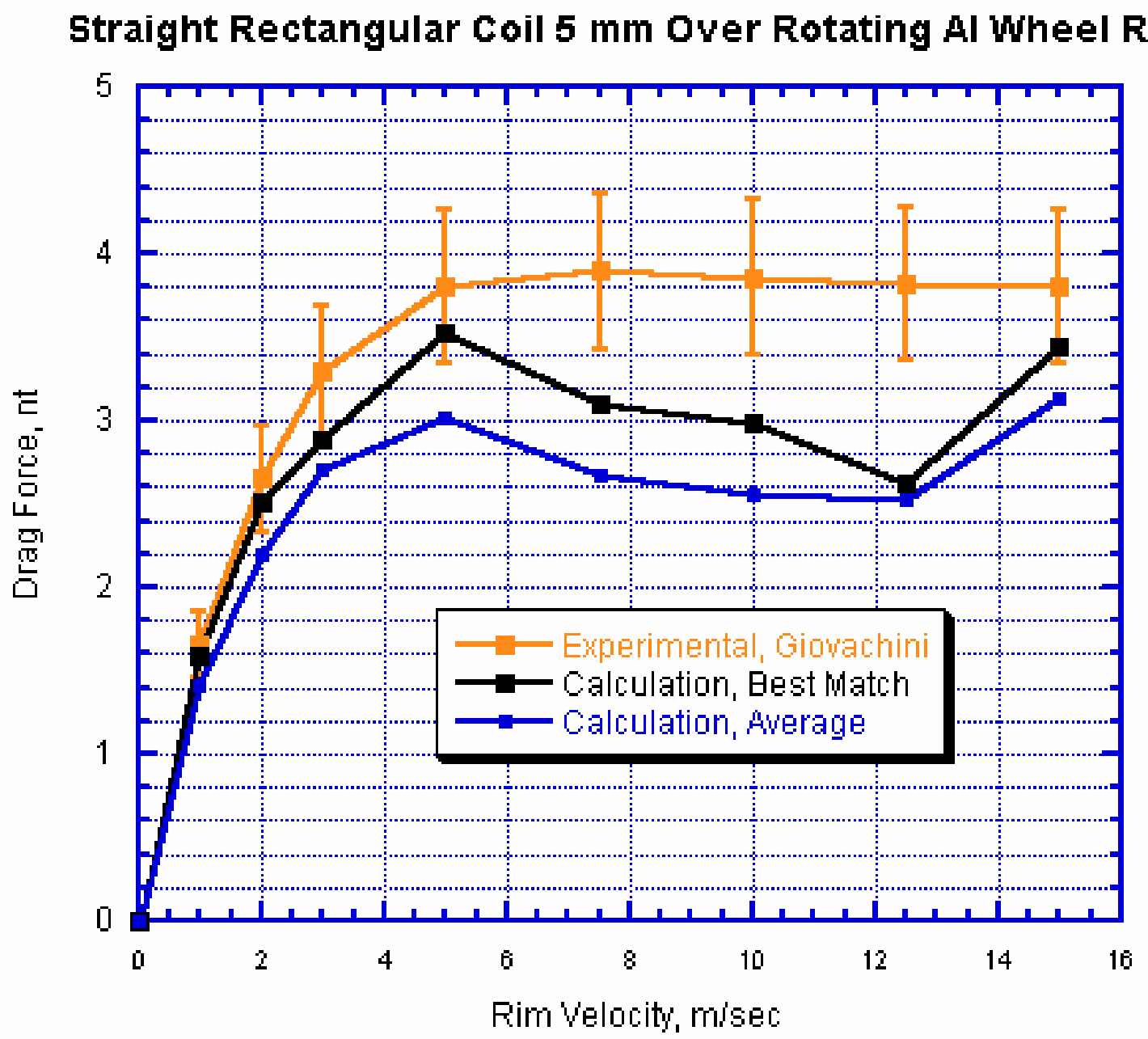

Figure 46 Best match and average calculated drag force results.

We have also tried to reproduce the theoretical results presented by Smythe in his classic analysis of eddy-current disk brakes [3]. In his paper, Smythe uses a scalar magnetic potential method to derive a formula for the steady-state eddy-current torque of a thin, conducting disk rotating between the ferromagnetic pole faces of permanent magnets and electromagnets. Smythe assumes that the B field or magnetic flux density is purely axial in direction, uniform over the area of the projection of the circular pole face on the disk, and constant in time. He further assumes that the disk is so thin that skin effects do not occur across the thickness of the disk, which means that the B field distribution through the thickness of the disk is uniform. He then specializes his formula to calculate the eddy-current torque measured by Lentz in an experiment [4]. Smythe states that Lentz's experimental eddy-current brake had the center of the disk cut out to simulate a ring whose width was roughly equal to the width of a thin conducting strip 
considered by Rudenberg [5] and Zimmerman [5]. Lentz's four poles were so far apart that they were magnetically independent. The inner radius of his ring was $5 \mathrm{~cm}$, and the outer radius was $25 \mathrm{~cm}$. The copper ring was $4 \mathrm{~mm}$ thick. The air gap between the poles was $1.2 \mathrm{~cm}$. The centers of the rectangular pole pieces were $20.75 \mathrm{~cm}$ from the axis of rotation. The pole pieces were $6 \mathrm{~cm}$ in radial extent by $8 \mathrm{~cm}$ in tangential extent. The magnetic flux density was 2150 gauss when the ring was at rest. Lentz presented torque (in $\mathrm{m}-\mathrm{kg}$ force) versus speed (in rpm) curves when the copper ring was hot (150-350 C degrees) and when it was cold. Smythe further states that he believes that the comparison of his formula with Lentz's experimental data will be difficult because Lentz used rectangular poles, Lentz's air gap was so large as to spread his magnetic flux over an unknown area, the center Lentz's disk was removed, and the point of Lentz's flux density measurement is unknown. Although Smythe feels that his formula is inaccurate at Lentz's large dimensions and high rotation speeds, he considers a case comparable to Lentz's experimental arrangement.

Smythe chooses a disk thickness of $4 \mathrm{~mm}$, a disk outer radius of $25 \mathrm{~cm}$, a pole center position at $21 \mathrm{~cm}$ from the axis of rotation, a circular pole radius a of $4 \mathrm{~cm}$, an air gap of $6 \mathrm{~mm}$, and a magnetic flux density of 2000 gauss. He considers an electromagnet with only one leg so that there is only one set of poles. He assumes that the reluctance is entirely in the air gap. He chooses a copper resistivity of $1 / 1700$ emu units, which gives $1.70010^{-8} \mathrm{ohm}-\mathrm{m}$. The corresponding conductivity is the reciprocal of $1.70010^{-8}$ or about $5.88210^{7}$ siemens $/ \mathrm{m}$. Smythe calculates that the peak torque will occur at $267 \mathrm{rpm}$. From his torque formula, he gets a peak torque of $1.1510^{8}$ dyne-cm $=11.5 \mathrm{nt}-\mathrm{m}=1.17 \mathrm{~kg}$ force-m for his single set of poles. He estimates that Lentz's peak torque should be about four times his value or $4.610^{8}$ dyne- $\mathrm{cm}=46.0 \mathrm{nt}-\mathrm{m}=4.68 \mathrm{~kg}$ force- $\mathrm{m}$. He plots a torque versus speed curve for 0 to $1600 \mathrm{rpm}$ as his Figure 6. From Smythe's reproduction of Lentz's torque versus speed results as Figure 5, Lentz's peak torques appears to be about $5.5 \mathrm{~kg}$ force-m. Smythe's estimate for the peak torque is thus about $14.9 \%$ lower than Lentz's measurement. Smythe further states that a comparison of his Figures 5 and 6 shows that his formula gives too rapid a decrease in torque at high speeds.

In order to simulate Smythe's model, we have used his dimensions to create a solid model consisting of a copper disk and an electromagnet with a single set of poles. This model is shown in Figure 47. The disk is to the left of the figure. The electromagnet is shown on the right side of the figure. It consists of a core, shown in blue, and a coil, shown in green. The core is constructed from the union of five right circular cylinders 4 $\mathrm{cm}$ in radius. The coil is an annulus with an outer diameter of $11.934 \mathrm{~cm}$ and an inner diameter of $8.354 \mathrm{~cm}$. The length of the coil is $12 \mathrm{~cm}$. The extent of the core perpendicular to the disk faces is $29.81 \mathrm{~cm}$. The center of the disk is located at the origin of the coordinate system. The flat faces of the disk are parallel to the xy-plane and $2 \mathrm{~mm}$ to each side of it. The positive z-axis extends upward to the right from the center of the disk through the center of the pole gap and the center of the winding leg of the core.

The disk is set to rotate clockwise in the view shown in Figure 47. The disk is made of copper with a conductivity of $5.88210^{7}$ siemens $/ \mathrm{m}$. The core is made of iron with a conductivity of $1.0310^{7}$ siemens $/ \mathrm{m}$ and a relative permeability of 4000 . The coil is made of copper with a conductivity of $5.8010^{7} \mathrm{siemsns} / \mathrm{m}$. The current in the stranded coil is 1009 A to give a B field magnitude of $0.200 \mathrm{~T}$ or 2000 gauss at the center of the pole projection on one of the disk surfaces when the disk is at rest. 
In order to estimate the average B field magnitude in the pole projection volume of the disk once a revolution, a cylinder, whose base is the shape of the pole circle, is created in the disk at 22 degrees above the pole projection area when the disk is in its initial position. Once a revolution, this pole projection cylinder will coincide with the pole projection on the disk. At this time, it will be easy to use the code's post processor calculator to estimate the average B field magnitude within the pole projection volume of the disk.

A simulation was run out to $0.238452 \mathrm{sec}$ with the disk spinning at $267 \mathrm{rpm}$ so that the disk would execute just more than one revolution and the pole projection cylinder would approximately line up with the projection of the pole circle on the disk. The solution space contained 37,321 tetrahedra. The disk contained 12,914 tetrahedra, the pole projection disk contained 376 tetrahedra, and the core contained 1816 tethedra. The timedependent torque on the disk is shown in Figure 48. The peak negative value of the torque on the disk is about $-11.595 \mathrm{nt}-\mathrm{m}$ at about $0.01 \mathrm{sec}$. After the negative peak is reached, the torque increases to about $-2.65 \mathrm{nt}-\mathrm{m}$ and stays close to this level for the rest of the simulation. The absolute value of the peak negative torque is very close to Smythe's prediction of $11.5 \mathrm{nt}-\mathrm{m}$, but this result most likely be due to the coincidental start up transient. The approximate steady-state absolute value of the torque is $23.0 \%$ of Smythe's prediction. Thus, we are a factor of 4.35 low, compared to Smythe's estimate of the steady-state torque. We think the reason for this may be that, as the speed of rotation of the disk is increased, the eddy currents induced in the disk have a stronger and stronger effect in modifying the B field in the disk This effect, known in the electric motor literature as the "armature reaction," is not included in Smythe's formulation. It is, however, discussed in the illuminating paper by Wouterse [7].

At a very low rotational speed, the initial distribution of the magnetic flux density in the disk is unaffected by the eddy currents in the disk because they are relatively weak. At higher rotational speeds, the eddy currents become stronger and begin to alter the external field in the disk. The peak B field in the disk under the pole increases in amplitude and shifts in the direction of the motion. The B field under the pole in the region opposite the direction of motion decreases. As the speed increases, these effects become more pronounced. The average B field within the volume within the pole projection circle decreases so that Smythe's assumption of a uniform, time-constant B field within the pole piece projection volume is no longer valid, and his formula becomes less and less correct. 


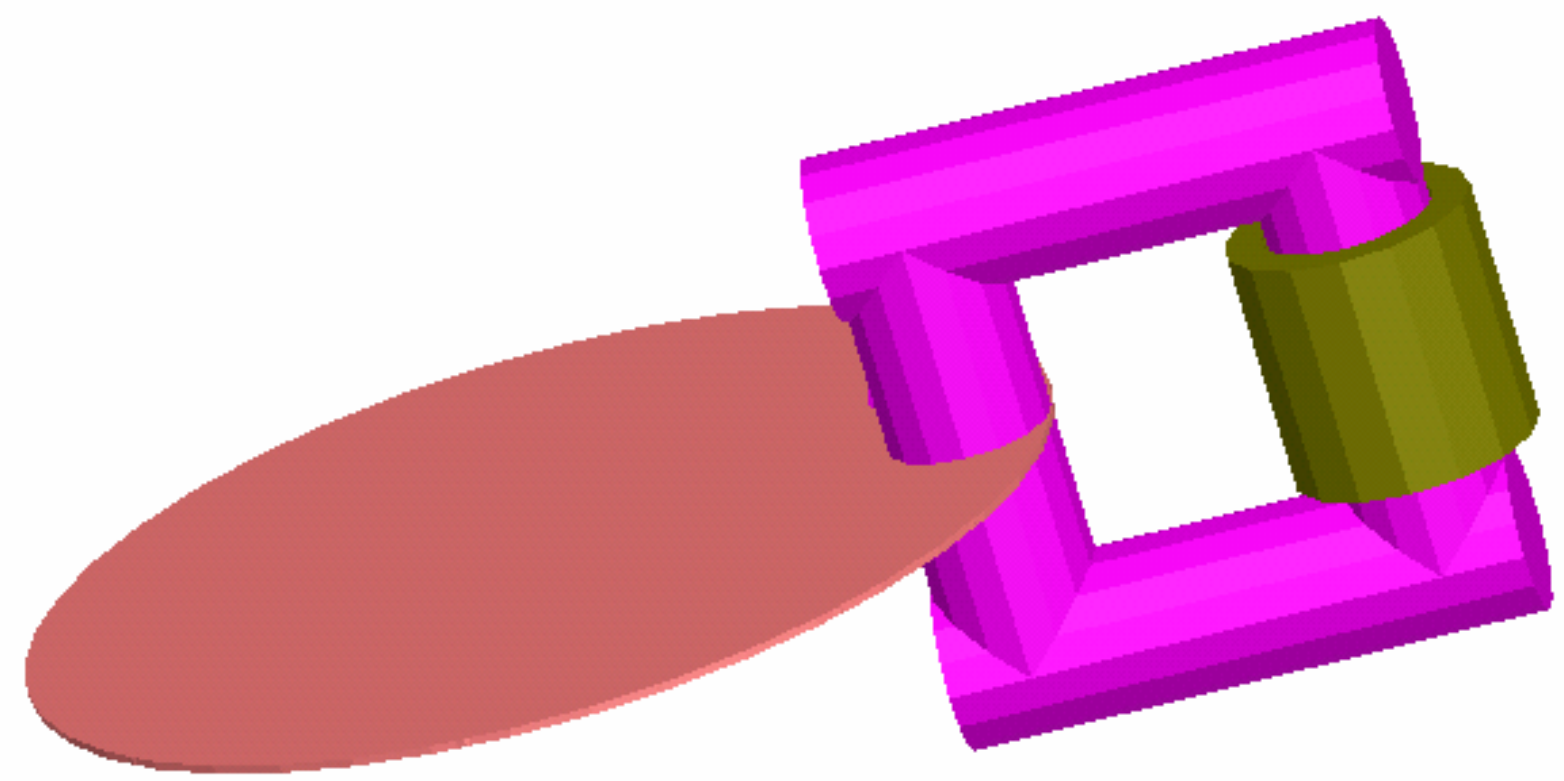

Figure 47 Model of an eddy-current brake disk and electromagnet. 


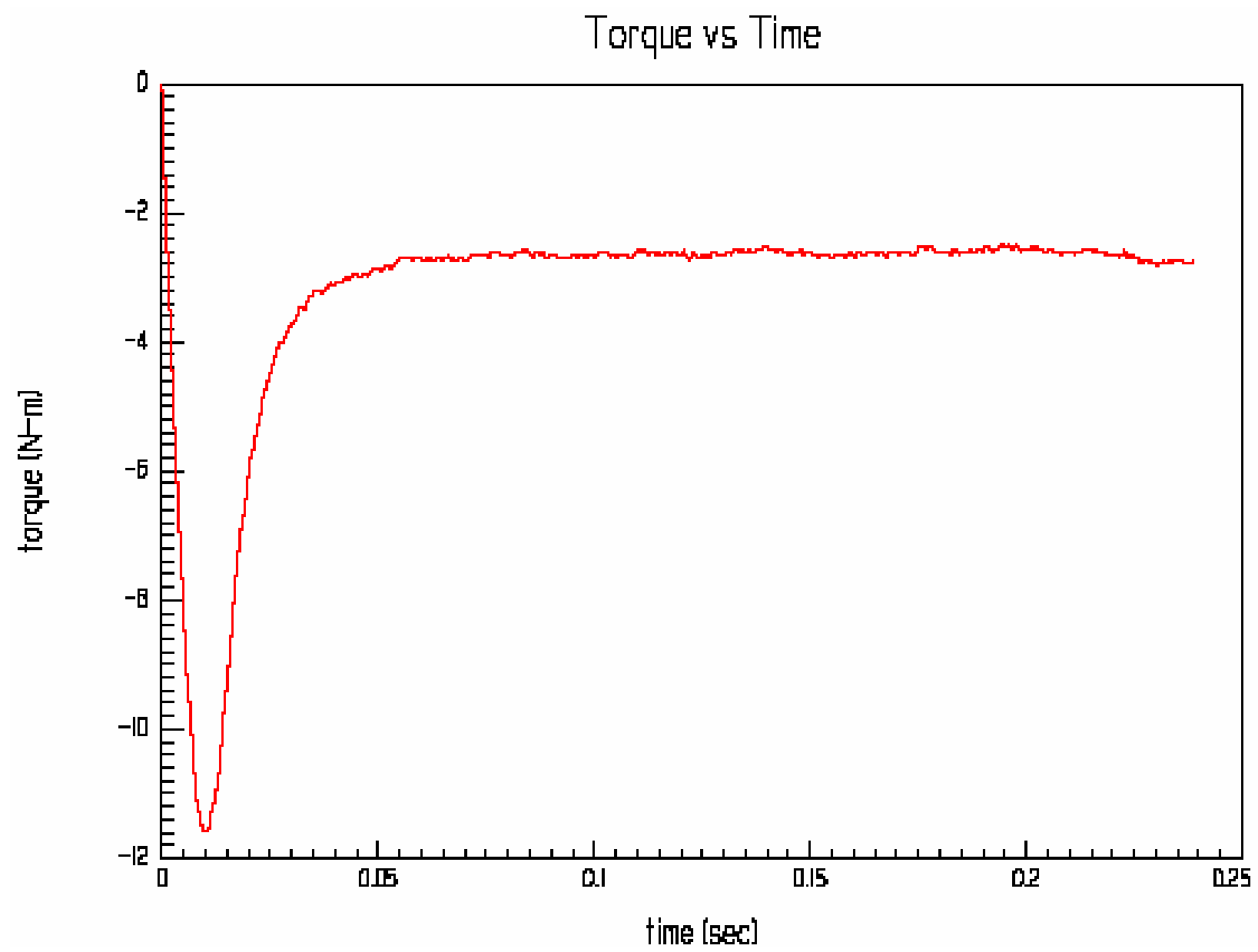

Figure 48 Time-dependent torque for the Smythe model with 37,321 tetrahedra.

Figure 49 shows the distribution of the calculated B field on the surface of the disk at $t$ $=0$. The field is nearly uniform across the pole projection area, which lies within the polygon of blue line segments bounding the pole face projection. The rectilinear blue lines are the wire frame view of the core. The B field level of $0.2122 \mathrm{~T}$ corresponds to the darkest red regions near the edge of the disk. The B field is almost everywhere $0.2011 \mathrm{~T}$ within the pole projection area. The motion of the disk is downward in this view. Figure 50 shows the distribution of the calculated $B$ field on the surface of the disk at $t=$ $0.00603 \mathrm{sec}$. The peak field has increased to $0.42144 \mathrm{~T}$. It has also moved to the very edge of the pole projection area and somewhat beyond in the direction of motion. Figure 51 shows the pattern of the B field on the surface of the disk at the end of the simulation at $\mathrm{t}=0.238452 \mathrm{sec}$, when the pole projection cylinder coincides with the pole projection area after one revolution. The peak field within the pole projection circle on the disk has now dropped to $0.18829 \mathrm{~T}$. The average $\mathrm{B}$ field over the volume of the pole projection cylinder is $0.05167 \mathrm{~T}$. If we scale Smythe's predicted peak torque with the square of the average field in the pole projection volume of the disk, a torque of $0.768 \mathrm{nt}-\mathrm{m}$ results, which is lower than the code calculated value of $\sim 2.65 \mathrm{nt}-\mathrm{m}$ by a factor of 3.45 . But, this scaled estimate ignores the contribution from the field and current density beyond the 
pole projection volume. A larger cylinder for volume averaging must be used to get a better estimate of the torque from an average B field scaling of Smythe's value.

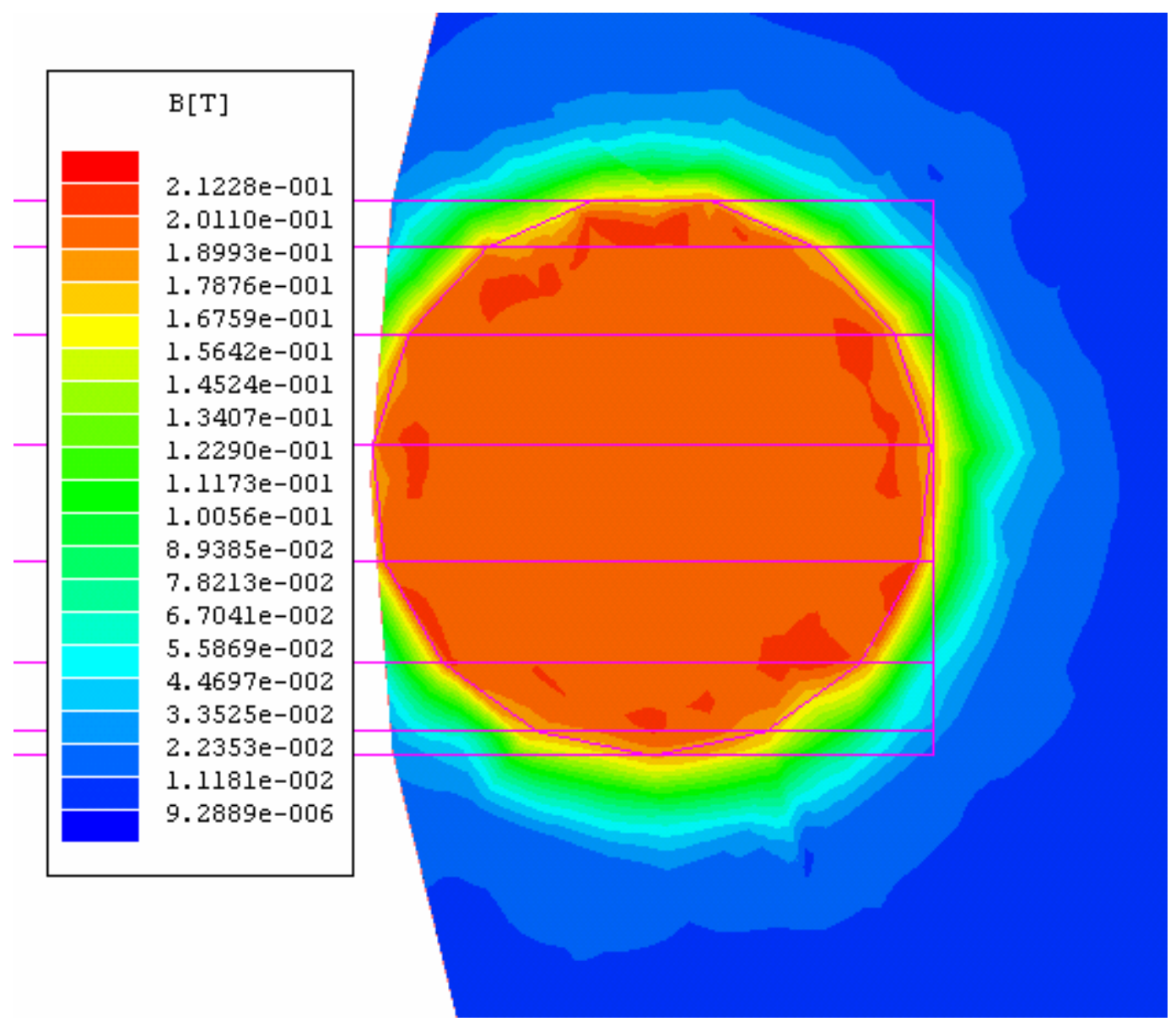

Figure 49 The calculated $B$ field on the surface of the disk at $t=0$. 


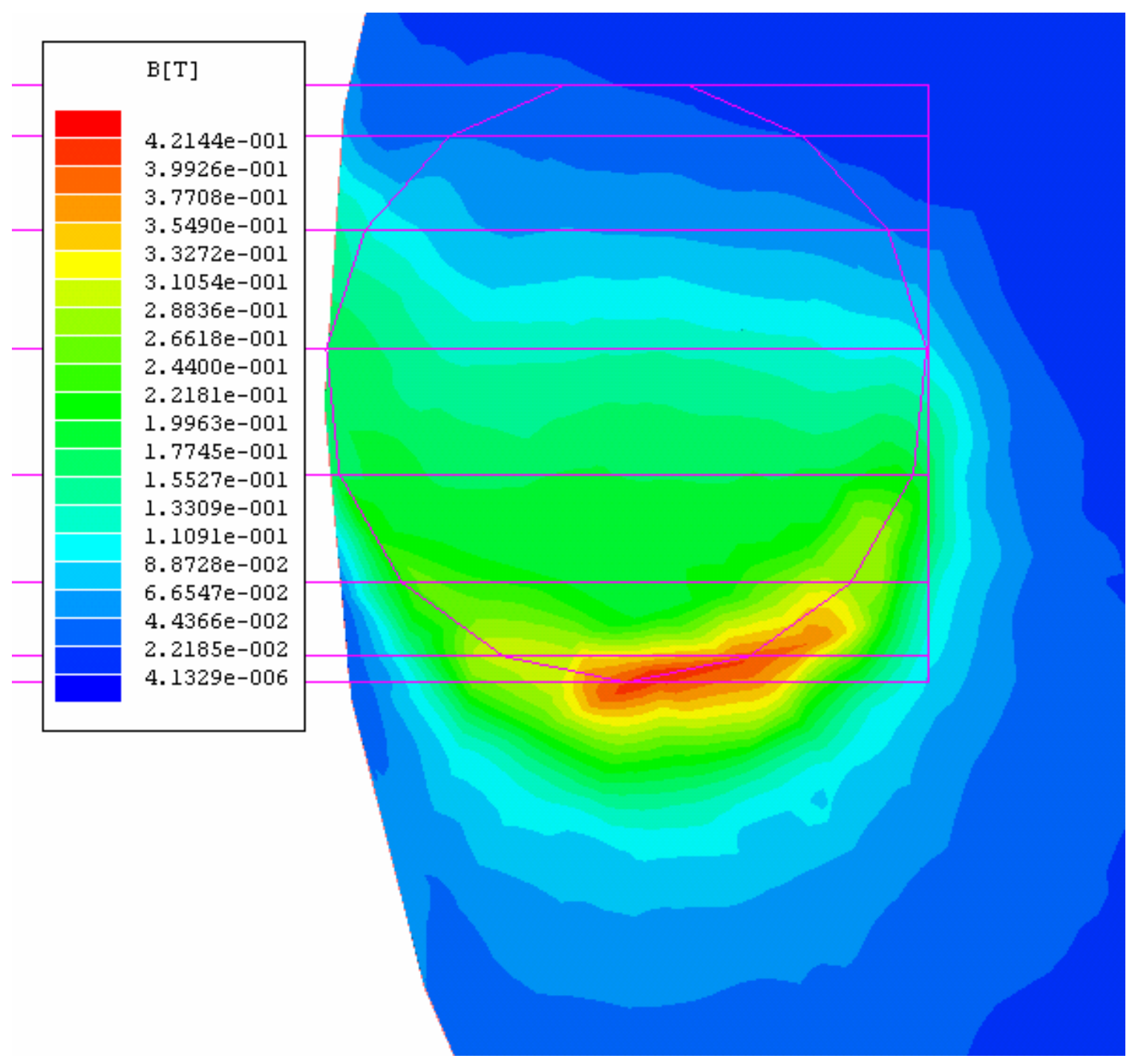

Figure 50 The calculated $B$ field on the surface of the disk at $t=0.006$ sec. 


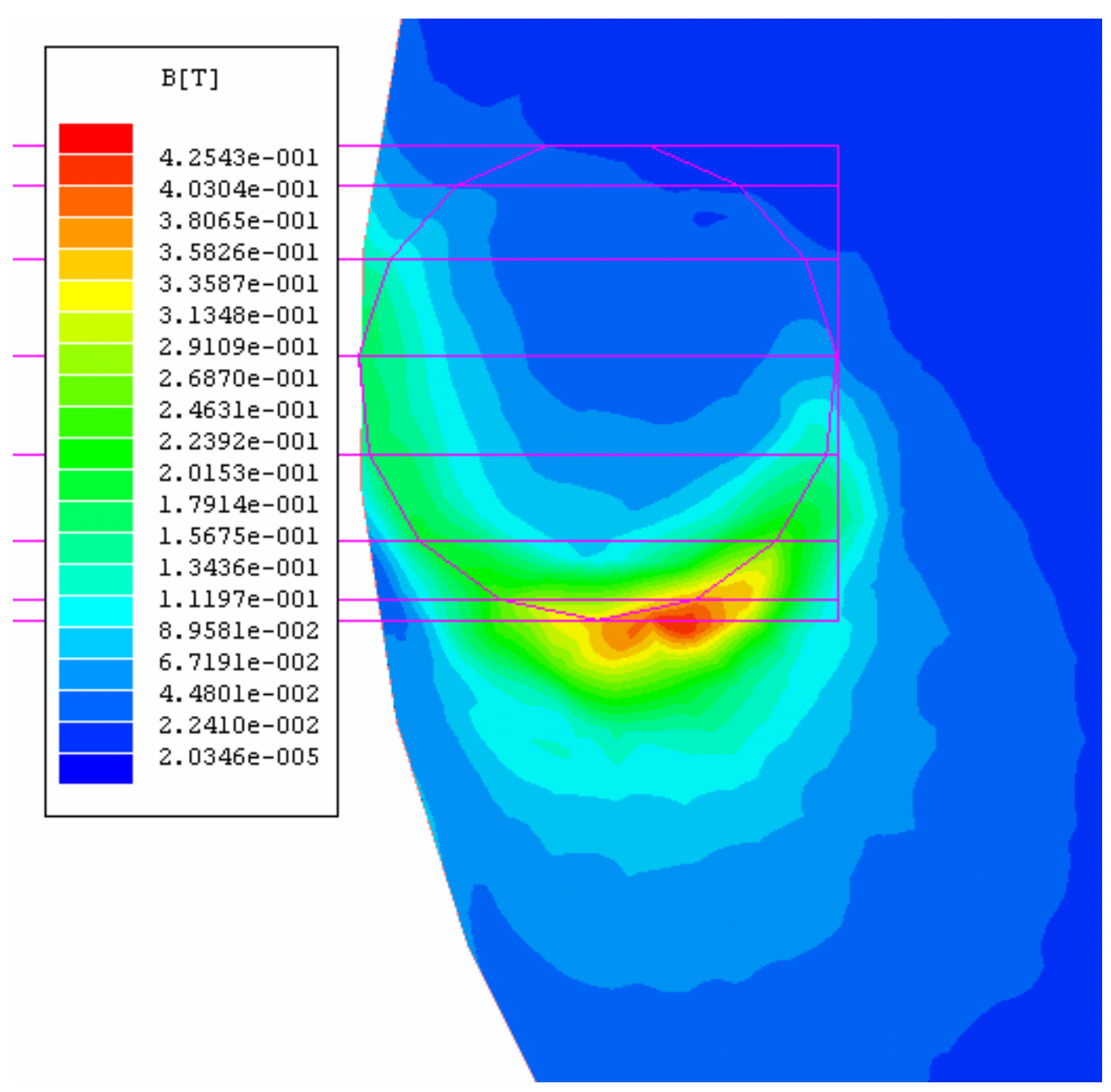

Figure 51 The calculated $B$ field on the surface of the disk at $t=0.238452$ sec.

We have performed simulations with the model in Figure 47 at steady angular frequencies of 1 to $450 \mathrm{rpm}$. All the simulations were run out to $0.800 \mathrm{sec}$. The results are compared to Smythe's formula in Figure 52. The black curve gives values of the eddycurrent torque from Smythe's formula. The minimal torque, that is, the torque with the greatest absolute value, occurs at $267 \mathrm{rpm}$. Beyond $267 \mathrm{rpm}$, the absolute value of the torque decreases. The blue curve shows estimated steady-state torque values from the code simulations. The minimal torque for the simulations appears to lie between 100 and $150 \mathrm{rpm}$. Beyond about $2 \mathrm{rpm}$, the code results differ strongly from the results from Smythe's analytic formula. The orange curve shows the results of a computer program implementation of Wouterse's estimation formulas [7] with the ratio $\xi$ assumed equal to one. We see that, above about $50 \mathrm{rpm}$, the simulation curve lies closer to the curve from Wouterse's formulas than to the curve from Smythe's formula. Wouterse's formulas predict a minimal torque at about $142 \mathrm{rpm}$; the simulation predicts a minimal torque between 100 and $150 \mathrm{rpm}$. Wouterse's formulas predict a minimal torque of about -5.462 $\mathrm{nt}-\mathrm{m}$; the simulations predict a minimal torque of about $-2.62 \mathrm{nt}-\mathrm{m}$. Although Wouterse's 
formulas appear to give better results than Smythe's formula, they give an estimate based on an idealized, although more accurate, model.

Wouterse starts his development with the frequently used formula for the power dissipation of a spatially uniform current density induced in a cylindrical volume of a conductive disk of speed $\mathrm{v}$ under a circular magnetic pole of diameter $\mathrm{D}$ with a uniform magnetic induction of $\mathrm{B}$. The power dissipation is $\mathrm{J}^{2} / \rho$, the power dissipation per unit volume, times the cylindrical volume, $\pi D^{2} d / 4$, where $J=B^{2} v^{2}$ is the current density, $v$ is the speed of the center of the pole projection on the disk, and $d$ is the disk thickness. The power dissipation or power loss is

$$
\mathrm{P}_{\mathrm{dis}}=\pi \mathrm{D}^{2} \mathrm{~dB}^{2} v^{2} /(4 \rho) \text {. }
$$

The eddy-current drag force felt by the disk is $\mathrm{P}_{\mathrm{dis}} / \mathrm{v}$ or

$$
\mathrm{F}_{\mathrm{e}}=\pi \mathrm{D}^{2} \mathrm{~dB}^{2} \mathrm{v} /(4 \rho)
$$

These two expressions ignore the effect of the eddy currents returning in the material beyond the pole projection cylinder in the disk. According to Wouterse, the analyses of Smythe [3] and Schieber [8], effectively introduce a correction $\mathrm{c}$ to the drag force expression so that it becomes

$$
\begin{aligned}
& \mathrm{F}_{\mathrm{e}}=\pi \mathrm{D}^{2} \mathrm{~dB}^{2} \mathrm{vc} /(4 \rho), \\
& \mathrm{c}=.5\left(1-1 /\left(4(1+\mathrm{R} / \mathrm{A})^{2}((\mathrm{~A}-\mathrm{R}) / \mathrm{D})^{2}\right)\right),
\end{aligned}
$$

where $\mathrm{R}$ is the distance from the disk center to the center of the pole projection, and $\mathrm{A}$ is the disk radius.

This corrected formula for the eddy-current drag force is believed to be good for low speeds only. To extend it to high speeds, Wouterse considers an idealization of the speedasymptotic case when $\mathrm{v}$ approaches an infinite value. In this case, because of the infinite speed, the magnetic flux from the pole face is completely excluded from the disk. The eddy currents are assumed to flow in a narrow rectangular distribution about the circumference of the circular pole face projection cylinder within the disk. The length of the eddy current path is taken to be the pole face circumference, $\pi \mathrm{D}$. The eddy current amplitude is estimated from a closed path to goes from pole face to pole face and then encloses one section of the circular current. This $\mathrm{H}$ times $\mathrm{dl}$ line integral gives $\mathrm{Bx} / \mu_{0}$, where $\mathrm{x}$ is the pole-to-pole gap, and mu 0 is the permeability of free space, which equals the enclosed current, I. The radial extent of the enclosed current distribution is assumed to be $\xi \mathrm{x}$. Its axial extent is the disk thickness d. The resistance of the eddy-current path is given by the familiar formula, the resistivity times the path length, divided by the current distribution area. Thus,

$$
\begin{aligned}
& \text { Resistance }=\rho \pi \mathrm{D} /\left(\xi_{x d}\right), \\
& \text { Current }=B^{*} \times / \mu_{0} .
\end{aligned}
$$

For small values of $x / D$, Wourtese says the asymptotic eddy current power loss is given by the resistance times the current squared or

$$
\begin{aligned}
& \mathrm{P}_{\text {inf }}=\rho \pi \mathrm{D} /\left(\xi_{\mathrm{xd}}\right) \mathrm{B}^{2} \mathrm{x}^{2} / \mu_{0}^{2}, \\
& \mathrm{P}_{\text {inf }}=\pi \rho \mathrm{B}^{2} \mathrm{xD} /\left(\mu_{0}^{2} \xi_{\mathrm{d}}\right) .
\end{aligned}
$$

The asymptotic eddy-current drag force will be the power dissipation divided by the speed $\mathrm{v}$ or

$$
\mathrm{F}_{\text {inf }}=\pi \rho \mathrm{B}^{2} \mathrm{xD} /\left(\mu_{0}^{2} \xi \mathrm{dv}\right) .
$$

Wouterse then rewrites the expression for the asymptotic drag force as

$$
\mathrm{F}_{\text {inf }}=\left[\left(1 / \mu_{0}\right)(\mathrm{c} / \xi)^{.5}(\pi 4) \mathrm{D}^{2} \mathrm{~B}^{2}(\mathrm{x} / \mathrm{D})^{.5}\right]\left[\left(2 / \mu_{0}\right)(1 /(\mathrm{c} \xi))^{.5}(\rho / \mathrm{d})(\mathrm{x} / \mathrm{D})^{.5}\right] 2 / \mathrm{v} \text {. }
$$


Wouterse then defines the grouping of terms within the first set of square brackets of the previous formula as $\mathrm{F}^{\wedge}$, the maximum value of the eddy-current drag force, and the grouping of terms within the second set of square brackets as $\mathrm{v}_{\mathrm{k}}$, the critical speed or the speed at which the maximal drag force occurs, so that

and

$$
\begin{aligned}
& \mathrm{F}_{\mathrm{e}}^{\wedge}=\left(1 / \mu_{0}\right)(\mathrm{c} / \xi)^{.5}(\pi / 4) \mathrm{D}^{2} \mathrm{~B}^{2}(\mathrm{x} / \mathrm{D})^{.5}, \\
& \mathrm{v}_{\mathrm{k}}=\left(2 / \mu_{0}\right)(1 /(\mathrm{c} \xi))^{.5}(\rho / \mathrm{d})(\mathrm{x} / \mathrm{D})^{.5},
\end{aligned}
$$

$$
\mathrm{F}_{\text {inf }}=\mathrm{F}^{\wedge}{ }_{\mathrm{e}} 2 \mathrm{v}_{\mathrm{k}} / \mathrm{v} \text {. }
$$

Wouterse calls $\mathrm{F}^{\wedge}{ }_{\mathrm{e}}$ the critical torque.

To obtain an estimated eddy-current drag force, $\mathrm{F}_{\mathrm{e}}(\mathrm{v})$, valid for all speeds $\mathrm{v}$, Wouterse then replaces $v_{k} / v$ with the function, $v_{v_{k}} /\left(v^{2}+v_{k}^{2}\right)=1 /\left(v_{k} / v+v / v_{k}\right)$, which has the same behavior as $\mathrm{v}$ approaches infinity, so that

$$
\mathrm{F}_{\mathrm{e}}(\mathrm{v})=\mathrm{F}_{\mathrm{e}}^{\wedge} 2 /\left(\mathrm{v}_{\mathrm{k}} / \mathrm{v}+\mathrm{v} / \mathrm{v}_{\mathrm{k}}\right) \text {, }
$$

which is his Equation (8). The formulas for $\mathrm{F}^{\wedge}$ and $\mathrm{v}_{\mathrm{k}}$ are his Equations 9 and 10.

Wouterse states that the only quantity not exactly known in has Equations $8-10$, is $\xi$, but that it can be estimated as 1 . He further suggests that $\xi$ can be more exactly estimated by finite element calculation.

Wouterse further cautions that many factors can cause his formulas to be inaccurate. For example, the iron yoke for the electromagnet flux return path can be close to the air gap so that the B field does not decay to zero just outside the pole face projection on the disk. Further, the $\mathrm{x} / \mathrm{D}$ ratio may not be small. Also, in actual experiments, the change in the disk temperature due to eddy-current heating can cause the disk resistivity to rise nonuniformly and thus affect the power dissipation. It must be noted that we have not yet included eddy-current heating of the target wheel in our calculations.

Wouterse's formulas are not completely accurate, but represent an improvement over Smythe's formula for high speeds, where the eddy-current fields strongly affect the externally applied field.

To obtain an expression for eddy-current torque from $\mathrm{F}_{\mathrm{e}}(\mathrm{v})$, we multiply $\mathrm{F}_{\mathrm{e}}(\mathrm{v})$ by $\mathrm{R}$, so that

$$
\begin{aligned}
& \text { Torque }=\mathrm{F}^{\wedge}{ }_{\mathrm{e}} 2 \mathrm{R} /\left(\mathrm{v}_{\mathrm{k}} / \mathrm{v}+\mathrm{v} / \mathrm{v}_{\mathrm{k}}\right), \\
& \text { Torque }=\mathrm{F}^{\wedge}{ }^{2} 2 \mathrm{Rvv}_{\mathrm{k}} /\left(\mathrm{v}^{2}{ }_{\mathrm{k}}+\mathrm{v}^{2}\right), \\
& \text { Torque }=\mathrm{F}^{\wedge}{ }^{2} 2 \mathrm{Rv}^{2} \mathrm{v}_{\mathrm{k}} /\left(\mathrm{v}\left(\mathrm{v}^{2}{ }_{\mathrm{k}}+\mathrm{v}^{2}\right)\right), \\
& \text { Torque }=\mathrm{F}^{\wedge}{ }_{\mathrm{e}} 2 \mathrm{Rv}^{2} \mathrm{v}_{\mathrm{k}}\left(\omega \mathrm{R}\left(\mathrm{v}^{2}{ }_{\mathrm{k}}+\mathrm{v}^{2}\right)\right), \\
& \text { Torque }=\mathrm{F}^{\wedge}{ }_{\mathrm{e}} 2 \mathrm{v}^{2} \mathrm{v}_{\mathrm{k}} /\left(\omega\left(\mathrm{v}_{\mathrm{k}}{ }_{\mathrm{k}}+\mathrm{v}^{2}\right)\right),
\end{aligned}
$$

where $\omega$ is the angular frequency of rotation in radians/sec. The last expression for the eddy-current torque is used in the computer program.

Acting on Wouterse's suggestion, we have run the simulations at higher and higher angular frequencies in an effort to approach an asymptotic state. We have used angular frequencies of $210^{4}, 210^{5}, 210^{7}, 210^{9}$, and $210^{12} \mathrm{rpm}$. The current distribution near the pole piece image on the disk looks generally similar as the angular frequency increases. At $210^{12} \mathrm{rpm}$, the current density on the upper surface of the disk at $\mathrm{t}=0.045 \mathrm{sec}$ is shown in Figure 53. We see that, as Wouterse predicts from experimental observation, a non-uniform layer of current density flows about the outer edge of the pole piece projection on the rotating disk. Wouterse implies through his Figure $8 \mathrm{~b}$ that the layer is azimuthally symmetric, but that is obviously not the case for the simulation. Wouterse 
may be referring to a configuration where the edge of the disk extends sufficiently far beyond the pole piece projection. In our case the edge of the disk and the outer edge of the pole piece projection are tangent at one point. As a result, the simulation current density is highly concentrated at the edge of the disk. In addition, current density flows about the outer edge of the disk beyond the pole piece projection. This outer current density is bipolar, that is both clockwise and counterclockwise, at different angles about the periphery of the disk. It encloses two other, weaker centers of circulation located at about 120 degrees in either direction from the pole piece projection. This current density pattern is shown in Figure 54. The symmetry of the centers of circulation of the current density vectors is striking.

We do not know for sure that the current density patterns in Figures 53 and 54 are the correct patterns for infinite angular frequency. The two secondary centers of current density circulation could be computational artifacts. But, for the present, we will assume that the current density patterns are correct. Figure 55 shows the distribution of the magnitude of the current density on the upper surface of the disk along the y-axis from $0.25 \mathrm{~m}$ to $+0.25 \mathrm{~m}$. The current density is strongly peaked at the left side of the figure, decreases to zero at the center of the pole piece projection, and then increases to form a bump on the right side of the pole piece projection, much like in Figure $8 \mathrm{~b}$ of Wouterse's paper. The current density decreases to zero at the right side of the disk, and then increase to a peak at right outer edge of the disk. The direction of the current density about the pole piece projection is clockwise until the far right side of the disk, where it becomes counterclockwise. We will estimate an equivalent uniform asymptotic pole piece projection current density layer width by the method indicated by Wouterse. We will assume, perhaps incorrectly, that all the current density flows around the pole piece projection, and that its average power loss, $\mathrm{P}_{\text {dis }}=\mathrm{I}^{2}$ equiv $\mathrm{R}_{\text {eqiuv }}$, equals the average power loss in the disk. From the time dependent power loss curve calculated by the code, the average power loss in the disk is estimated as $111 \mathrm{w}$. If we integrate the current density distribution shown in Figure 55 from the left edge of the disk over $4 \mathrm{~cm}$ to the center of the pole piece projection and multiply by the disk thickness, $\mathrm{d}$, of $4 \mathrm{~mm}$, we get an estimated circulating current of about $826 \mathrm{~A}$ for $\mathrm{I}_{\text {equiv }}$. We assume that the central radius of the circulating current layer to be a $+\Delta y / 2$, where a is the pole piece radius of $4 \mathrm{~cm}$, and $\Delta \mathrm{y}$ is the equivalent circulating current density width. The equivalent resistance is

$$
\mathrm{R}_{\text {equiv }}=\rho(\text { length/area })=\rho 2 \pi(\mathrm{a}+\Delta \mathrm{y} / 2) /(\mathrm{d} \Delta \mathrm{y}) \text {. }
$$

The equation for $\Delta y$ is then

$$
\mathrm{I}_{\text {equiv }}^{2} \mathrm{R}_{\text {equiv }}=\mathrm{I}_{\text {equiv }}^{2} \rho 2 \pi(\mathrm{a}+\Delta \mathrm{y} / 2) /(\mathrm{d} \Delta \mathrm{y})=\mathrm{P}_{\text {dis, }}
$$

so that the formula for $\Delta y$ is

$$
\Delta \mathrm{y}=\mathrm{I}_{\text {equiv }}^{2} 2 \pi \mathrm{a} /\left(\mathrm{dP}_{\mathrm{dis}} / \rho-\mathrm{I}_{\text {equiv }}^{2} \pi\right) \text {. }
$$

Inserting the proper numbers into the Equation 37 gives $\Delta y=0.00715 \mathrm{~m}$. Division of $\Delta y$ by the pole piece gap distance of $0.006 \mathrm{~m}$ gives 1.192 as an estimate for $\xi$ for our geometry. When we use this value of $\xi$ in Wouterse's formulas, we get the red curve for the torque shown in Figure 52. When compared with the curve from the simulations, this estimate with $\xi=1.19$ is an improvement over the curve for $\xi=1$. Thus, use of finite element code calculations to estimate Wouterse's factor $\xi$ does improve the agreement of Wouterse's formulas with the simulated torque curve. One possible reason the agreement is not better may be that our asymptotic current density distribution differs from assumption that the asymptotic current density flows only about the pole piece projection 
in an azimuthally uniform layer. The existence of three centers of current density circulation in the simulation, instead of one, may also affect the agreement. This assumption may be true for a disk whose outer edge extends far beyond the pole piece projection. If we take $\xi$ as 1.8 , we get the yellow green curve shown in Figure 52. This choice of $\xi$ gives a better match to most of the simulated torque curve, but it is merely a guess, extrapolated from the results of $\xi=1.19$.

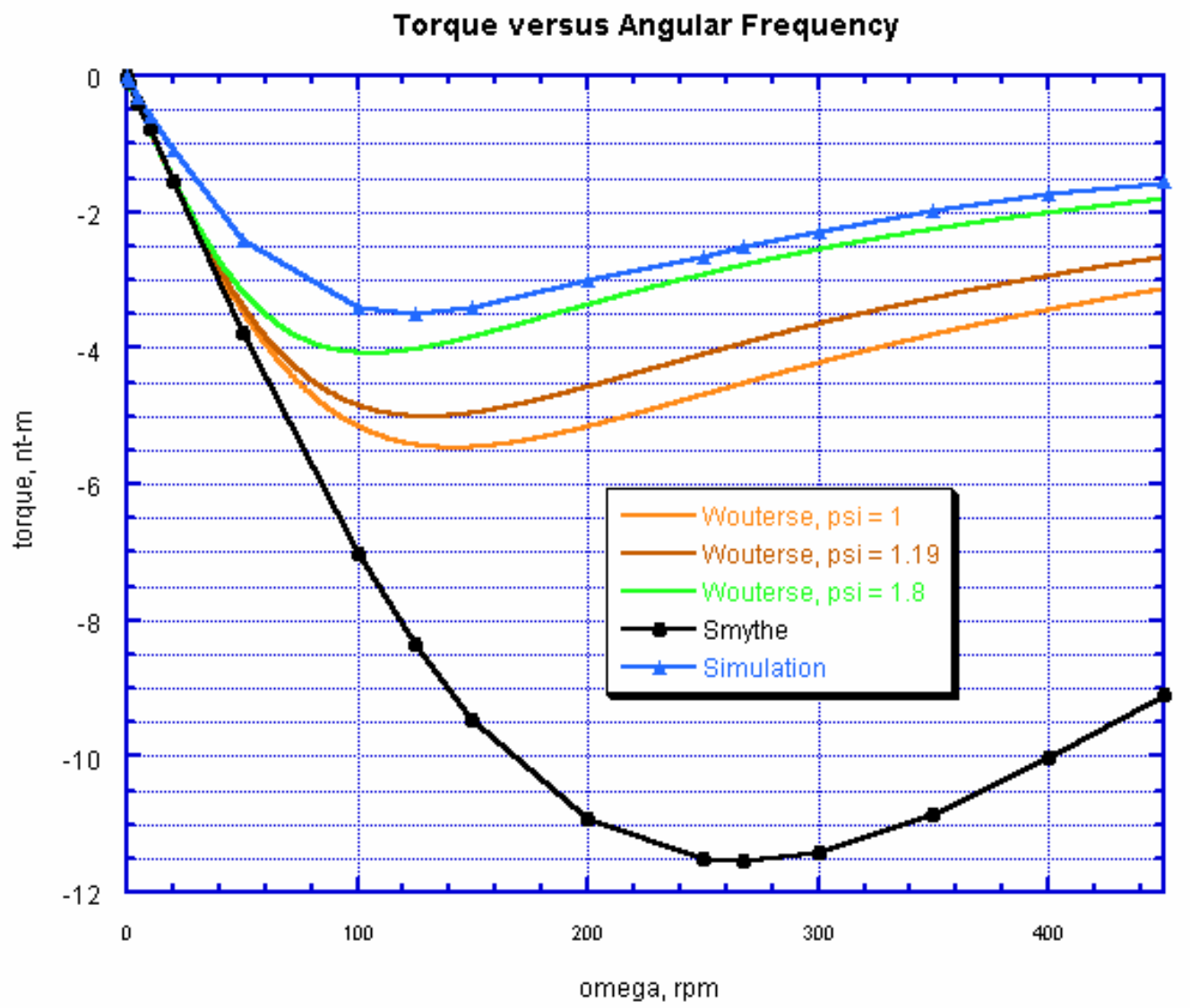

Figure 52 Simulated and calculated torque versus speed curves for Smythe's formula. 


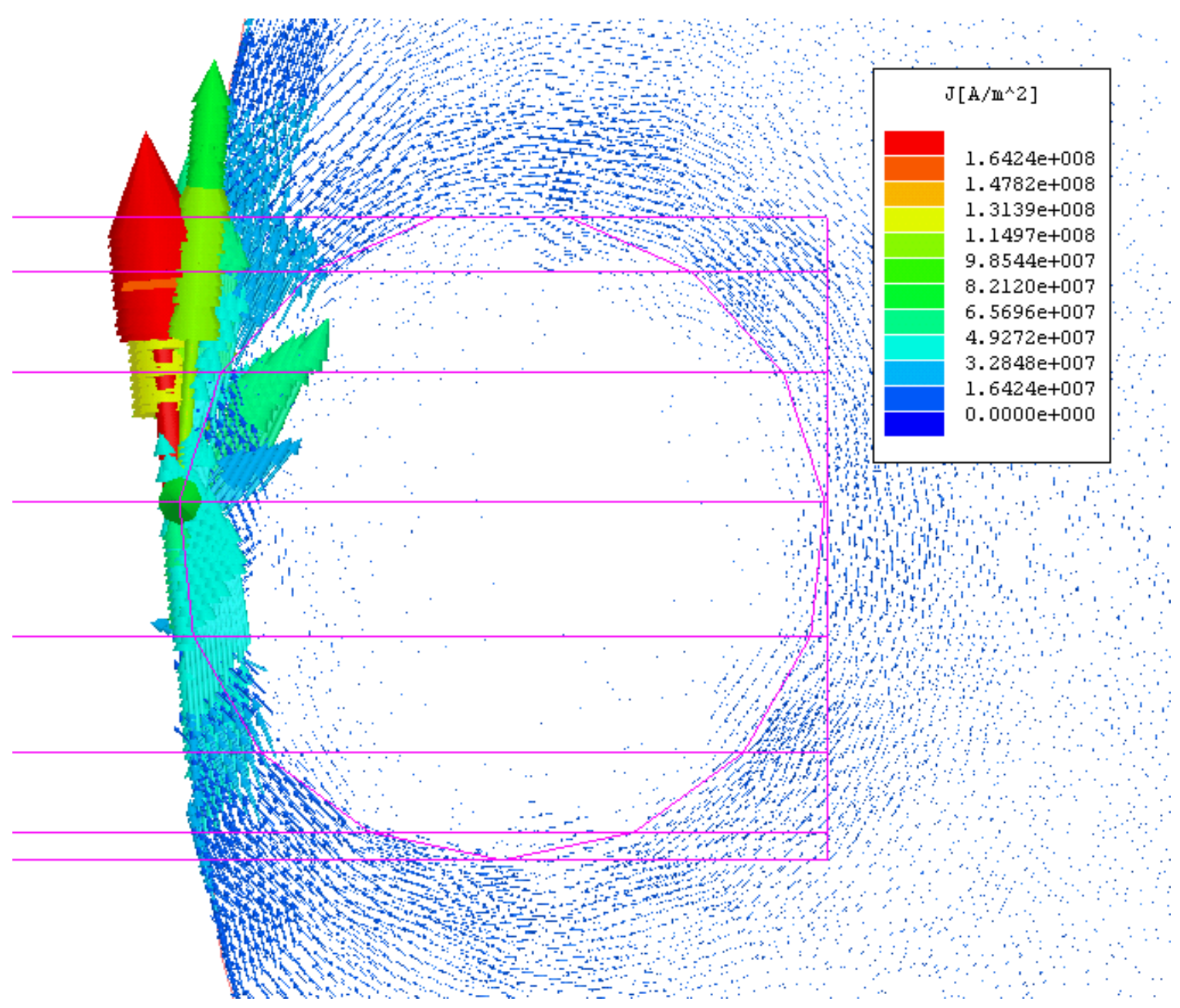

Figure 53 Upper surface Current density vectors around the pole projection at $2 \mathrm{e} 12 \mathrm{rpm}$. 




Figure 54 Upper surface current density vectors about the whole disk at $2 \mathrm{e} 12 \mathrm{rpm}$. 


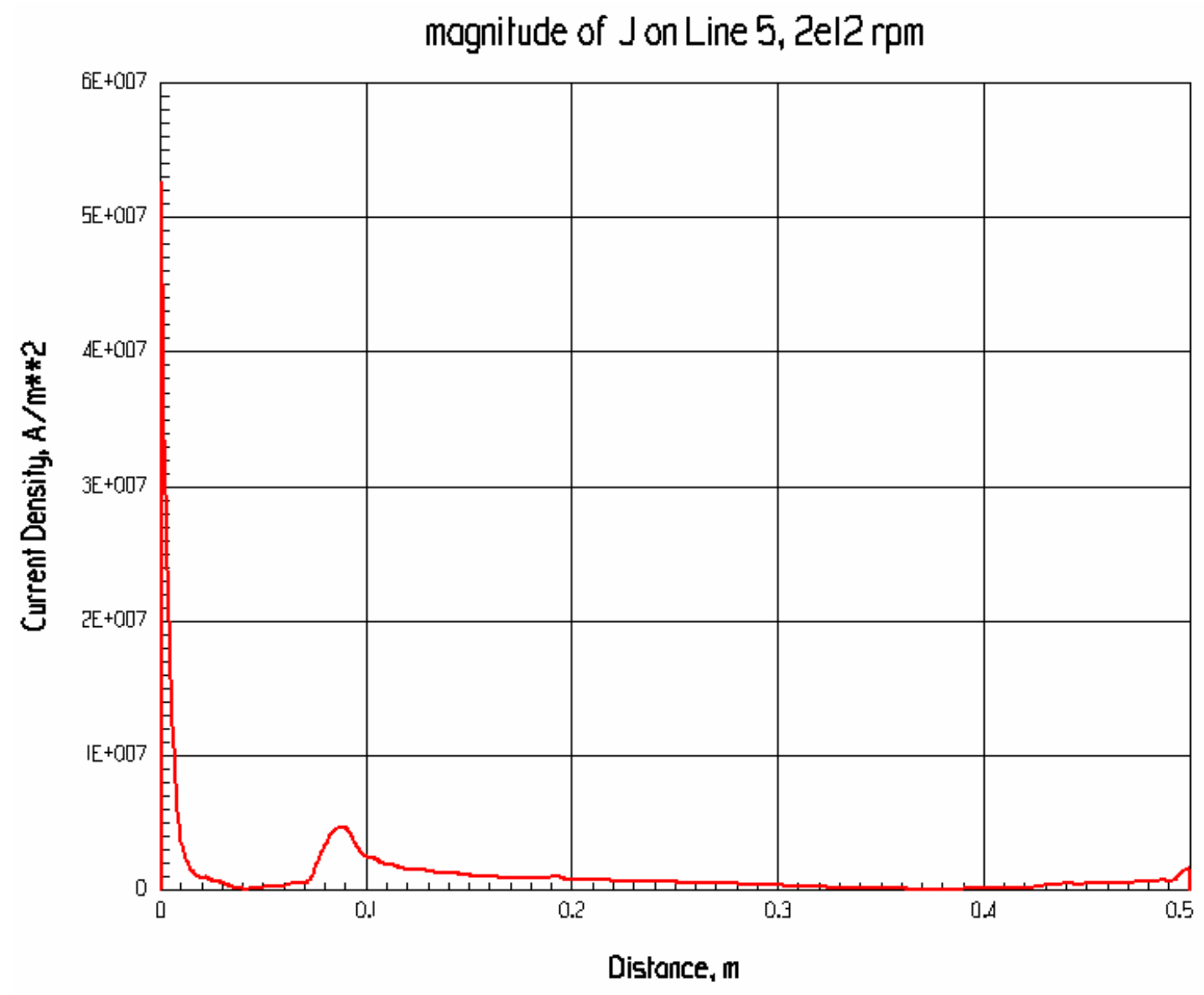

Figure 55 The magnitude of the Upper surface current density along the y-axis.

The difference between the torque for the simulation and that from Smythe's formula is shown in a different way in Figure 56, which shows the ratio of the torque from the code simulations to the torque from Smythe's formula versus angular frequency. 


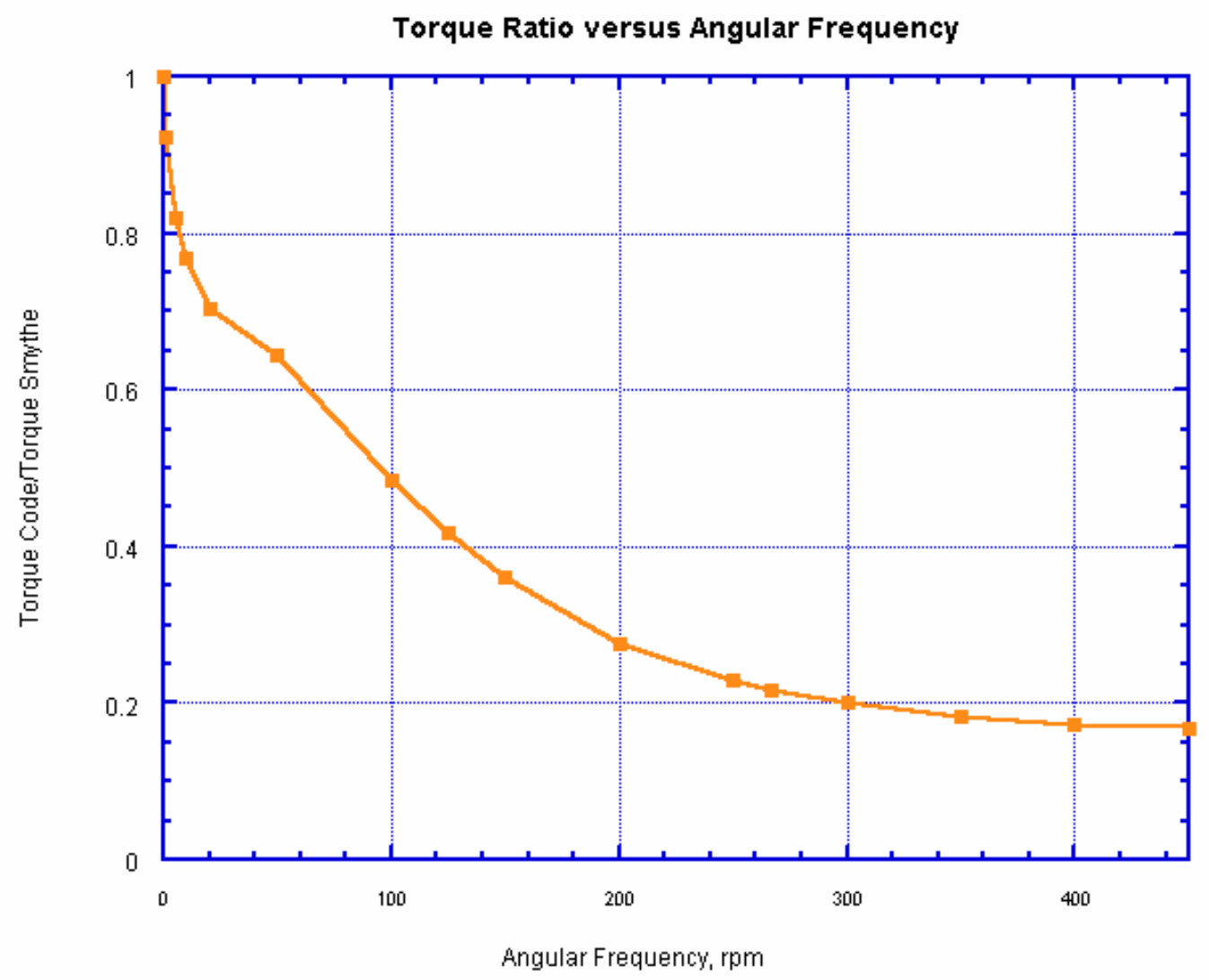

Figure 56 Ratio of code torque to Smythe's formula torque versus angular frequency.

\section{Possible Future Work}

In the future, another experiment we hope to simulate is the configuration of four permanent magnets rotating over an aluminum disk, reported by Lorimer, Lieu, Hull, Mulcahy, and Rossing [2].

\section{Access to References}

Reference 1 may be conveniently accessed in the digital archives of the Journal of Applied Physics. References 2, 7, and 8 can be easily accessed from the digital archives of the IEEE Xplore facility. Reference 3 may available only in the bound copies of the Transactions of the American Institute of Electrical Engineers in university and other technical libraries. References 4-6, which are in German, may be available only in university libraries. Reference 9 is the second volume of a well-known three-volume set of textbooks on electromechanics by two MIT professors. It may still be in print and is in many technical libraries. 


\section{References}

1. Boulnois, J.-L., and Giovachini, J.-L., "The Fundamental Solution in the Theory of Eddy Currents and Forces for Conductors in Steady Motion," J. of Applied Physics, Vol. 49, No. 4, April 1978, pp. 2241-2249.

2. Lorimer, W. L., Lieu, D. K., Hull, J. R., Mulcahy, T. M., and Rossing, T. D., "Correlation of Experimental Data and Three-Dimensional Finite Element Modeling of a Spinning Magnet Array,” IEEE Trans. on Magnetics, Vol. 30, No. 5, Sept. 1994, pp. 3004-3007.

3. Smythe, W. R., "On Eddy Currents in a Rotating Disk," Trans. American Institute of Electrical Engineers, Vol. 61, Sept. 1942, pp. 681-684.

4. Lentz, E., "Zum Problem der Berechnung scheibenformiger Wirbelstrombremsen," Electrotechnik und Maschinenbau, Vol. 52, No. 9, 1934, pp. 99-102.

5. Rudenberg, R., "Energie der Wirbelstrome in Elektrischen Bremsen und Dynamomaschinen," Sammlung Elektrotechnischer Vortrage, Verlag Enke, Stuttgart, 1907, Vol. 10, p. 269 and following.

6. Zimmermann, W., Elektrotechnik und Maschinenbau, Vol. 40, 1922, p. 11.

7. Wouterse, J. H., "Critical Torque and Speed of Eddy Current Brake with Widely Separated Soft Iron Poles,” IEE Proc.-B, Vol. 138, No. 4, July 1991, pp. 153-158.

8. Schieber, D., "Braking Torque on Rotating Sheet in Stationary Magnetic Field," IEE Proc., Vol.121, No. 2, Feb. 1974, pp. 117-122.

9. Woodson, H. H., and Melcher, J. R., "Electromechanical Dynamics, Pt. II: Fields, Forces, and Motion,” J. Wiley and Sons, New York, 1968, pp.347-351. 